\title{
Improving adherence to ongoing treatments in young adults through design
}

by

Sanaz Hafezi

A thesis submitted to the Faculty of Graduate and Postdoctoral Affairs in partial fulfillment of the requirements for the degree of

Master of Design

in

Industrial Design

Carleton University

Ottawa, Ontario

(C) 2018, Sanaz Hafezi 


\begin{abstract}
Medication non-adherence is a major issue and young adults have unique circumstances leading to non-adherence. User-centered design methods and a constructivist approach were used to address this issue through exploratory, qualitative research. An initial review of the literature framed the project scope and identified knowledge on the issues/interventions for medication adherence. Interviews were conducted with individuals in the target demographic to identify their current approach and issues with medication adherence. Information collected informed co-design sessions, which gathered information on users needs and desires to improve adherence. Results from the literature review, interview and co-design sessions were analysed to create design considerations for a tool that assists in medication taking for the target demographic. These considerations include functional, experiential and healthcare system guidelines. Findings of this study are an initial step towards developing a solution to this issue and the methods used can be applied to future research.
\end{abstract}

Keywords: medication adherence, young adults, design, designing for medication adherence 


\section{Acknowledgments}

I would like to thank my advisor, Professor Lois Frankel, and co-advisor, Professor Michel Rod who supported and guided me through my thesis. I would also like to thank my family, friends and classmates who encouraged and assisted me throughout the process. Finally, I would like to thank the participants who offered their time and expertise to make this research possible. 


\section{Table of Contents}

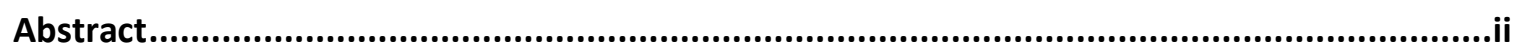

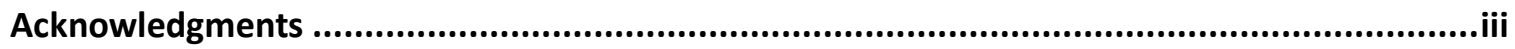

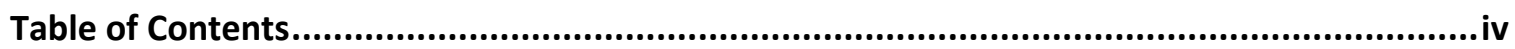

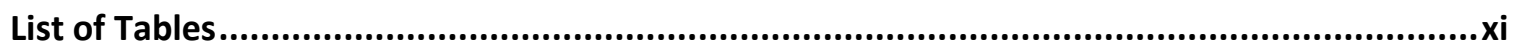

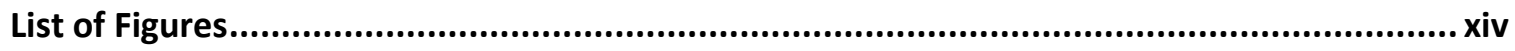

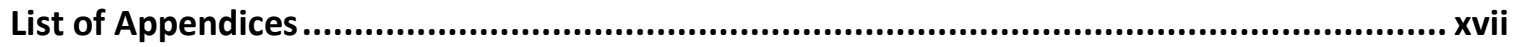

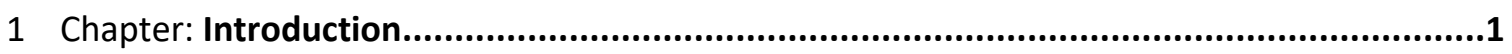

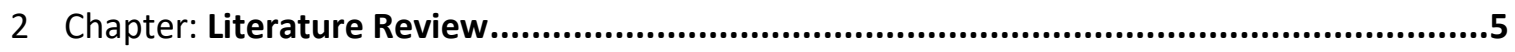

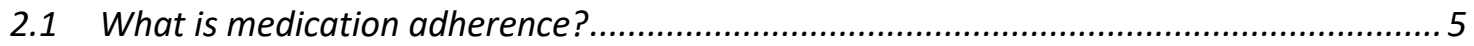

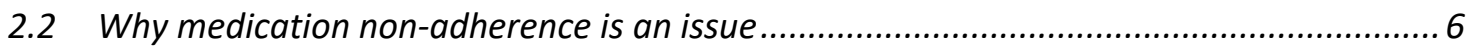

2.3 Medication non-adherence in chronic illness ............................................................ 7

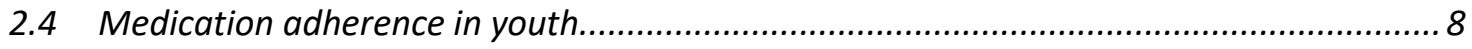

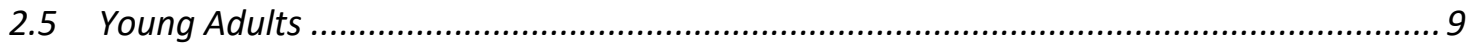

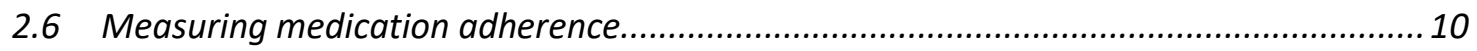

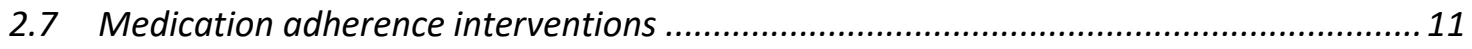

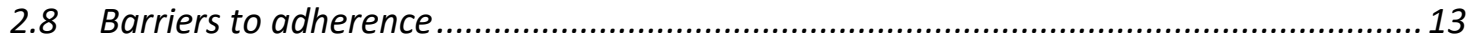

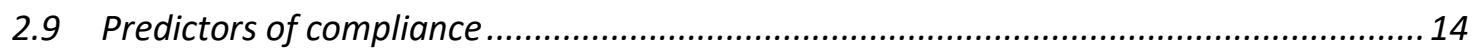

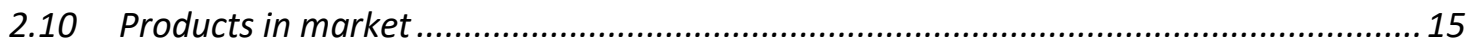

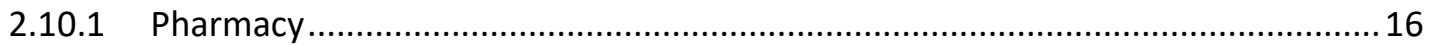

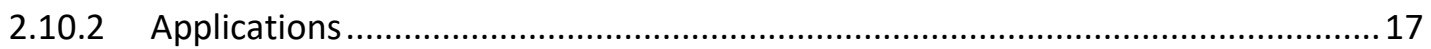




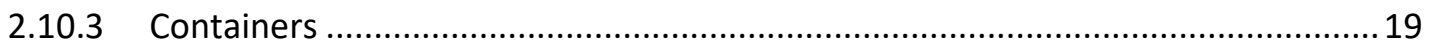

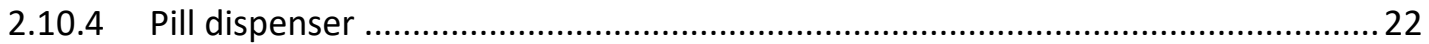

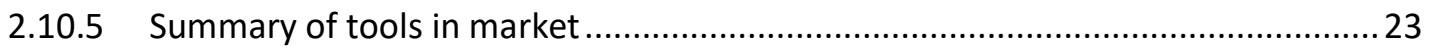

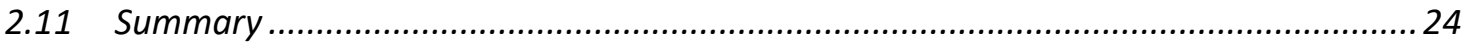

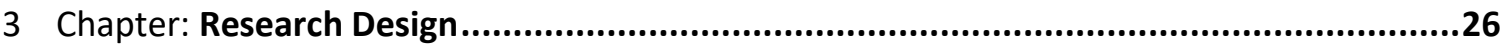

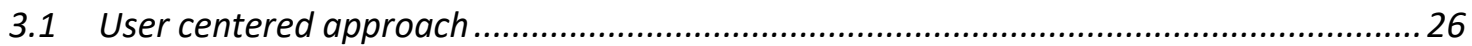

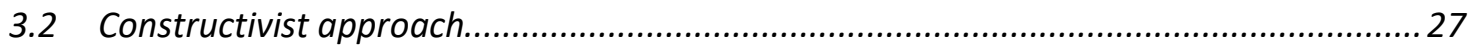

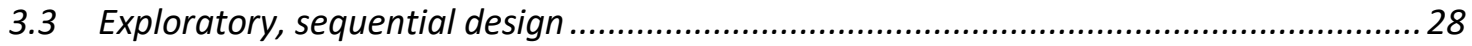

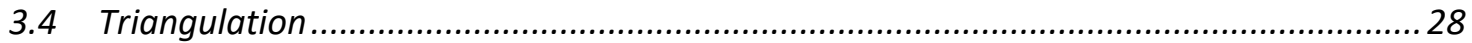

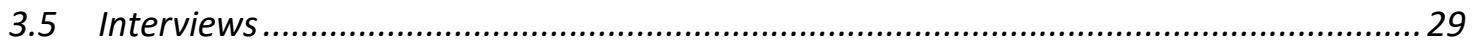

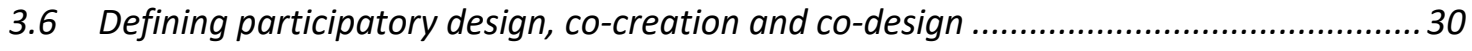

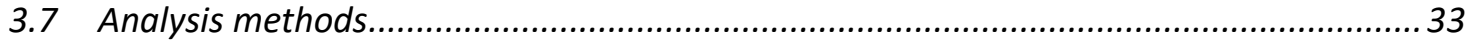

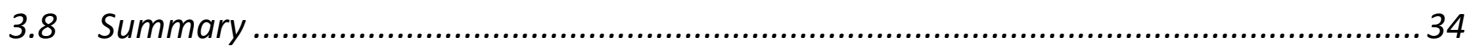

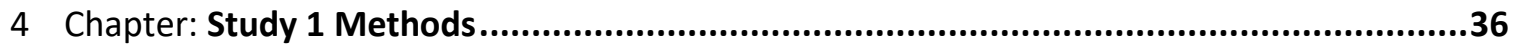

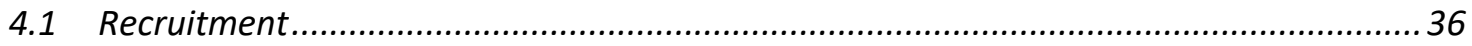

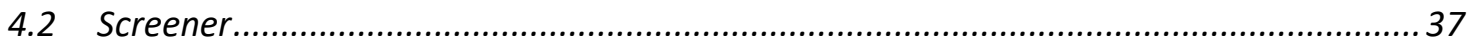

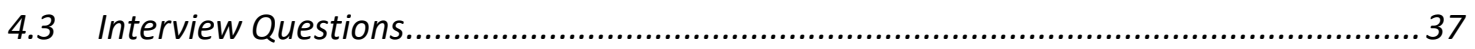

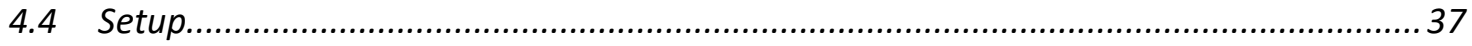

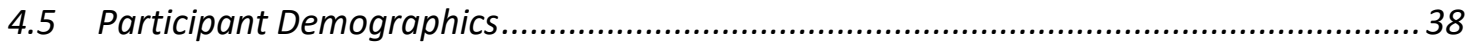

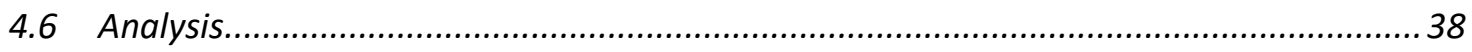

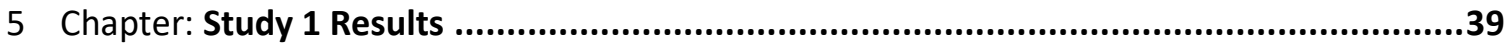

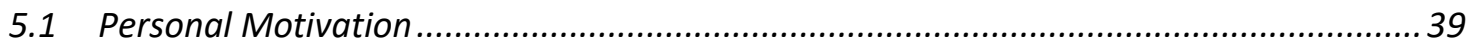

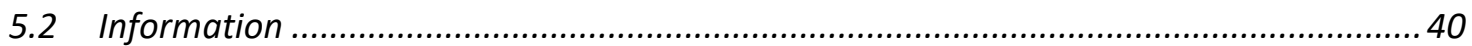




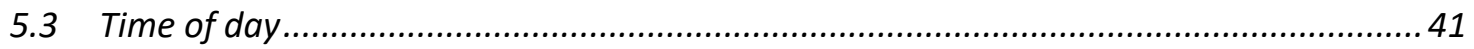

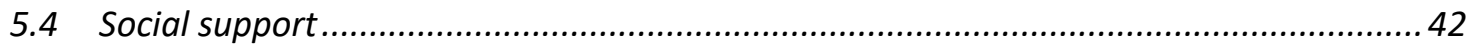

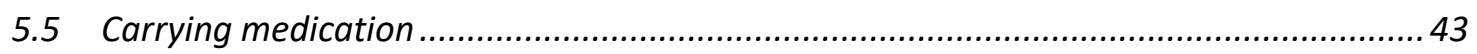

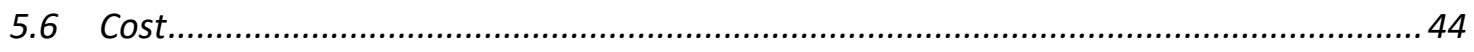

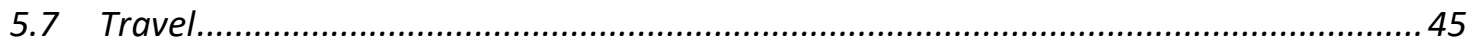

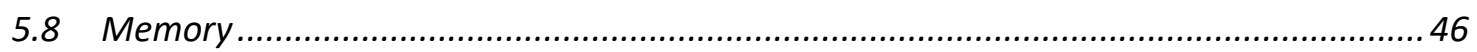

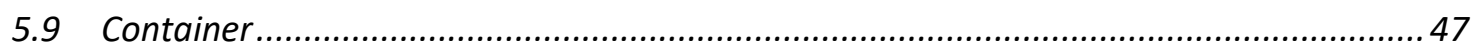

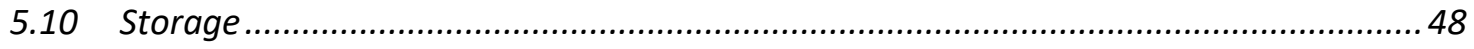

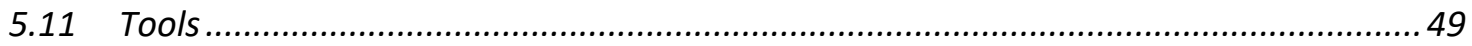

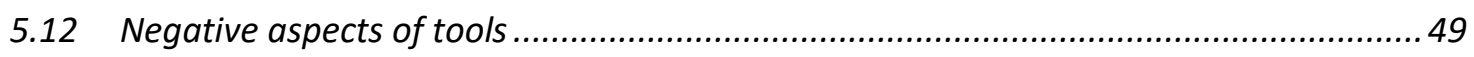

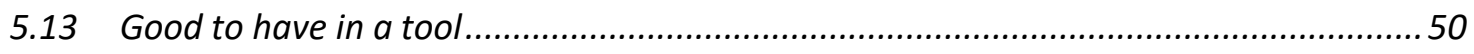

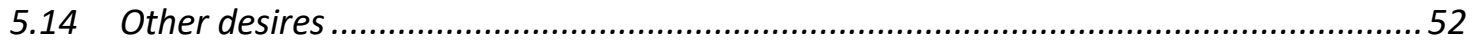

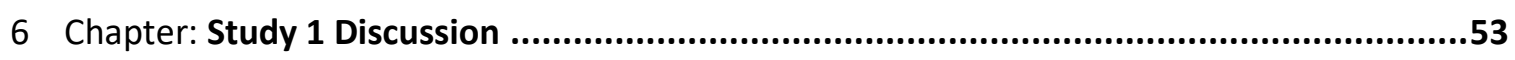

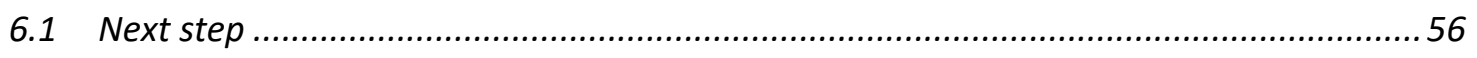

7 Chapter: Study 2 Methods .......................................................................................58

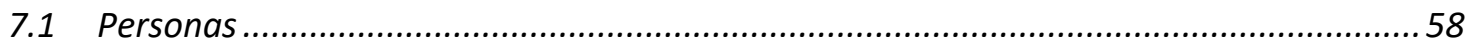

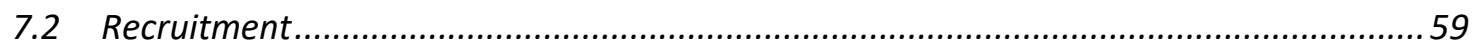

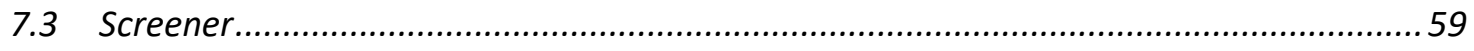

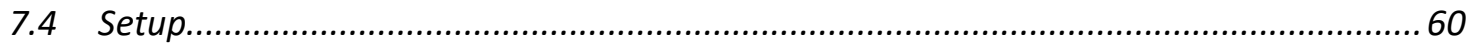

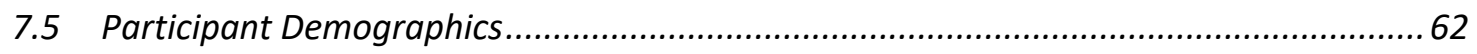

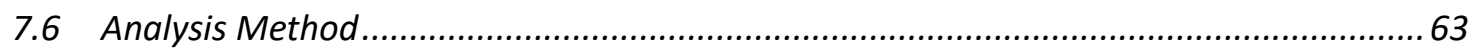

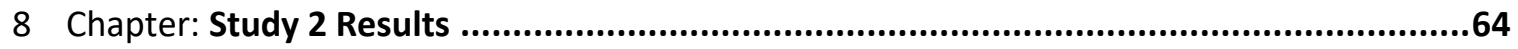

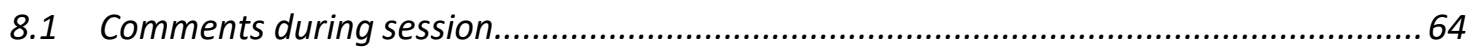




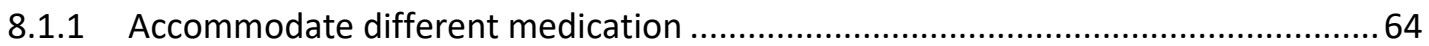

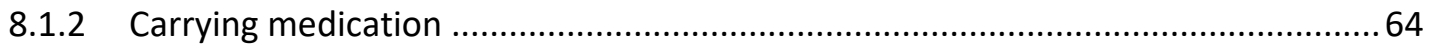

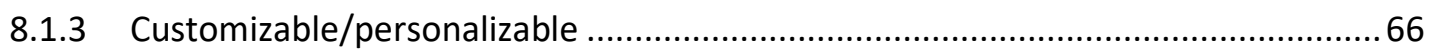

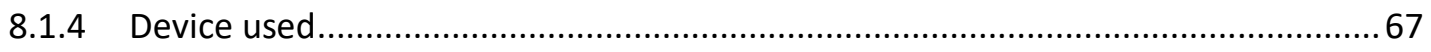

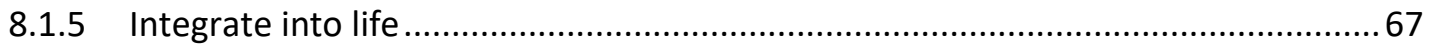

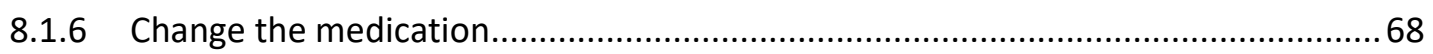

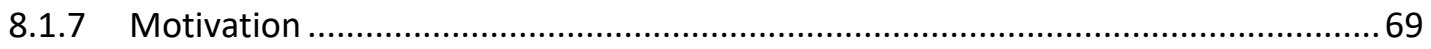

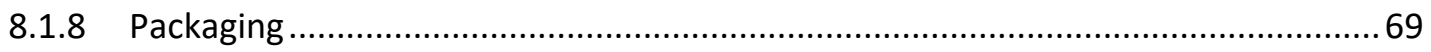

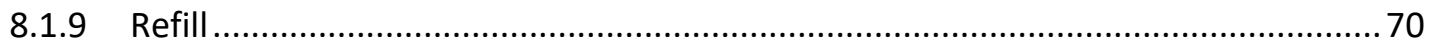

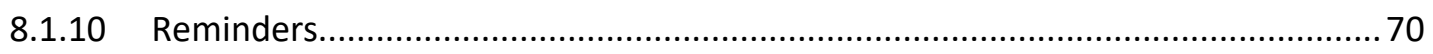

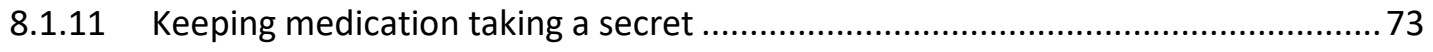

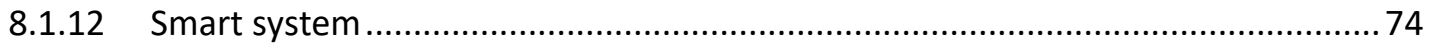

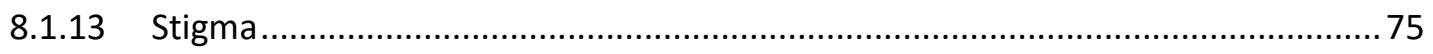

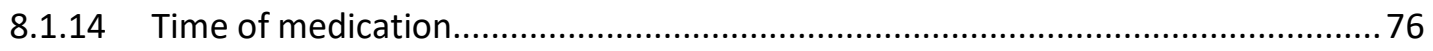

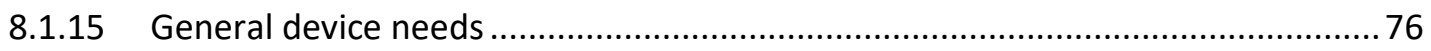

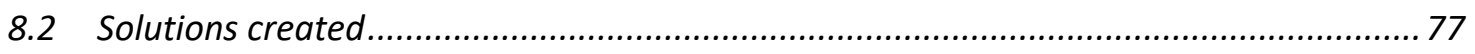

8.2.1 Cup/bottle with a refillable cartridge - Group 1 ................................................ 79

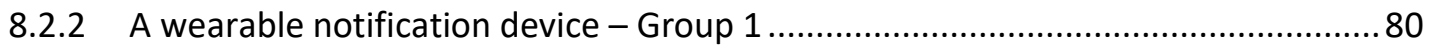

8.2.3 Cup/bottle with refillable cartridge connected to wearable device - Group 1 .......81

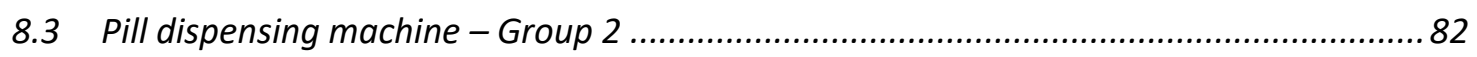

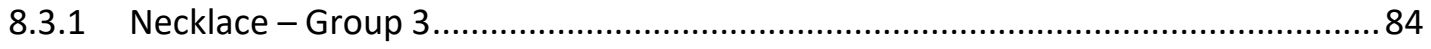

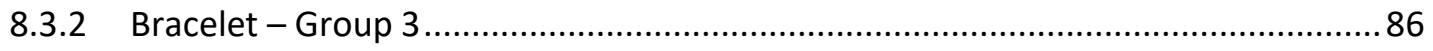

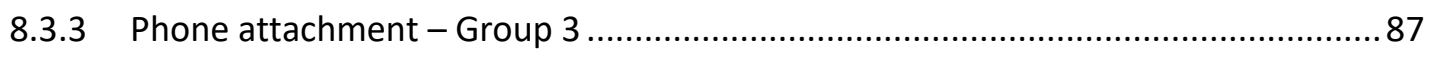

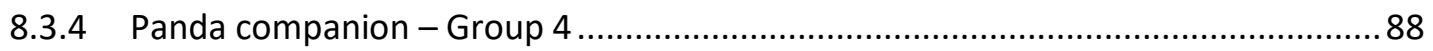


8.3.5 Water bottle with integrated pill storage - Group 4......................................... 89

8.4 Presentation comments comparison...................................................................... 91

8.4.1 Accommodate different medications ...............................................................91

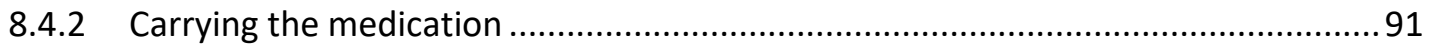

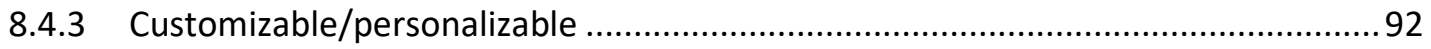

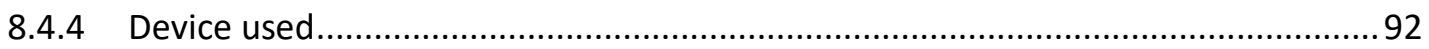

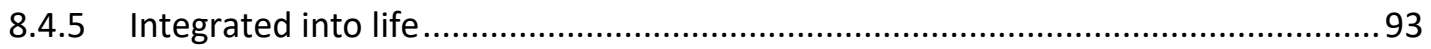

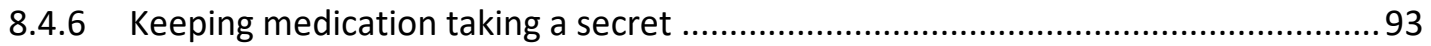

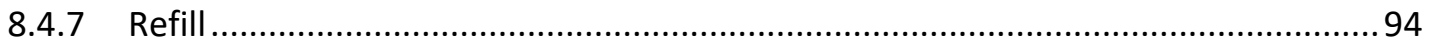

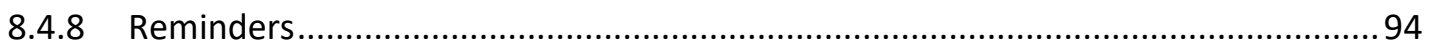

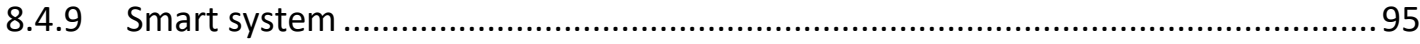

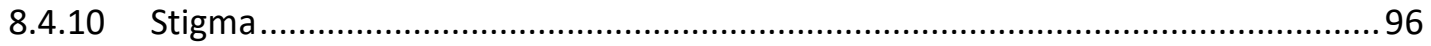

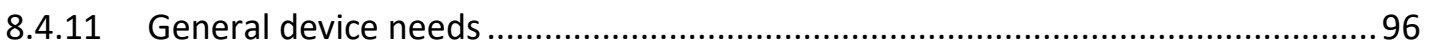

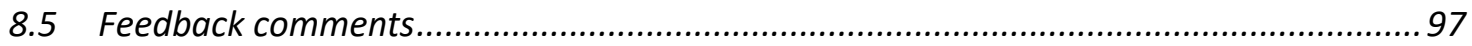

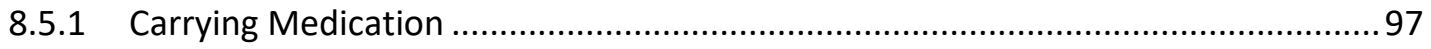

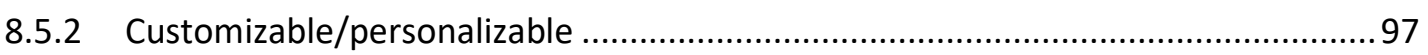

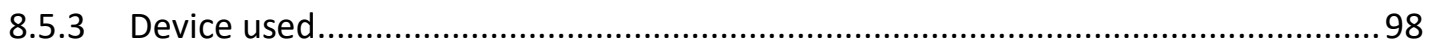

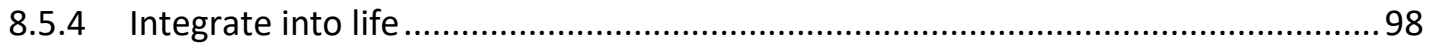

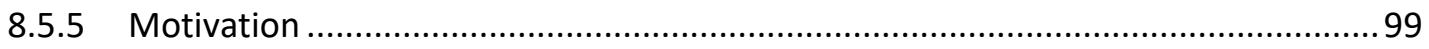

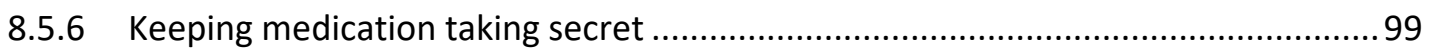

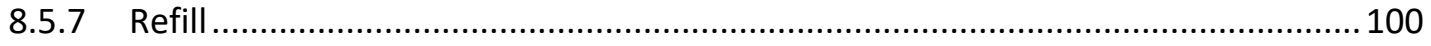

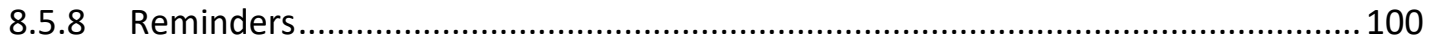

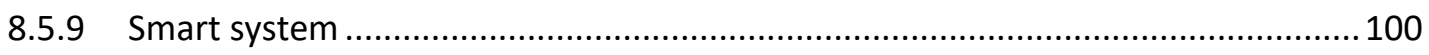

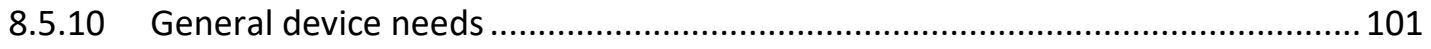




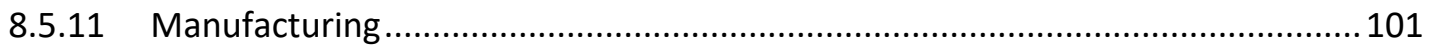

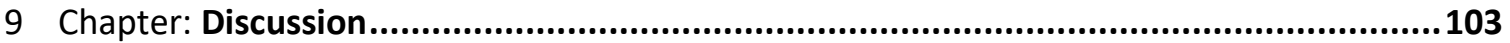

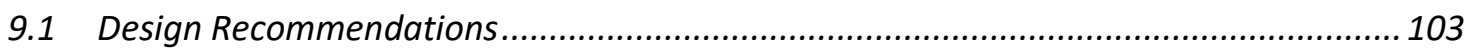

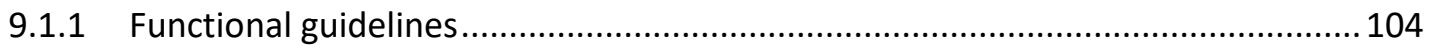

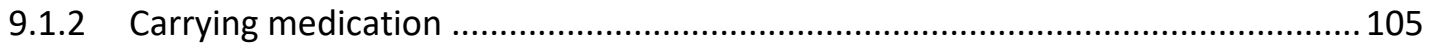

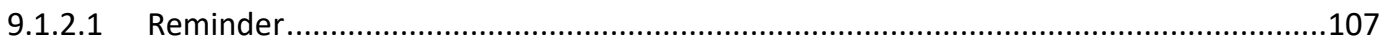

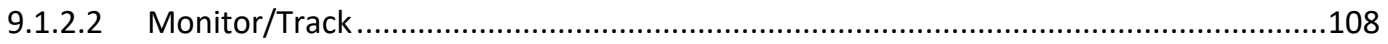

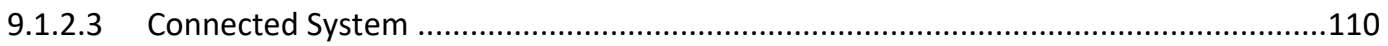

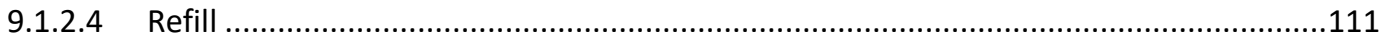

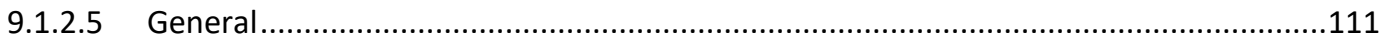

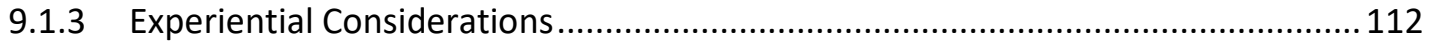

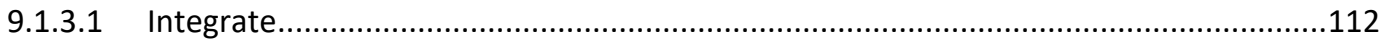

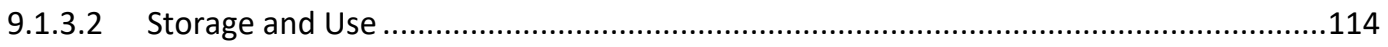

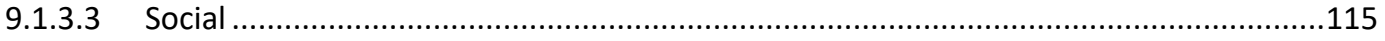

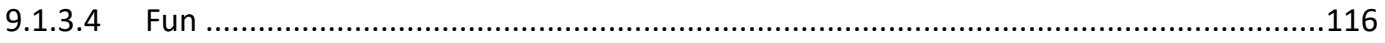

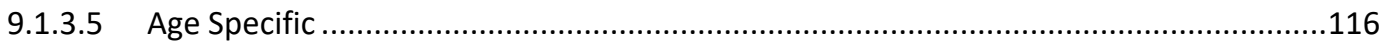

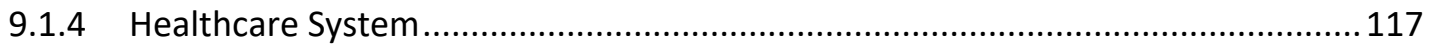

9.1.4.1 Healthcare Team ...............................................................................................118

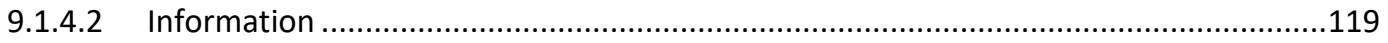

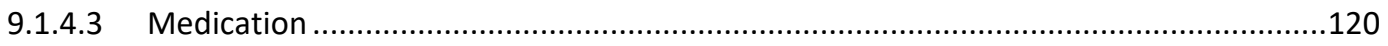

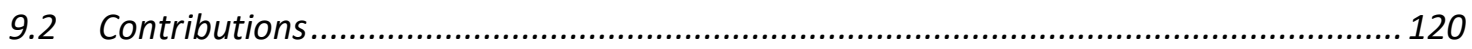

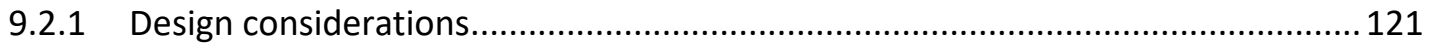

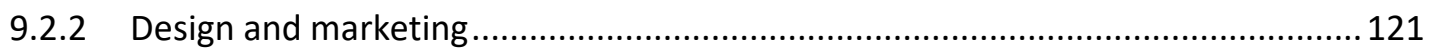

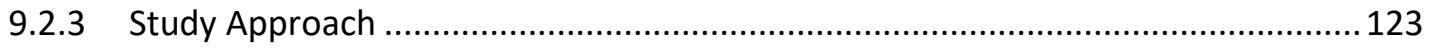

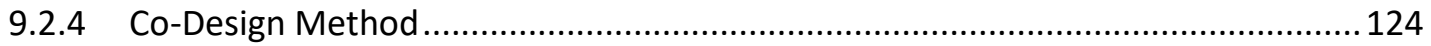




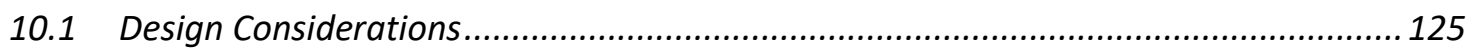

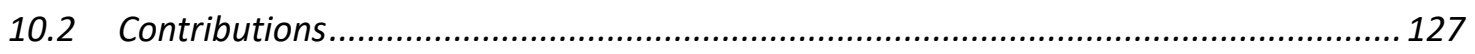

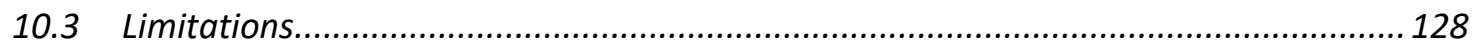

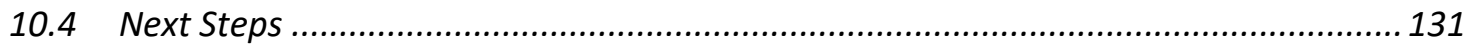

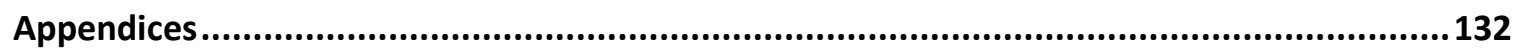

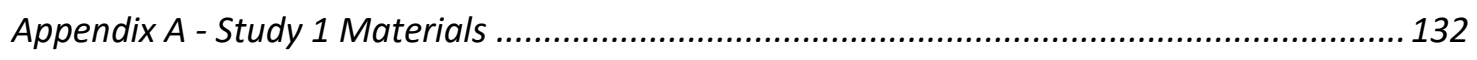

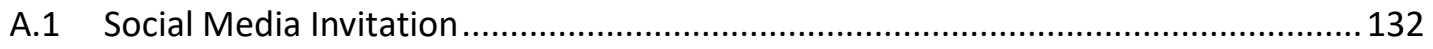

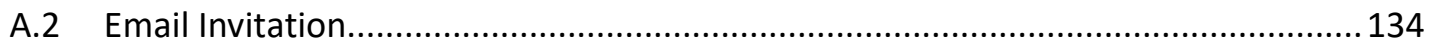

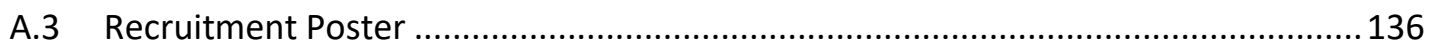

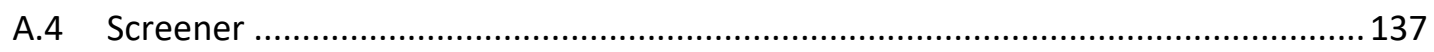

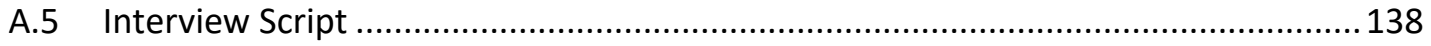

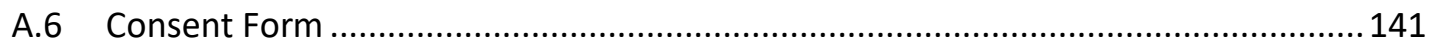

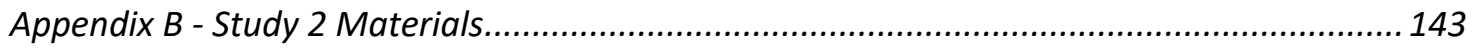

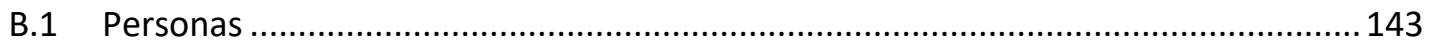

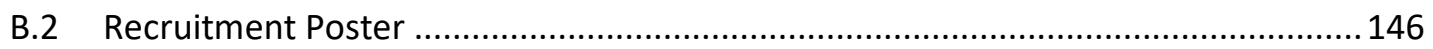

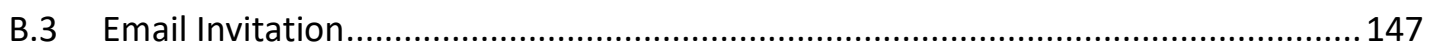

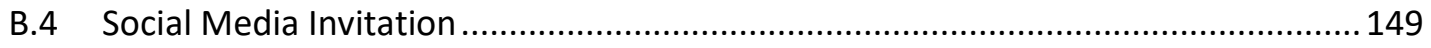

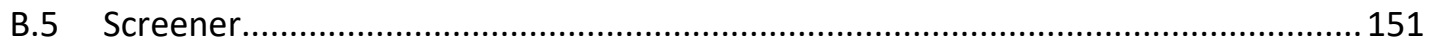

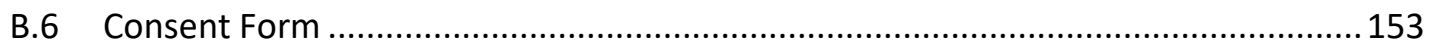

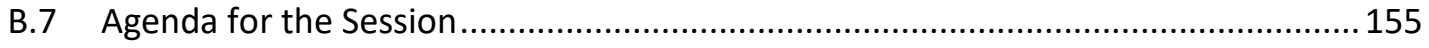

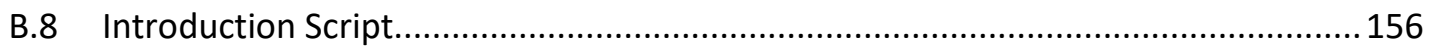

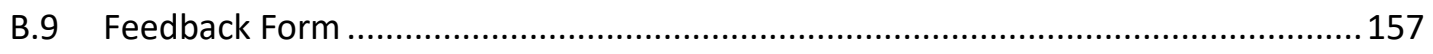

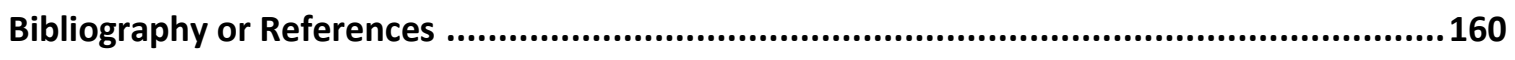




\section{List of Tables}

Table 1 Various methods that can be used to monitor patient adherence (Osterberg \&

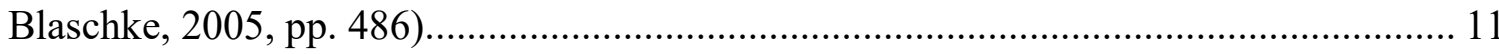

Table 2 Comparing Functions of the Solutions currently on the market ....................... 23

Table 3 Distribution of participant ages for study one. Two participants did not provide

an age 38

Table 4 Personal motivation comments distribution. ................................................. 40

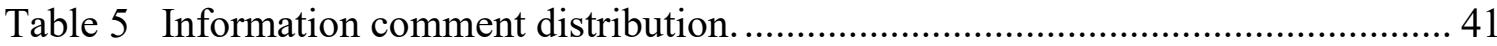

Table 6 Time of day comment distribution............................................................. 42

Table 7 Social support comment distribution......................................................... 43

Table 8 Carrying medication comment distribution. ............................................... 44

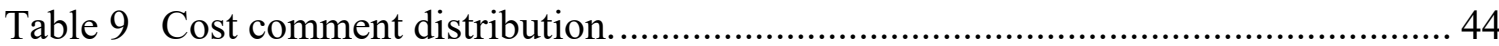

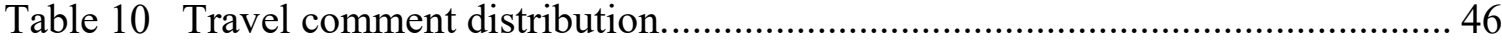

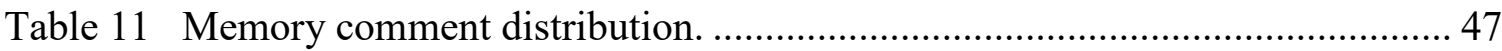

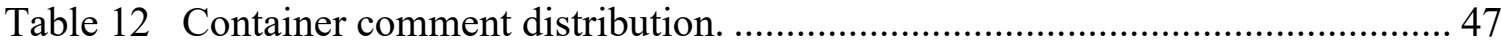

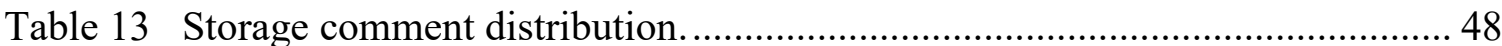

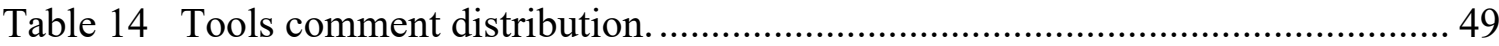

Table 15 Negative aspects of tools comment distribution....................................... 50

Table 16 Good to have in a tool comment distribution. ............................................. 51

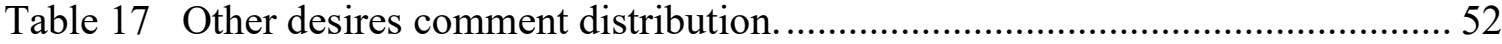

Table 18 Distribution of participant ages for study two. One participant did not provide

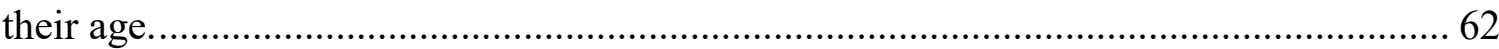


Table 19 Distribution of participant expertise for study two. One participant did not respond.

Table 20 Accommodate different medications comments during development phase of co-design. 64

Table 21 Carrying medication comment during development phase of co-design. ....... 66

Table 22 Customizability and personalization comments during development phase of co-design. 66

Table 23 Types of devices comment during development phase of co-design. 67

Table 24 Integrate into life comment during development phase of co-design. 68

Table 25 Change the medication comment during development phase of co-design..... 68

Table 26 Motivation comment during development phase of co-design...................... 69

Table 27 Packaging comment during development phase of co-design....................... 69

Table 28 Refill comment during development phase of co-design. ........................... 70

Table 29 Reminders comment during development phase of co-design. .................... 73

Table 30 Keeping medication taking a secret comments during development phase of

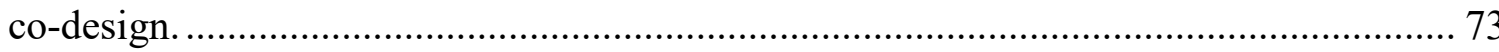

Table 31 smart system comments during development phase of co-design................... 75

Table 32 Stigma comment during development phase of co-design. …....................... 75

Table 33 Time of medication comment during development phase of co-design......... 76

Table 34 General device needs comment during development phase of co-design. ...... 77

Table 35 Accommodating different medications comments during co-design sessions. 91

Table 36 Carrying the medication comments during co-design sessions.................... 91

Table 37 Customizable/personalizable comments during co-design sessions............... 92 
Table 38 Device used comments during co-design sessions. .................................... 93

Table 39 Integrated into life comments during co-design sessions. ............................ 93

Table 40 Keeping medication taking a secret comments during co-design sessions. .... 93

Table 41 Refill comments during co-design sessions........................................... 94

Table 42 Reminders comments during co-design sessions....................................... 95

Table 43 Smart System comments during co-design sessions.................................. 96

Table 44 Stigma comments during co-design sessions......................................... 96

Table 45 General device needs comments during co-design sessions......................... 97

Table 46 Carrying medication comments on feedback form................................... 97

Table 47 Customizability/personalizability comments on feedback form. .................. 98

Table 48 Device used comments on feedback form............................................. 98

Table 49 Integrate into life comments on feedback form........................................ 99

Table 50 Motivation comments on feedback form................................................. 99

Table 51 Keeping medication taking secret comments on feedback form.................. 99

Table 52 Refill comments on feedback form...................................................... 100

Table 53 Reminders comments on feedback form. ........................................... 100

Table 54 Smart system comments on feedback form........................................ 101

Table 55 General device needs comments on feedback form................................. 101

Table 56 Manufacturing comments on feedback form....................................... 102 


\section{List of Figures}

Figure 1 Med Organizer provided by Rexall (Rexall PharmaPlus, 2018, https://www.rexall.ca/pharmacy/medicationmanagement/medorganizer) ....................... 17

Figure 2 Screenshots of the MyTherapy mobile application. From left to right, they are images of the screen to set up a medication, the home screen showing medications and the navigation bar (MyTherapy, 2018).

Figure 3 Screenshots of the Medisafe mobile application. From left to right, they are images of the screen to set up a medication, the home screen showing medications and the navigation bar (Medisafe, 2018).

Figure 4 I mage of the GlowCap taken from NantHealth (2018, https://nanthealth.com/vitality/)

Figure 5 Image of the AdhereTech bottle taken from AdhereTech (2018, https://www.adheretech.com/)

Figure 6 The Maya and jon devices sold by MedMinder. Images taken from MedMinder (2018, https://www.medminder.com/pill-dispensers-2/) 21

Figure 7 Three of the solutions sold by PILBOX. From left to right they are the Classic (PILBOX, 2018, https://pilbox.ca/en/weekly-dispensers/10-pilbox-classic.html) Liberty (PILBOX, 2018, https://pilbox.ca/en/weekly-dispensers/25-pilbox), and Electro (PILBOX, 2018, https://pilbox.ca/en/daily-dispensers-/7-pilbox-electro3401545542449.html)

Figure 8 Image of the Hero device taken from HeroHealth (2017, https://herohealth.com/) 
Figure 9 Visualization of the exploratory framework of the study............................. 35

Figure 10 Materials provided to participants during the co-design sessions................. 60

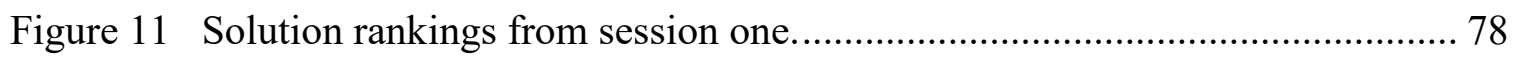

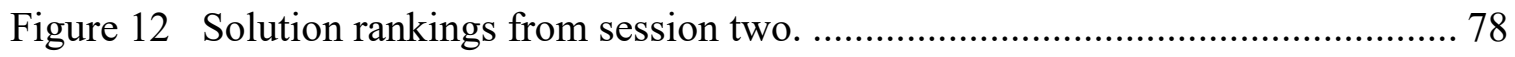

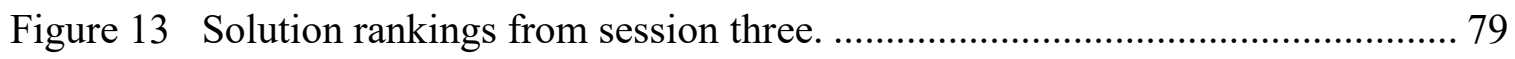

Figure 14 Solution ratings for the cup/bottle with a refillable cartridge from session one.

Figure 15 The model created by group one for the cup/bottle with a refillable cartridge.

Figure 16 Solution ratings for the wearable notification device from session one......... 81

Figure 17 Solution ratings for the combination of the cup/water bottle with a refillable cartridge and the wearable notification device from session one. ............................... 82

Figure 18 Solution ratings for the pill-dispensing machine from session two. ............. 83

Figure 19 Model and sketches of the pill dispensing machine created by group two.... 84

Figure 20 Solution ratings for the necklace from session two................................. 85

Figure 21 Model created of the necklace solution by group three.............................. 85

Figure 22 Solution ratings for the bracelet from session two................................. 86

Figure 23 Model of the bracelet solution created by group three.............................. 86

Figure 24 Solution ratings for the phone attachment from session two. ...................... 87

Figure 25 Model created by group three of the phone attachment. ............................. 88

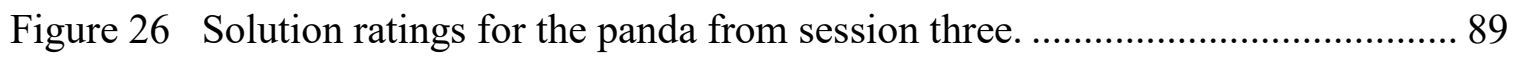

Figure 27 Model of the panda solution created by group four. ................................. 89 
Figure 28 Solution ratings for the bottle with integrated pill storage from session three.

Figure 29 Group four's sketch of the water bottle with integrated pill storage............. 90

Figure 30 The three guidelines identified as design considerations and their key topics.

Figure 31 An outline of the functional guidelines and the key factors identified in each.

Figure 32 An outline of the experiential guidelines and the key factors identified in each.

Figure 33 An outline of the healthcare system guidelines and the key factors identified in each. 118 


\section{List of Appendices}

Appendix A - Study 1 Materials............................................... 130

A.1 Social Media Invitation.................................................130

A.2 Email Invitation.....................................................

A.3 Recruitment Poster....................................................... 134

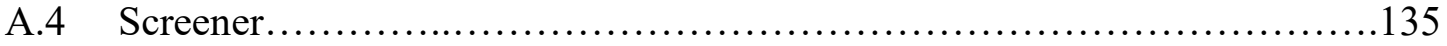

A.5 Interview Script.........................................................

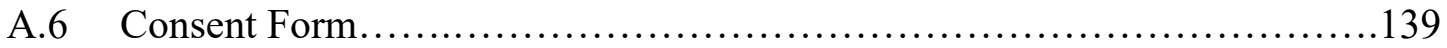

Appendix B - Study 2 Materials.................................................... 141

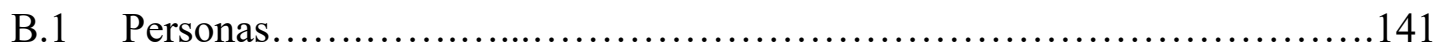

B.2 Recruitment Poster..................................................... 144

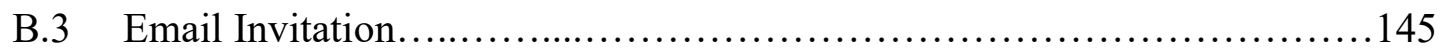

B.4 Social Media Invitation............................................. 147

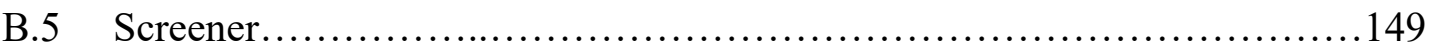

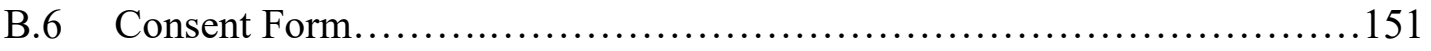

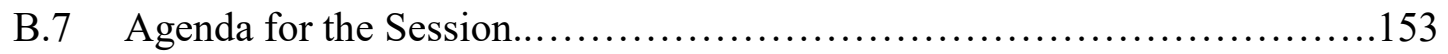

B.8 Introduction Script............................................... 154

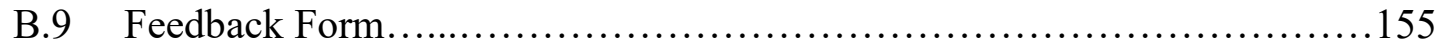




\section{Chapter: Introduction}

Adherence to a medical regimen is critical in order for treatment to have a positive outcome, yet non-adherence remains a prevalent issue. Patients with ongoing treatment plans are more likely to deviate from a given medication regimen and young adults have unique circumstances which could result in non-adherence. Solutions need to be created which can assist patients in improving medication adherence. This study explores how design techniques may provide a unique way of addressing these issues.

Medication adherence is the degree to which a patient follows a treatment plan prescribed to them by their healthcare practitioners (DiMatteo, 2004; Osterberg \& Blaschke, 2005; Matsui, 2007; Gloyd, 2003; DiMatteo, 2003; Butz, 2006). It is crucial to the success of the treatment (Osterberg \& Blaschke, 2005; Becker, Drachman \& Kirscht, 1972), and non-adherence can lead to serious consequences (DiMatteo, 2003). Despite the importance of adherence to positive health outcomes, there is still only an average adherence rate of $50 \%$ in patients with long-term treatment plans in developed countries (World Health Organization, 2003). Ongoing treatment plans, mainly those lasting over six months, are shown to have lower adherence rates (Osterberg \& Blaschke, 2005). In addition, young adults are going through a period of transition, which can cause a decrease in adherence rates (Annunziato, Emre, Shneider, Barton, Dugan \& Shemesh, 2007).

Though young adults may be a unique population, with their own needs, much of the research on adherence to date has been done on adult populations (Rao, Kekwaletswe, Hosek, Martinez \& Rodriguez, 2007; Dean, Walters \& Hall, 2010) and may not necessarily be applicable, or cover all the needs of young adults (Dean et al., 2010). 
Young adults can be viewed as a specific market segment, with unique needs. If one looks at them from a marketing perspective, one could, in 2018 when this study was conducted, classify them as mostly Generation Y with some in Generation Z. Within generational cohorts, individuals can be seen as having similar behaviours, attitudes and values (Smith \& Nichols, 2015; Grewal et al., 2011). With these specific cohorts, being technologically savvy is also a major factor (Grewal et al., 2011; Nichols \& Wright, 2018; Smith \& Nichols, 2015). These factors suggest that they may be in need of their own solutions, instead of having the needs of other populations generalized to them.

All of this seems to point to medication adherence being a major issue, presenting an opportunity for more research on interventions for specific populations. This is an issue that may benefit from a design approach. The literature on medication adherence shows that there may be a need to target young adults with ongoing treatment plans when it comes to interventions aimed at improving adherence. Therefore, the following study used design methods, with a marketing influence, to see how design research can contribute to improving medication adherence in young adults on ongoing treatment plans.

Taking a user-centered approach, the research captured insights into the users' specific needs (Mao, Vredenburg, Smith \& Carey, 2005; Duarte \& Guerra, 2012; Wilkinson \& De Angeli, 2014), potentially improving the effectiveness, efficiency (Mao et al., 2005; Duarte \& Guerra, 2012) and adoption rates (Wilkinson \& De Angeli, 2014) of products it may inform. A constructivist approach was used, which allowed participants to inform the research through their experiences (Creswell, 2014). Since there was not much literature targeting this specific population's needs with medication 
adherence, the research conducted was exploratory (Creswell, 2003). The methods were also conducted sequentially, allowing them to build and expand on each other's findings (Creswell, 2003).

To define the scope and need for research on improving adherence in young adults, a literature review was conducted. This is discussed in the next chapter, chapter two. It also identifies the known issues and interventions for medication adherence as well as some of the products on the market. In chapter three, the research design of this paper is described, which will define the methods and approaches used as well as explaining why they were chosen for this study.

Based on findings from the literature review, interviews were conducted with young adults on ongoing treatment plans to identify how they approached medication adherence and what they saw as barriers. The method used for this study is described in chapter four and the results are displayed in chapter five. Chapter six provides an overview of the results from study one and compares them to the findings from the literature review to inform the second study. Based on findings from the literature review about medication adherence while travelling and the interviews, personas were created to guide users in a co-design session. These personas identify key findings of barriers to adherence for young adults on ongoing treatment plans while travelling.

Through the co-design sessions, while the participants were designing potential solutions, information was gathered on what young adults wanted or believed they needed to help them improve adherence. The method for this study is explained in detail in chapter seven and the results are reported in chapter eight. Findings from all three 
studies were compared to identify what should be considered when developing a solution to help improve medication adherence in young adults on ongoing treatment plans.

This can be seen in chapter eight which provides a discussion of the results of this research, comparing the literature review to the first and second study. Through this, a set of design considerations is identified and the contributions of the study are defined. There are four major contributions of this work: the first is a set of design considerations to inform solutions to adherence in this demographic; the second is the design and marketing perspective used; third is the methods used, which can be applied to future work; and the last contribution is the way in which the co-design sessions were conducted.

The final chapter, chapter nine, provides a summary of the research as well as the findings. It also identifies the limitations of this study and future research that can be done to expand on this work. 


\section{Chapter: Literature Review}

Initially, the researcher was interested in the role design could play in healthcare. A literature review in this area revealed that adherence to treatment plans was an area that needed to be studied. It was also found that there was a need to understand and target young adults who are on ongoing treatment plans. This chapter presents findings from the literature review that identify what medication adherence is and why it is an issue, as well as defining why research needed to be done on individuals with chronic illness and young adults. A marketing approach was also used to define youth as a market segment. It then describes current knowledge and practices around measuring medication adherence, interventions to improve adherence, barriers preventing adherence and predictors of compliance. Finally, it will briefly highlight some of the tools on the market for medication adherence.

\subsection{What is medication adherence?}

Medication adherence or compliance is defined as the degree to which patients' behaviour corresponds to the recommendations of their health professionals (DiMatteo, 2004; Osterberg \& Blaschke, 2005; Matsui, 2007; Gloyd, 2003; DiMatteo, 2003; Butz, 2006). This can include taking medication (including the doses and timing of that medication), making lifestyle changes and/or following a diet (Matsui, 2007). Though the meanings of adherence and compliance are similar, adherence is often preferred by healthcare providers because the term compliance implies that the patent follows their doctor's orders (Osterberg \& Blaschke, 2005). The term adherence is still not ideal (Osterberg \& Blaschke, 2005), but it is preferred since it acknowledges that the patient has a role in the decision-making process (Matsui, 2007) and is perceived as a 
nonjudgmental term to assess patient behaviour (Butz, 2006). Hence, throughout this paper, the term medication adherence is used to mean the degree to which an individual follows a treatment plan prescribed to them by a healthcare professional.

The threshold for non-adherence can differ depending on the patient, drug and disease; however, it is significant when it changes the desired therapeutic effect (Alsous, 2017). In most studies, there is no standard operational definition of adherence (Becker \& Maiman, 1975; DiMatteo, 2004) since the division between adherence and non-adherence is not consistent (Matsui, 2007). Matsui (2007) states that there is an arbitrary cut-off where anything over an $80 \%$ compliance rate is considered adherent. For the purpose of this paper, the exact cut-off between adherence and non-adherence is not relevant, since the degree to which individuals followed a plan was not measured or reported on. The focus was more on patients' behaviours and perceptions around adherence.

\subsection{Why medication non-adherence is an issue}

Adherence to treatment regimens is crucial in successful treatment (Osterberg \& Blaschke, 2005; Becker et al., 1972) and poor medication adherence may lead to serious consequences (DiMatteo, 2003). Non-adherence may directly affect treatment by negatively impacting the potential benefits of the medication (Becker \& Maiman, 1975; Matsui, 2007; Dean et al., 2010; DiMatteo, 2003; Butz, 2006; Alsous, 2017), reducing the patients' quality of life (DiMatteo, 2004), and potentially leading to suffering (DiMatteo, 2004) or higher mortality rates (DiMatteo, 2004). This could lead to frustration, anger or hopelessness for both the healthcare provider and the patient (DiMatteo, 2004). Failure to accurately relay adherence rates to healthcare professionals may lead to incorrect clinical conclusions (DiMatteo, 2004) that make it impossible to assess quality of the treatment 
(Becker \& Maiman, 1975). This may lead to the patient having to undergo unnecessary procedures and treatments (Becker \& Maiman, 1975; Matsui, 2007; Butz, 2006), cause dissatisfaction with the healthcare system (Becker \& Maiman, 1975) and ultimately impact the relationship between a doctor and their patient (Becker \& Maiman, 1975). In some cases, poor adherence may also lead to virus strains that are drug resistant (Rao et al., 2007; Hinkin, Hardy, Mason, Castellon, Durvasula, Lam \& Stefaniak, 2004;

DiMatteo, 2003). On another note, DiMatteo (2004) states that the choice to not adhere can be a way for patients to maintain a personal identity and quality of life. Through the literature, it can be seen that medication adherence is an issue. One that can lead to negative consequences in a patient's health.

\subsection{Medication non-adherence in chronic illness}

The issue of non-adherence can be worse in patients who are on ongoing medication plans. Long-term adherence is critical to the management of chronic diseases since the disease is lifelong and can encompass all aspects of daily life (DiMatteo, 2003). Unfortunately, poor medication adherence is especially common in chronic illnesses (Dean et al., 2010; Gardiner \& Dvorkin, 2006; Matsui, 2007). Of patients with chronic illness, approximately 30 to 70 percent have poor adherence (Gardiner \& Dvorkin, 2006; Osterberg \& Blaschke, 2005). This may be due to periods of symptomatic remission, extended treatment duration and taking multiple medications (Gardiner \& Dvorkin, 2006). In chronic illness, adhering to daily medication interventions can be overwhelming (DiMatteo, 2003). Rates of adherence tend to be higher in acute conditions and typically decline severely after six months of therapy (Osterberg \& Blaschke, 2005). The literature shows that that non-adherence is more prevalent when the duration of 
treatment increases; therefore, patients on ongoing treatment plans are at a higher risk of not following their treatment plans.

\subsection{Medication adherence in youth}

The issue of adherence has been extensively studied, though most of the literature and interventions focus on the adult population, leaving out issues of adherence in youth (Rao et al., 2007; Dean et al., 2010). There are different factors that may influence adherence in youth, leading to a need for interventions targeting this population specifically, as opposed to translating findings from research done on adults (Dean et al., 2010); design may be able to play a part in identifying these factors and interventions.

Adolescents tend to be less adherent to their medical regimens than younger children (DiMatteo, 2004; Annunziato et al., 2007). During adolescence, patients begin to take over their healthcare responsibilities that may have previously been managed by their caregivers (Annunziato et al., 2007). When they become young adults, they have another transition where they shift from child-centered services to adult facilities (Annunziato et al., 2007). In a study conducted by Annunziato et al. (2007), they believe that this transition to adult services decreased the rate of patient adherence, leading to deteriorated medical outcomes in transplant patients. They believe some factors responsible for the adherence issues during transition include: the paediatric clinic is more 'hands-on' and treats non-adherence more aggressively; there may be changes in insurance status causing a lapse in service; the transition to less familiar providers may cause distress and increase individual risk factors. Rao et al. (2007) found that due to age, youth may view healthcare providers as an authority figure, and inaccurately report adherence out of fear. In a study, Hinkin et al. (2004) identified that in HIV infected 
adults, patients above the age of 50 were significantly better at adhering to their medication regimens than younger patients. According to these studies, young adults may be a population with their own needs in terms of interventions to improve adherence, though there does not seem to be much research addressing their specific needs.

\subsection{Young Adults}

Young adults can roughly be defined as individuals aged 18 to 35 (Petry, 2002). They can be seen as a unique market segment and defined in terms of their generational cohorts. During the time these studies were conducted, between 2017 and 2018, the majority of young adults belong to the Generation Y, or the Millennial cohort and some of the younger individuals in this range may be Generation Z. A generational cohort is generally identified by age, years of birth, location or significant events which can impact their behaviours, attitudes and values, leading to them being relatively homogeneous in these character traits (as cited by Smith \& Nichols, 2015; Nichols \& Wright, 2018; Grewal et al., 2011).

Smith \& Nichols (2015) define Generation Y as individuals who were born from 1980 to 2000 , though Nichols \& Wright (2018) defines them as individuals born between the 1981 and 1995. Generation Y is described as being technologically and internet savvy (Grewal, Levy, Persaud \& Lichti, 2011; Nichols \& Wright, 2018; Smith \& Nichols, 2015). This generation is connected with social media (Nichols \& Wright, 2018) and enjoys the use of technology (Grewal et al., 2011; Smith \& Nichols, 2015). Nichols \& Wright (2018) identifies Generation $Z$ as anyone born after 1996. Generation $Z$ is more technologically savvy than Generation Y since technology has always been available to them (Nichols \& Wright, 2018; Grewal et al., 2011). 
This marketing perspective allows us to see that young adults may have similarities that differentiate their needs from those of older adults, children and youth. Their age and the generational cohort they fall under can also impact what types of solutions could be most effective for them as a market segment. As seen in the literature, they may benefit from the integration of technology in solutions tailored to them.

\subsection{Measuring medication adherence}

Due to the detrimental consequences of not adhering to medication, the ability to assess adherence is crucial. Though it is necessary, there is no ideal method to measure adherence in clinical practice (Matsui, 2007). There are many methods available for monitoring adherence, and according to Osterberg \& Blaschke (2005), these can be divided into direct and indirect methods (see Table 1 for a list of methods of monitoring adherence). Direct methods of monitoring adherence involve measuring the concentration of the drug in a patient's blood or urine. These methods are typically difficult for the health care provider, expensive and may be distorted by the patient. Indirect methods of measuring adherence include questioning the patient, pill counts, the use of electronic monitors, and medication diaries. These methods are easy to use but can be inaccurate and often result in an overestimation of adherence (Osterberg \& Blaschke, 2005). The most common methods used to measure medication adherence are medical records, selfreports (DiMatteo, 2004) and pill counts (DiMatteo, 2004; Osterberg \& Blaschke, 2005).

Through a meta-analysis of studies on medication adherence, DiMatteo (2004) found that the method of measurement for medication adherence could have an impact on the patients' level of adherence. Some of their findings include that there are higher levels of adherence when pill counts are used. They also found that there is a slightly 
lower adherence in studies which use a physical test to measure adherence and on average, studies which use subjective measurements of adherence have lower adherence scores than those which use objective measures.

Though this study focuses on patient perspectives more than measuring their exact adherence, a knowledge of these monitoring techniques may be useful when developing a solution to the issues of non-adherence; whether it be allowing physicians and researchers to monitor adherence or allowing patients to track their own behaviours.

\begin{tabular}{|c|c|c|c|}
\hline Method & Test & Advantages & Disadvantages \\
\hline \multirow[t]{3}{*}{ Direct } & Directly observed therapy & Most accurate & $\begin{array}{l}\text { Patients can hide pills in the mouth and } \\
\text { then discard them; impractical for routine } \\
\text { use }\end{array}$ \\
\hline & $\begin{array}{l}\text { Measurement of the level of medicine } \\
\text { or metabolite in blood }\end{array}$ & Objective & $\begin{array}{l}\text { Variations in metabolism and 'white coat } \\
\text { adherence' can give a false impression of } \\
\text { adherence; expensive }\end{array}$ \\
\hline & $\begin{array}{l}\text { Measurement of the biologic marker in } \\
\text { blood }\end{array}$ & $\begin{array}{l}\text { Objective; in clinical trials, can also } \\
\text { be used to measure placebo }\end{array}$ & $\begin{array}{l}\text { Requires expensive quantitative assays } \\
\text { and collection of bodily fluids }\end{array}$ \\
\hline \multirow[t]{8}{*}{ Indirect } & $\begin{array}{l}\text { Patient questionnaires, patient self- } \\
\text { reports }\end{array}$ & $\begin{array}{l}\text { Simple; inexpensive; the most } \\
\text { useful method in the clinical setting }\end{array}$ & $\begin{array}{l}\text { Susceptible to error with increases in time } \\
\text { between visits; results are easily distorted } \\
\text { by the patient }\end{array}$ \\
\hline & Pill counts & $\begin{array}{l}\text { Objective, quantifiable, and easy to } \\
\text { perform }\end{array}$ & $\begin{array}{l}\text { Data easily altered by the patient (e.g., } \\
\text { pill dumping) }\end{array}$ \\
\hline & Rates of prescription refills & Objective; easy to obtain data & $\begin{array}{l}\text { A prescription refill is not equivalent to } \\
\text { ingestion of medication; requires a closed } \\
\text { pharmacy system }\end{array}$ \\
\hline & $\begin{array}{l}\text { Assessment of the patient's clinical } \\
\text { response }\end{array}$ & Simple; generally easy to perform & $\begin{array}{l}\text { Factors other than medication adherence } \\
\text { can affect clinical response }\end{array}$ \\
\hline & Electronic medication monitors & $\begin{array}{l}\text { Precise; results are easily } \\
\text { quantified; tracks patterns of taking } \\
\text { medication }\end{array}$ & $\begin{array}{l}\text { Expensive; requires return visits and } \\
\text { downloading data from medication vials }\end{array}$ \\
\hline & $\begin{array}{l}\text { Measurement of physiologic markers } \\
\text { (e.g., heart rate in patients taking beta- } \\
\text { blockers) }\end{array}$ & Often easy to perform & $\begin{array}{l}\text { Marker may be absent for other reasons } \\
\text { (e.g., increased metabolism, poor } \\
\text { absorption, lack of response) }\end{array}$ \\
\hline & Patient diaries & Help to correct for poor recall & Easily altered by the patient \\
\hline & $\begin{array}{l}\text { When the patient is a child, } \\
\text { questionnaire for caregiver or teacher }\end{array}$ & Simple; objective & Susceptible to distortion \\
\hline
\end{tabular}

Table 1 Various methods that can be used to monitor patient adherence (Osterberg \& Blaschke, 2005, pp. 486). 


\subsection{Medication adherence interventions}

Through the literature, some interventions were also identified. Some of the more common interventions to date include simplifying the medication schedule by reducing the frequency of dosing (Matsui, 2007; Butz, 2006), especially when it avoids dosing in the middle of the day (Matsui, 2007). This can help reduce the disruptiveness of taking the medication and help patients avoid social stigmas around taking medication (Matsui, 2007). Another common intervention is setting reminders or aligning medication doses with daily events (Matsui, 2007; Butz, 2006; Nair et al., 2011). Effective communication between the patient and healthcare team is also essential in improving adherence (Matsui, 2007; Butz, 2006). Education is also an important component to improving adherence (Matsui, 2007; Butz, 2006; Osterberg \& Blaschke, 2005). Patients should understand the disease, as well as the benefits and purpose of the treatment (Matsui, 2007; Osterberg \& Blaschke, 2005). When possible, patients should be provided with explicit, preferably written instructions in addition to verbal (Matsui, 2007). There is a stronger relationship between adherence and education in chronic illnesses than in acute illness (DiMatteo, 2004). In a literature search conducted by Dean et al., (2010) they found that education alone as an intervention was unlikely to improve adherence in children and adolescents; though, when paired with behavioural interventions, it had more beneficial effects (Dean et al., 2010). Games are also often used as an intervention to increase adherence (Kato et al., 2008) especially in the form of educational health games (Nikkila et al., 2012). Any method implemented should be followed by incremental feedback and adjustment of the interventions as necessary (Matsui, 2007). Osterberg \& Blaschke (2005) state that methods to improving medication adherence can be divided into four main categories; 
these include better patient-physician communication, increased clinic hours (leading to shorter wait times), better patient education, and improved dosing schedules. They also state that most interventions include a combination of these and behavioural interventions (Osterberg \& Blaschke, 2005) and often a combination of different interventions is the most successful to improving adherence (Osterberg \& Blaschke, 2005; Matsui, 2007). It is also beneficial to identify patients who may be in need of more intensive interventions or targeted support (Matsui, 2007).

The interventions found in the literature were mostly identified as solutions for the general population. They do not specifically target young adults.

\subsection{Barriers to adherence}

The literature also thoroughly covers some of the barriers to adherence. It states that one of the most common causes of missing doses is forgetfulness (Matsui, 2007; Osterberg \& Blaschke, 2005; Nair et al., 2011; Hanghøj \& Boisen, 2014). Others include alternate priorities, deciding to skip doses, lack of treatment information and emotional factors (Osterberg \& Blaschke, 2005; Hanghøj \& Boisen, 2014). Hanghøj \& Boisen (2014) and Nair et al. (2011) found that support from friends and family impacted rates of adherence. Rao et al. (2007) found that in youth living with HIV, discrimination and social stigma were driving factors in non-adherence. They also found that depressive symptoms negatively impacted adherence. Physicians can also create barriers in adherence by prescribing complex treatments, inadequately educating the patients, having a poor patient-physician relationship and not considering the patient needs or lifestyle when prescribing treatment (Osterberg \& Blaschke, 2005; Hanghøj \& Boisen, 2014). Limited access to healthcare and expensive drugs can also be a barrier to adherence (Osterberg \& 
Blaschke, 2005; Hanghøj \& Boisen, 2014). In a systematic review, Hanghøj \& Boisen (2014) found that with adolescents, other activities, such as traveling, vacation, sleepovers with friends and parties negatively impacted adherence. This finding was supported by Nair et al. (2011), who found interferences or changes in daily routines, such as travel, negatively impacted patient adherence rates.

Though there is a lot of literature on the barriers to adherence, as with the interventions, it too targets the general population. There was not a lot of literature that identified barriers young adults may face that may not be as prevalent in other patient segments.

\subsection{Predictors of compliance}

There aren't any known factors that reliably predict patient adherence (Matsui, 2007; Becker \& Maiman, 1975), however there are some factors which have a strong correlation with patient adherence. There is a significant, positive correlation between adherence and income/socioeconomic status (DiMatteo, 2004). Adherence to clinical instructions is especially poor in low-income populations, often over 60\% (Becker \& Maiman, 1975). There is also a significant, positive correlation between patient education and adherence (DiMatteo, 2004). Though patients with greater income and education have higher levels of adherence (DiMatteo, 2004), demographic characteristics such as age and gender don't have much of an effect (DiMatteo, 2004; Osterberg \& Blaschke, 2005). The specific disease is also a factor that can impact the rate of adherence (DiMatteo, 2004). In a meta-analysis, DiMatteo (2004) found that factors such as depression, support and income that can be changed or treated have a greater impact on adherence rate than factors like age and gender that cannot. Adherence is also often 
dependent on the regimen itself (Becker \& Maiman, 1975; DiMatteo, 2004). Regimens that use medicine more than pervasive health behaviours tend to achieve higher levels of compliance (DiMatteo, 2004).

Other studies claim that these factors do not explain why patients adhere to medication regimens (Becker \& Maiman, 1975) and instead look at the motivations behind compliance. One theory that is used to explain health actions is the valueexpectancy model, which describes decision making or behaviour under uncertainty (Becker \& Maiman, 1975; Becker et al., 1972). It states that behaviour can be predicted based on the value of a given outcome to the individual and their expectation that the action will lead to the desired outcome (Becker \& Maiman, 1975). Another common model is the Health Belief Model which describes health behaviour as a combination of the perceived susceptibility to the disease, perceived disease severity, the costs or benefits of the preventative action and a trigger that prompts the action (as cited in Becker, Drachman \& Kirscht, 1972; Becker \& Maiman, 1975).

The factors stated here as predictors to compliance are, like the other literature, tailored to the patient population as a whole. Though some or most of these factors may apply to young adults, there may be some needs specific to young adults that are not reported. This gap adds to the motivation for this study.

\subsection{Products in market}

A quick scan was done of some of the solutions for medication adherence in the market that target patients. In this scan, solutions found which are meant to be used by doctors or pharmacists were left out. These solutions fit broadly in four categories. These include pharmacy provided solutions, applications, containers, and pill dispensers. 


\subsubsection{Pharmacy}

By taking a look at websites for some Canadian pharmacies, including Rexall PharmaPlus (2018), Shoppers Drug Mart (2018), as well as Guardian and IDA Pharmacies (2018), it was found that they provide some solutions to assist their clients with adherence. Rexall PharmaPlus (2018) mentioned that they offer a 'Med Organizer' which they define as an easy way to track medication and a convenient tool for travel. It is a blister pack that organizes medication for seven days (Rexall PharmaPlus, 2018); an image of the Med Organizer can be seen in Figure 1. Some pharmacies also offer automatic refills where they refill the prescription and have it ready before the last set of medication runs out. With this, they integrate it with a notification system that allows the patient to know when the refill is ready for pickup (Rexall PharmaPlus, 2018; Shoppers Drug Mart, 2018). All three pharmacies offered a personal account which allows patients to view a record of their medications, refill prescriptions and access health information as well as providing special offers (Rexall PharmaPlus, 2018; Shoppers Drug Mart, 2018; Guardian and IDA Pharmacies, 2018). Some pharmacies also provide information on different medications and conditions which patients can browse online (Rexall PharmaPlus, 2018; Guardian and IDA Pharmacies, 2018) as well as offering in-person explanations of medication (Guardian and IDA Pharmacies, 2018). Guardian and IDA Pharmacies (2018) offer consultations with patients to align their prescription refill times if they have multiple medications, as well as adjust some aspects of the prescriptions and provide advice on lifestyle changes. They also offer home visits and conduct some lab tests. 


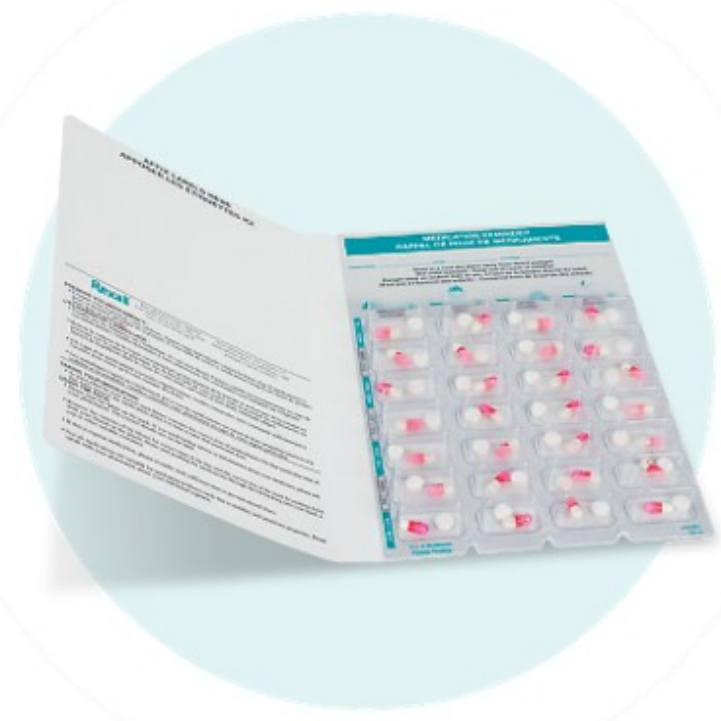

Figure 1 Med Organizer provided by Rexall (Rexall PharmaPlus, 2018, https://www.rexall.ca/pharmacy/medicationmanagement/medorganizer)

\subsubsection{Applications}

Two applications from the Android Play store were identified, both the company websites and applications were used to find the highlights of each. These were MyTherapy (2018) and Medisafe (2018). Screenshots of the MyTherapy application can be seen in Figure 2 and Medisafe can be seen in Figure 3. Both applications are free on the Android Play store, track adherence through self-reporting and share patient data with the healthcare team and/or family. Both applications require patients to input their treatment plan and allow them to choose a notification method between auditory, tactile vibrations, and/or notifications on the phone screen. MyTherapy (2018) keeps track of whether medication was taken, as well as other patient entered medical information; including measurements (heart rate, weight, blood pressure, blood sugar, etc.), lab test results (cholesterol, Triglyceride, etc.), activities (walking, Cycling, Physiotherapy, etc.) 
and symptoms. It can also generate reports for the patient with this data. Medisafe (2018) also tracks if medication was taken through patient self report and creates a report of this information. It also allows patients to enter measurements and lab results, keep a diary, track appointments and refills as well as add doctors and friends.
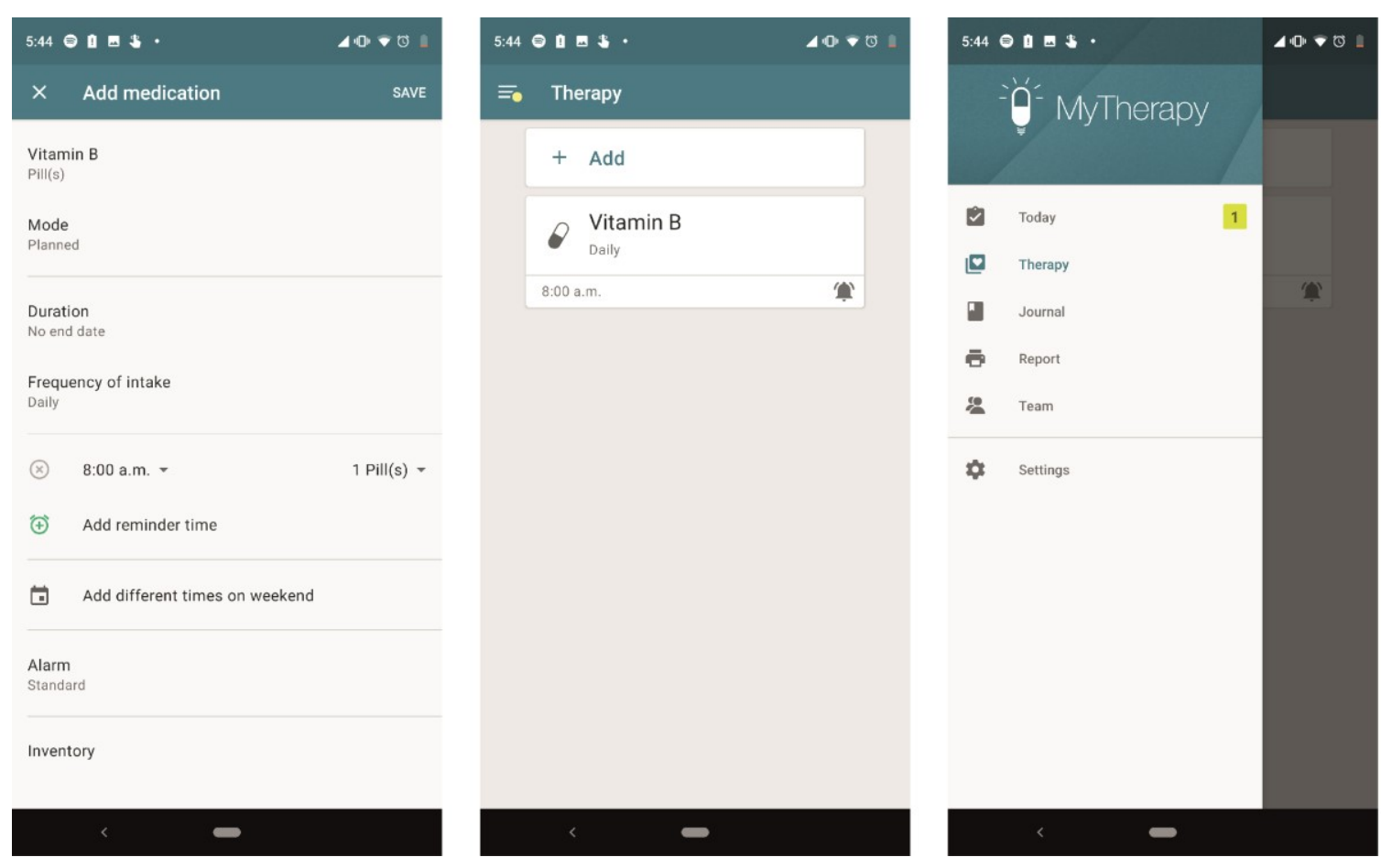

Figure 2 Screenshots of the MyTherapy mobile application. From left to right, they are images of the screen to set up a medication, the home screen showing medications and the navigation bar (MyTherapy, 2018). 

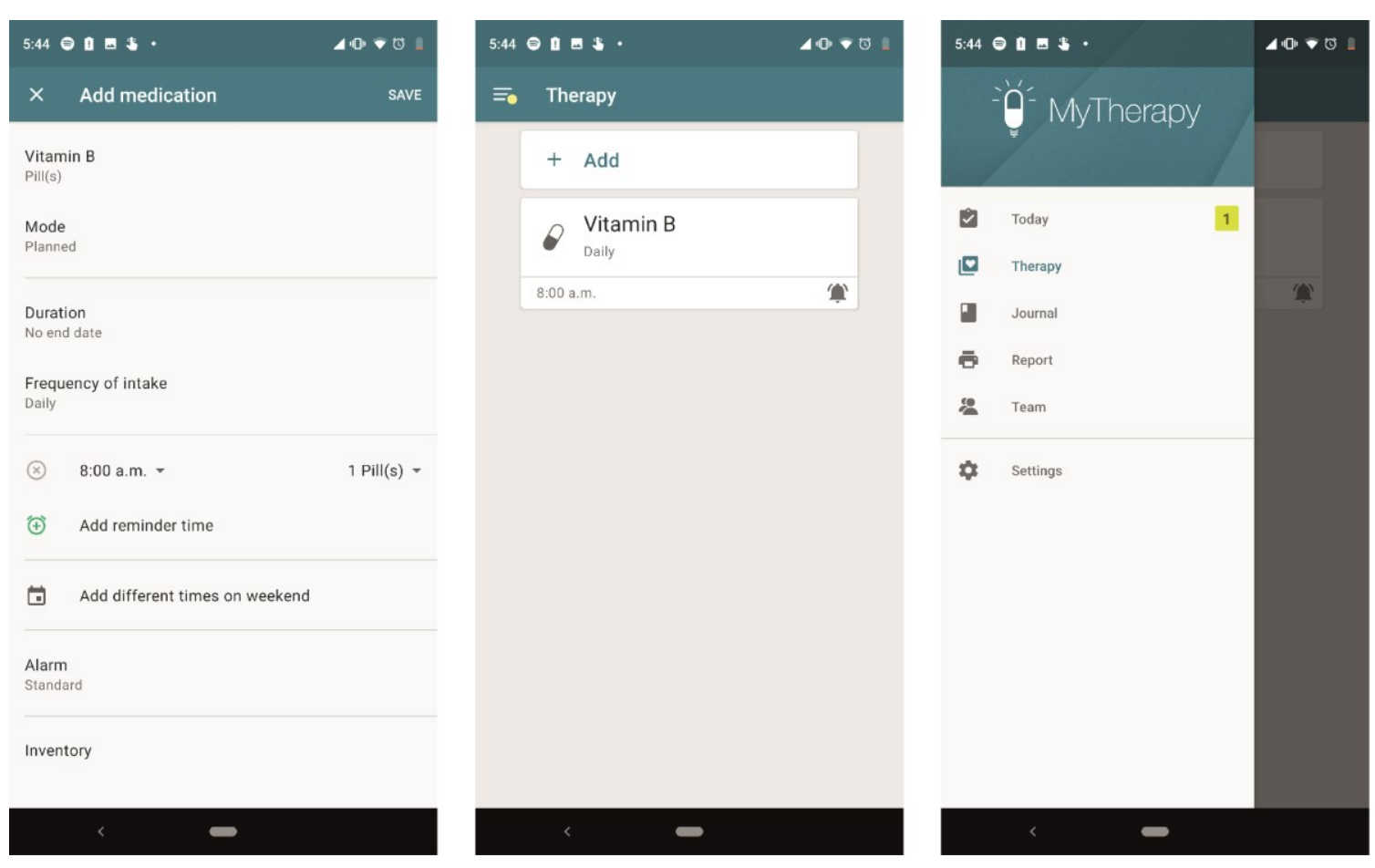

Figure 3 Screenshots of the Medisafe mobile application. From left to right, they are images of the screen to set up a medication, the home screen showing medications and the navigation bar (Medisafe, 2018).

\subsubsection{Containers}

There are also various products on the market that are containers to organize and store medication. Some of the products/companies that were looked at here are the Vitality GlowCap by NantHealth (2018), AdhereTech (2018), MedMinder (2018) and PILBOX (2018). GlowCap can be seen in Figure 5, AdhereTech can be seen in Figure 6, two of the MedMinder solutions can be seen in Figure 6 and three of the PILBOX solutions can be found in Figure 7. AdhereTech (2018) and the Vitality GlowCap (NantHealth, 2018) are both pill bottle solutions with a built in notification system to remind users when it is time to take their medication. MedMinder (2018) has a line of products that are smart pillboxes. These systems can all store multiple weeks worth of medication. PILBOX 
(2018) is a company that sells various pill bottles, which range from daily to weekly storage.

The Vitality GlowCap (NantHealth, 2018), AdhereTech (2018) and MedMinder (2018) all have both visual and auditory notifications on the device storing medication. In addition to those notifications, AdhereTech (2018) allows customizable notifications for missed doses, including calls, texts and a live agent. MedMinder (2018) also allows calls, text messages and emails as notifications. Of the PILBOX (2018) devices, only one has a reminder system, which is a programmable alarm on the device.

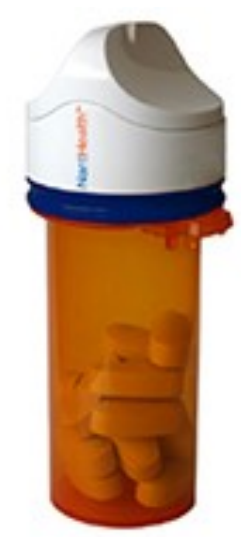

Figure 4 I mage of the GlowCap taken from NantHealth (2018, https://nanthealth.com/vitality/)

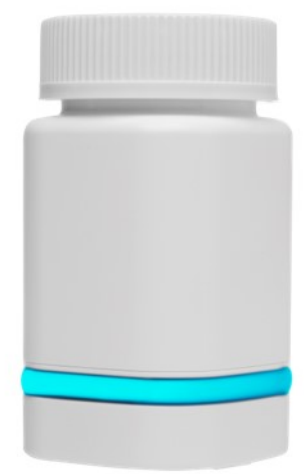

Figure 5 Image of the AdhereTech bottle taken from AdhereTech (2018, https://www.adheretech.com/) 

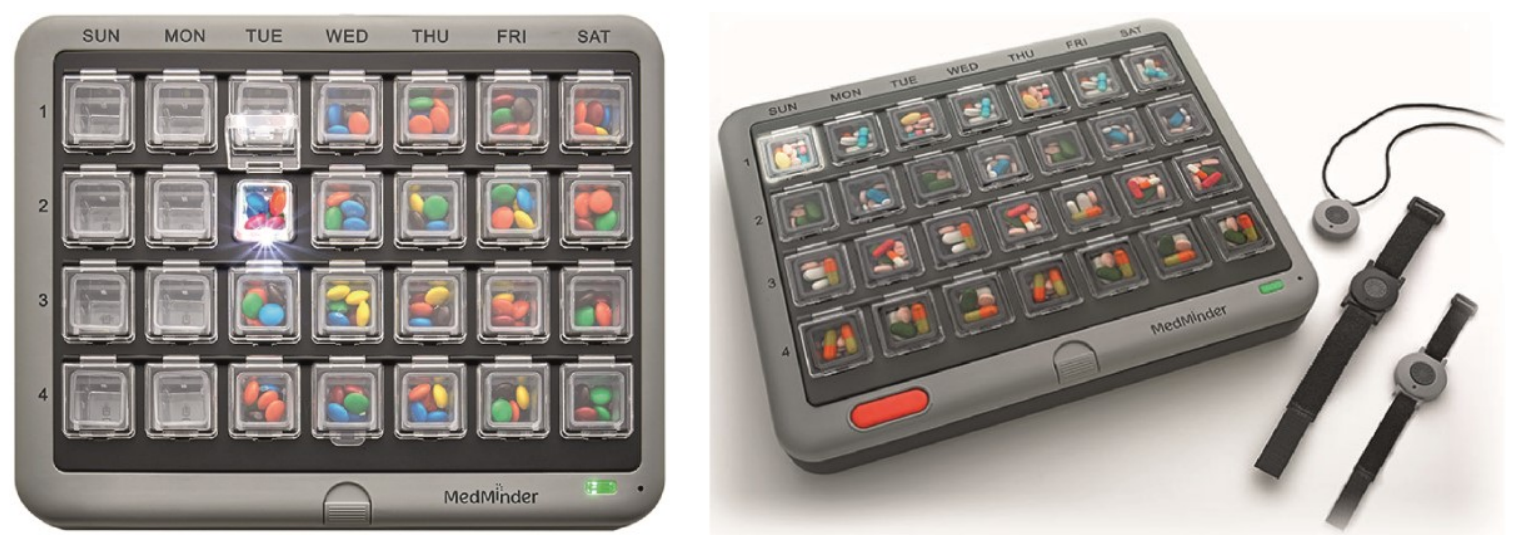

Figure 6 The Maya and jon devices sold by MedMinder. Images taken from MedMinder (2018, https://www.medminder.com/pill-dispensers-2/)
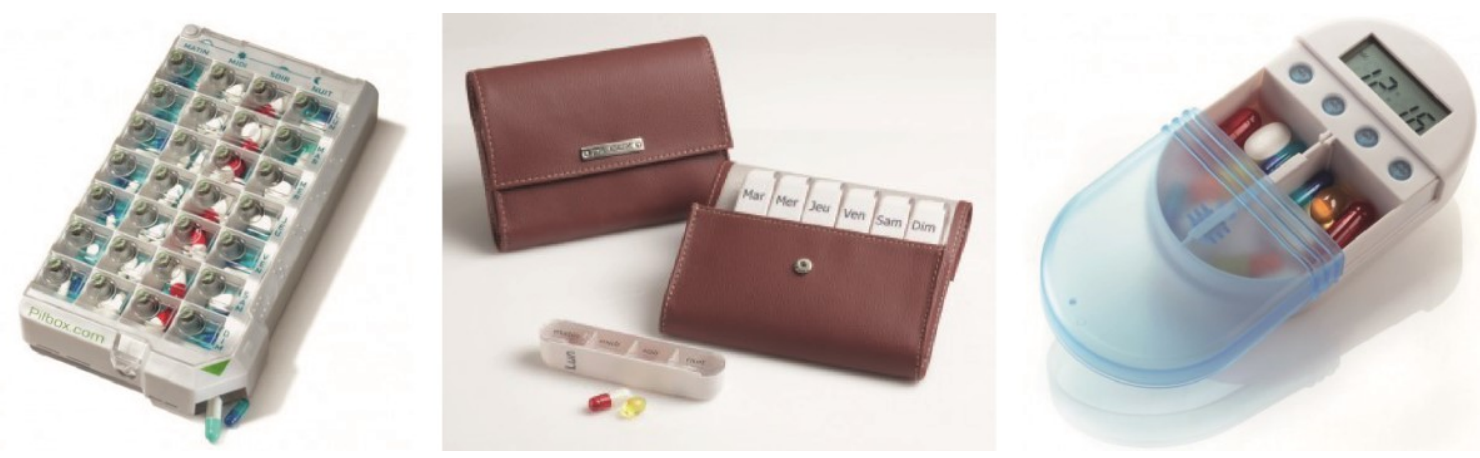

Figure 7 Three of the solutions sold by PILBOX. From left to right they are the Classic (PILBOX, 2018, https://pilbox.ca/en/weekly-dispensers/10-pilbox-classic.html) Liberty (PILBOX, 2018, https://pilbox.ca/en/weekly-dispensers/25-pilbox), and Electro (PILBOX, 2018, https://pilbox.ca/en/daily-dispensers-/7-pilbox-electro-3401545542449.html)

AdhereTech (2018), Vitality GlowCap (NantHealth, 2018) and MedMinder (2018) all collect, record and analyze patient adherence data that they can display for the patient on a personal portal. In addition to this, the Vitality GlowCap (NantHealth, 2018) and MedMinder (2018) devices can share this information with the patient's healthcare team and family if requested by the patient. Some of the MedMinder (2018) devices also 
allow for customizable greetings to be set for the patient and provide a call center for the patient to contact.

AdhereTech (2018) highlights that it does not require the patient to do any set-up. Some of the PILBOX (2018) devices have functions where they can grind patient medication. Vitality GlowCap (NantHealth, 2018) highlights that it is cost-effective. MedMinder (2018) has an option of prefilled trays prepared by a pharmacist or caregiver.

\subsubsection{Pill dispenser}

One of the devices found was a pill dispenser called HERO (HeroHealth, 2017), seen in Figure 8. This is a "smart appliance that stores, dispenses, and manages pills" (HeroHealth, 2017, https://herohealth.com/). This device allows patients to load various medications, which are stored so that they cannot be accessed by children. It provides reminders to the patient when medication needs to be taken and the medication is then dispensed as needed. This appliance is plugged in at home and connected over Wi-Fi. It also provides reminders when it needs to be refilled. It also allows family to track whether medication is taken.
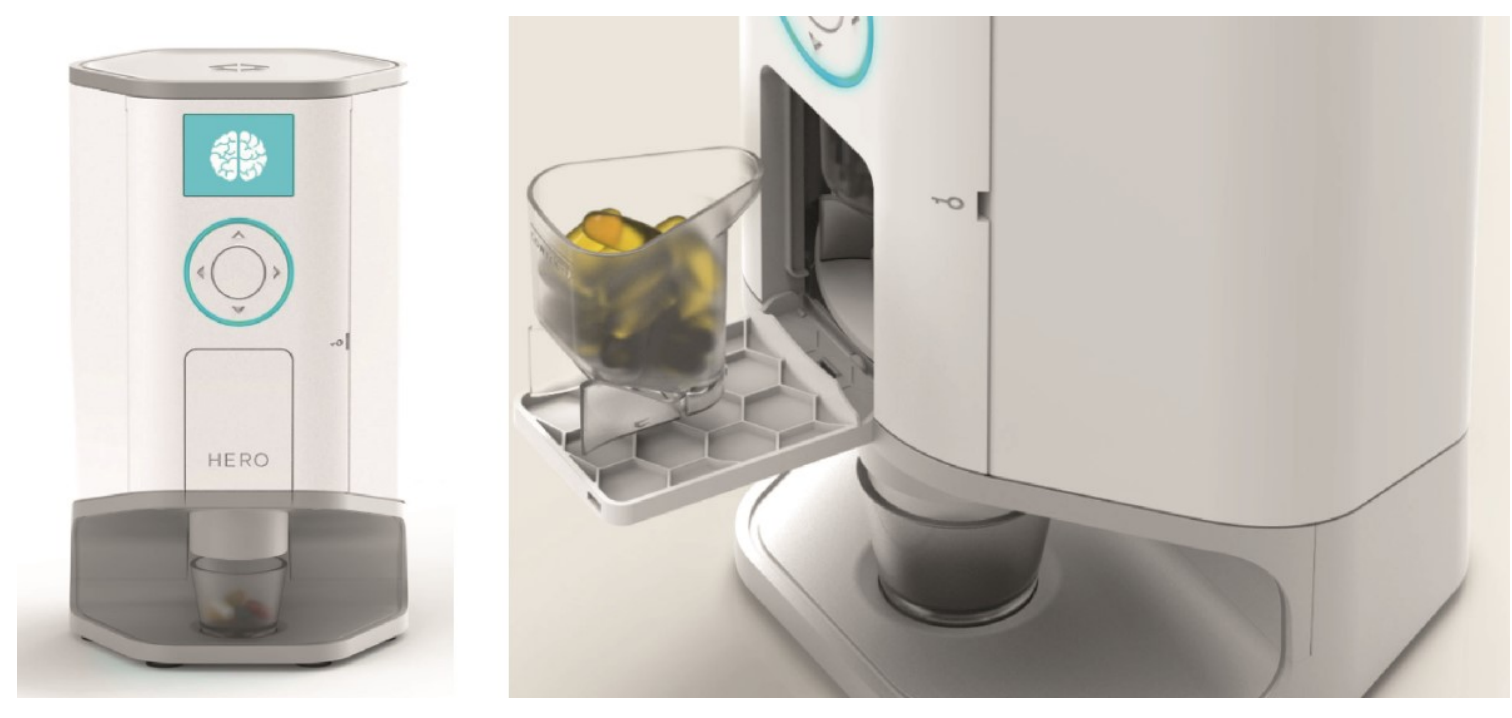

Figure 8 Image of the Hero device taken from HeroHealth (2017, https://herohealth.com/) 


\subsubsection{Summary of tools in market}

None of the solutions found seem to specifically target young adults. Most solutions seem to be focused on any individual taking medication, regardless of age. The various functions of each solution can fit into six broad categories, which can be seen in Figure 2.

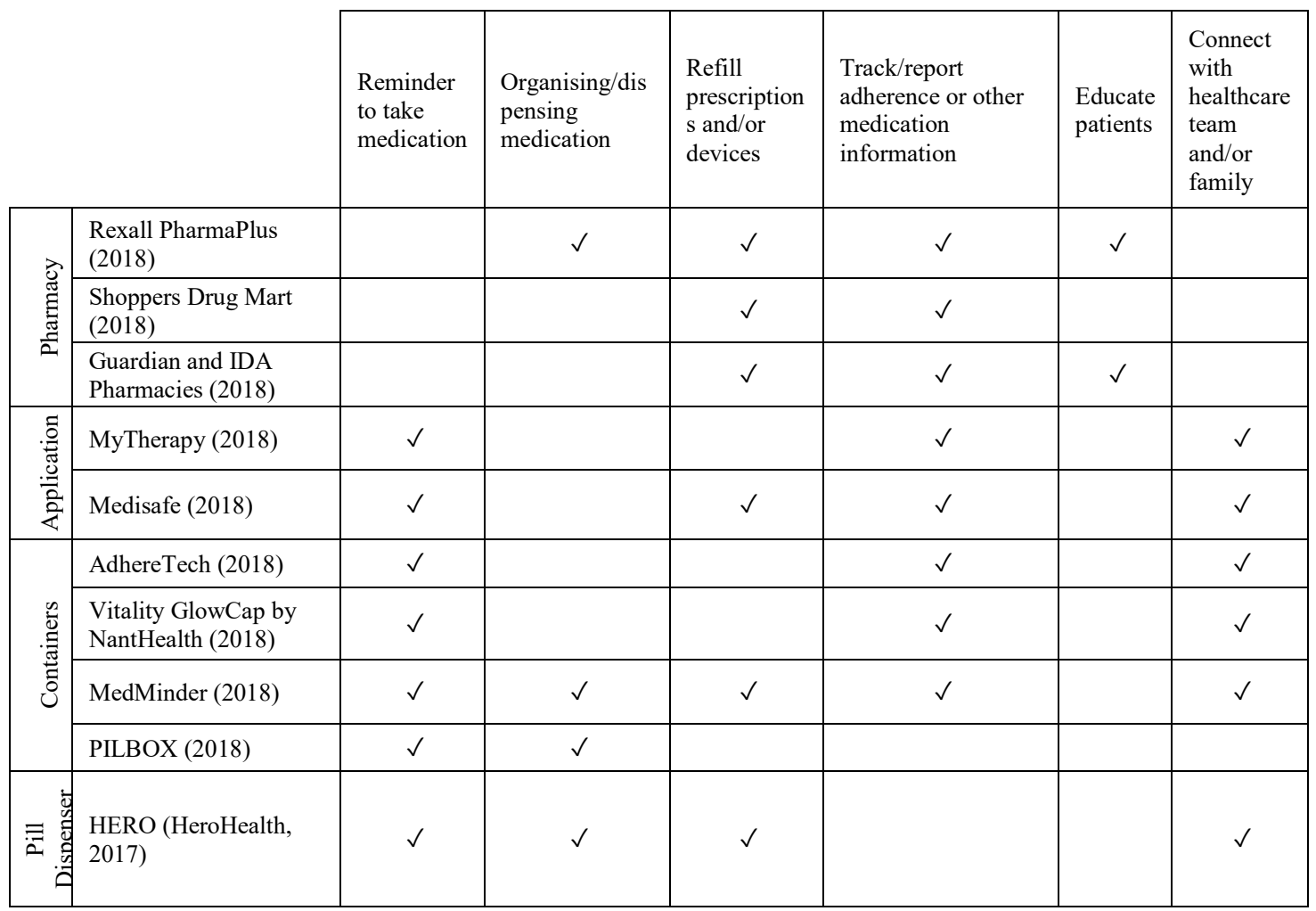

Table 2 Comparing Functions of the Solutions currently on the market

These categories include: reminding the patient to take their medication (MyTherapy, 2018; Medisafe, 2018; AdhereTech, 2018; NantHealth, 2018; MedMinder, 2018; PILBOX, 2018; HeroHealth, 2017), organising/dispensing the medication to be taken (Rexall PharmaPlus, 2018; MedMinder, 2018; PILBOX, 2018; HeroHealth, 2017), refilling prescriptions and devices (Rexall PharmaPlus, 2018; Shoppers Drug Mart, 2018; Guardian and IDA Pharmacies, 2018; Medisafe, 2018; MedMinder, 2018; HeroHealth, 2017), tracking and reporting on adherence or relevant medical information (Rexall PharmaPlus, 2018; Shoppers Drug Mart, 2018; Guardian and IDA Pharmacies, 2018; 
MyTherapy, 2018; Medisafe, 2018; AdhereTech, 2018; NantHealth, 2018; MedMinder, 2018), educating patients (Rexall PharmaPlus, 2018; Guardian and IDA Pharmacies, 2018) as well as connecting with the healthcare team and/or family (MyTherapy, 2018; Medisafe, 2018; AdhereTech, 2018; NantHealth, 2018; MedMinder, 2018; HeroHealth, 2017).

\subsection{Summary}

The literature shows that medication adherence is an issue that can lead to serious consequences for the patient (DiMatteo, 2003). Medication adherence has also been found to be more prevalent in patients with chronic illness (Dean et al., 2010; Gardiner \& Dvorkin, 2006; Matsui, 2007). Young adults can be at risk of lower adherence rates due to their age and the fact that they are in a period of transition where they take over a lot of aspects of their healthcare (Annunziato et al., 2007). Though there is a risk of nonadherence in younger populations, most of the research in the area of medication adherence seem to be conducted on older populations (Rao et al., 2007; Dean et al., 2010). Young adults are a unique market segment, with their own needs, behaviours, attitudes and values (Smith \& Nichols, 2015; Grewal et al., 2011), all of which may impact their need in a medication adherence solution. Most of the solutions on the market and interventions in the research focus on general populations, with nothing found that specifically targets young adults. There seems to be a lack of knowledge and solutions that target young adults specifically; therefore, the following research focuses on identifying the needs of this demographic and what needs to be considered when designing solutions to help them improve their adherence. 
Based on the findings from the literature review, the following research question was developed which this research attempts to answer: How can design contribute to improving medication adherence in young adults on ongoing treatment plans? To study this question, there are three sub questions that should first be answered:

1. What are the known issues and interventions for medication adherence?

2. How do young adults currently approach medication adherence?

3. What could designers learn from young adults who are designing solutions they could use to help improve their adherence?

While the literature provides the context that sheds light on the issues, this study focuses on participants, whose lived experiences may provide valuable insights. 


\section{Chapter: Research Design}

A design approach with a business influence was used to address the research questions defined in the previous chapter. Here, user-centered design, a constructivist approach to analyzing the data, exploratory sequential study design, triangulation, interviews, codesign and coding analysis have been defined. Each of these topics has been described as they relate to the research being conducted in this study and why they were appropriate methods to answer the research questions defined.

\subsection{User centered approach}

User centered design is an approach which actively involves a product's end users throughout the design process to gain insights on their needs (Mao, Vredenburg, Smith \& Carey, 2005; Duarte \& Guerra, 2012; Wilkinson \& De Angeli, 2014). User involvement can help generate ideas for new products as well as develop necessary features (Wilkinson \& De Angeli, 2014). The application of this process improves the effectiveness and efficiency of the end product (Mao et al., 2005; Duarte \& Guerra, 2012) as well as improving adoption rates (Wilkinson \& De Angeli, 2014). Johnson, Johnson \& Zhang (2005) applied a user-centered design process to the redesign of a healthcare interface and found that the methods they used "show the benefits toward system usefulness, information quality, and interface quality" (pp. 86). They go on to mention that the implementation of user centered design throughout the design process can improve the quality of healthcare systems. Using this approach can create "systems that are easy to learn, increase user productivity and satisfaction, increase user acceptance, decrease user errors, and decrease user training time" (Johnson et al., 2005, pp. 75); 
whereas not using this approach often leads to issues which require the system to be redesigned (Johnson, et al., 2005).

During this study, a user centered design approach will be used to ensure that user needs are understood and communicated. This approach should ensure that if the considerations defined by the research were used to guide the development of a solution, it would meet the needs of the end users; increasing adoption of the product and making it more effective at improving adherence rates for young adults.

\subsection{Constructivist approach}

Creswell (2014) describes a constructivist approach as an "approach to qualitative research" (pp. 8) where "individuals develop subjective meanings of their experiences" (pp.8). He describes these subjective meanings as being developed through an individual's social interactions with others as well as their cultural and historical context. In constructivist research, the goal is to rely on the participants' view of a given situation. In this approach, open-ended questions are typically used to allow participants to give the situation meaning through their interactions and discussions. The researchers role is to listen to what the participant says and observe what he or she does to interpret that individual's experiences. With a constructivist approach, insights are developed inductively and the researcher should recognize that their interpretation of the data stems from their background (Creswell, 2014).

For the following research, a constructivist approach will be used to understand the experiences young adults have had with medication adherence. Qualitative research methods will be used to allow participants to share their views and experiences through both discussions and creative exercises. These will include interviews and co-design 
sessions. When analysing the data, it will be inductively coded and categorised to allow insights to arise from the data.

\subsection{Exploratory, sequential design}

Creswell (2003) describes qualitative research as being exploratory. He mentions that an exploratory approach can be useful when the topic being studied is new, or when it has not been addressed for a specific population being studied. In the case of this research, the goal is to understand the needs specific to young adults, whereas most of the literature found does not study them directly; therefore, an exploratory approach will be used to address the research question.

Creswell (2003) defines sequential methods for data collection as a process where a researcher expands or elaborates on one method's findings through a second method. Through the research conducted in this paper, a sequential approach will be used, where the first method informs the second. This allows the second method to build on the findings of the first.

Hanson, Creswell, Plano Clark, Petska \& Creswell (2005) describe a sequential exploratory approach as a mixed methods study, often starting with a qualitative method, then a quantitative one, though the qualitative data is given priority. In this study, though, a sequential, exploratory method will be used, and all research will be qualitative, therefore it will not be a mixed methods study.

\subsection{Triangulation}

Triangulation in studies refers to the use of multiple methods in the investigation of the same phenomenon to support the validity of the results (Greene et al., 1989; Bui, 2009). Since all methods have their own limitations and biases, the use of a single method will 
inevitably lead to results that are bias and limited (Greene et al., 1989). For studies with smaller sample sizes, triangulation can be used to increase validity of a study's findings by ensuring that different perspectives of an issue are captured and support one another (Sanders \& Stappers, 2012). Since the research in this study consists of qualitative methods with small sample sizes, two methods will be used to increase the validity of the findings. These methods will be semi-structured interviews and co-design sessions. The results of these methods will be compared to each other as well as findings from the literature to capture different perspectives of the issue.

\subsection{Interviews}

Kuniavsky, Moed \& Goodman (2012) state that "to really know the users experience, you have to ask him or her about it" (pp129). In-depth interviews are a good way of gathering knowledge or an understanding of users (Crouch \& McKenzie, 2006). Semi-structured interviews allow researchers to gather information on key topics while allowing for exploration as new topics emerge (Chauncey, 2014). Crouch \& McKenzie (2006) claim that using a small sample size, which they define as under 20 , is best for exploratory studies. In a study conducted by Guest, Bunce \& Johnson L (2006), it was identified that data saturation occurred after 12 interviews, if the goal of the research was to "describe a shared perception, belief or behaviour among a relatively homogeneous group" (pp76). They also state that six interviews is enough to develop meaningful themes and interpretations (Guest et al., 2006). In order for this small sample size to work, however, participants have to be homogeneous and experts in the domain. They also have to be interviewed separately and have some degree of similarity in the interview structure/content (Guest et al., 2006). Since the research for this study is exploratory, 
semi-structured interviews will be used to gain an understanding of the needs of the target demographic as well as their current state. For these interviews, only participants within the demographic will be recruited to ensure that they are experts in the domain and are a relatively homogeneous group, as defined by (Guest et al., 2006). They will also be individually interviewed, using a semi-structured script so there is some consistency in what is asked of them. With this, saturation of the data should be reached within 12 interviews according to Guest et al. (2006).

\subsection{Defining participatory design, co-creation and co-design}

Sanders \& Stappers (2008) state that co-design evolved from the process of user centered design. In user-centered design, the users are passive members of the design process. In this process, users are often observed and/or interviewed by trained researchers as they perform various tasks and/or give their opinions. Within a user-centered design approach, the users are not the ones generating the product concepts, the experts are (Sanders \& Stappers, 2008).

According to Martin \& Hanington (2012), the term participatory design includes various methods that actively involve stakeholders (such as users and clients) in the design process. One of the methods encompassed by a participatory design approach is co-design sessions. They state that participatory design uses the participants' creative insight to guide the design process, though designers then translate these insights into design criteria and products/services (Martin \& Hanington, 2012). Sanders \& Stappers (2008) believe that term participatory design was the initial name for collective creativity practices in design and that the term is synonymous with co-design. 
Co-design, as defined by Sanders \& Stappers (2012), refers to the collective creativity of designers and individuals not trained in design collaborating throughout the design process. In some instances, co-design refers to collective creativity of designers working together (Sanders \& Stappers, 2012). Throughout this paper, co-design will refer to the collaboration of designers and non-designers. The process of co-design shifts the traditional role of the user from a passive recipient of a given product or service, to an active role as a co-designer (Bate \& Robert, 2006; Sanders \& Stappers, 2008); empowering users (Pilemalm \& Timpka, 2008) by making them integral to the innovation and improvement of the product/service (Bate \& Robert, 2006). In this process, each user is considered the "expert of his/her experience" (Sanders \& Stappers, 2008, pp.12), giving them a "role in knowledge development, idea generation and concept development"(Sanders \& Stappers, 2008, pp.12).

Sanders \& Stappers (2008) define the term co-creation as any act of creativity between two or more individuals, making co-design an instance of co-creation. Sanders \& Stappers (2012) identify three types of value that can be created through co-creation; these include monetary value, use/experience value, and societal value. The goal of cocreation which leads to monetary value is to make money in a new, more efficient or more long-lasting way. Co-creation which results in use/experience aspires to create products/services that better meet the users wants/needs. Co-creation for societal value is driven by a desire for more sustainable, long-term ways of living. This method supports exploration and there is typically no preconceived notion of what the outcomes will be. All three types of value are linked and often work together. In light of the second value, 
this study will engage users in generating design ideas for products or services that better meet the needs of youth.

Moreover, co-design actively involves stakeholders in the design process, allowing them to inspire and guide the design (Martin \& Hanington 2012). Co-design allows researchers to gain insights through observations of what people do during sessions, the things they say and the objects that they make (Sanders \& Stappers, 2012). This is an object based, generative technique, which allows participants to express their thoughts and emotions through the creation of objects (Kuniavsky et al., 2012). This can help researchers gather insights about things that may be difficult for participants to express in words (Kuniavsky et al., 2012). According to Kuniavsky et al. (2012), these methods can help supplement what is learned through other methods, such as interviews.

Participatory design is frequently applied to the design and development of health information systems (Revenäs, Opava, Martin, Demmelmaier, Keller \& Åsenlöf, 2015; Bate \& Robert, 2006; Pilemalm \& Timpka, 2008). The use of these methods in healthcare are driven by findings that the involvement of experts and major stakeholders in the early stages of the design process leads to more effective and useable systems (Pilemalm \& Timpka, 2008). Revenäset al. (2015) used a co-design method to identify system requirements for an application to assist individuals with rheumatoid arthritis in selfmanaging their physical activity. They believed that a co-design method was best suited because individuals living with chronic disease would be able to use their knowledge and experiences to improve their healthcare services. They also believed that for individuals with rheumatoid arthritis, the knowledge that the application was developed with the help of their peers could create intrinsic value. 
In this study, co-design will be used as a user-centered method of gathering feedback. The use of this as a second data collection method is a way to gather insight into the users' tacit knowledge, which may not have come out in the interview stage.

\subsection{Analysis methods}

To analyse the data, coding will be used as a method to organize and gather insights from the findings. According to Saldaña (2016), in qualitative data analysis, coding is the process of assigning a word or short phrase to a data set. The code should capture the essence of the original data set and allow the researcher to compare and group data into categories. Saldaña (2016) states that once the data has been coded and categorized, the researcher can recode the data based on emerging patterns. Saldaña (2016) also defines specific methods of coding for the first coding cycle, categorizing the data and recoding of the data, though here, only the methods that will be used in this research will be defined. For the initial coding method, an exploratory method called holistic coding will be used. In holistic coding, codes are applied to large units of data, which capture their overall meaning. For categorization of the data, a tabletop method will be used. In this method, coded sections of the data are printed on individual pieces of paper and arranged into categories of similar codes. These are then rearranged into categories of broader concepts. For second cycle coding, both pattern coding and focused coding will be used. Pattern coding is the application of category labels to similarly coded data, in order to organize and give it meaning. Focused coding categorizes coded data based on similar themes and concepts (Saldaña, 2016). In the methods sections of each study, there will be a description of the coding methods used, though in general this cyclical coding method will be used as defined by Saldaña (2016). 


\subsection{Summary}

A user-centered design approach was selected for this study to ensure that the needs and experiences of patients, who would be the primary users of a solution in this space, can be accurately reported. This approach may lead to the creation of design considerations to inform solutions that are useful for and adopted by young adults on ongoing treatment plans. A constructivist approach will be used in these studies, in which qualitative methods are used and data is inductively analysed. Since the methods used are qualitative, more than one method will be used and the results compared. This comparison of the data may help validate the results of the study. An exploratory, sequential method will be used, where the studies build on one another, allowing for findings to be further explained and expanded on with each study. The first method used will be semi-structured interviews to get an initial understanding of individuals in the target population. This may be followed by co-design sessions that could allow the collection of users' tacit knowledge that may supplement the interviews. The data will be analysed through cyclical coding methods, as described by Saldaña (2016), which should allow the themes in the research to evolve as information from new studies are added.

As described in the literature review, the goal of this study is to see how design can contribute to improving medication adherence in young adults with ongoing treatment plans. To do this, three sub questions are addressed; the first of which is what are the known interventions for medication adherence. This sub question has been addressed in the review of the literature, which highlights what is currently known in this field and what solutions exist. The second question studies how young adults currently approach medication adherence. This is answered through the initial method, a set of 
semi-structured interviews. The third and final question is meant to identify what designers could learn from young adults who are invited to create solutions for themselves to use when improving their adherence. This is addressed in the co-design sessions, the second method. These methods are both qualitative, since it is an exploratory study, and the different methods are used sequentially so they could each inform the next. At the end, all the data found in the two methods and the literature review, will be synthesized to create a set of design considerations and answer the primary question of the research. This can be seen in the exploratory framework for the study in Figure 9.

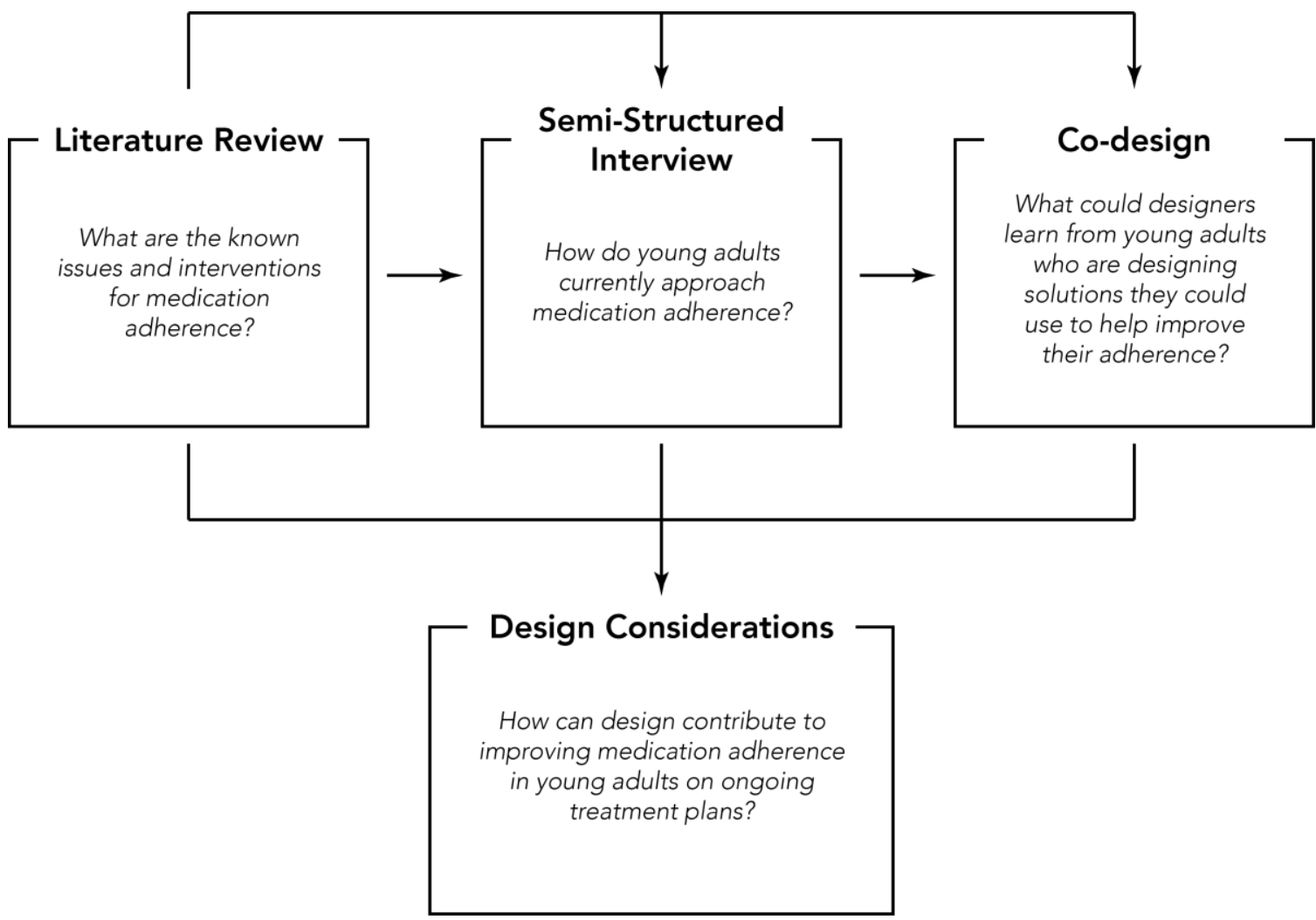

Figure 9 Visualization of the exploratory framework of the study. 


\section{Chapter: Study 1 Methods}

Semi-structured interviews were conducted with young adults ages 18-30 on daily medication plans lasting at least six months. The goal of these interviews was to understand some factors that either help or hinder medication adherence in the target user group. In addition, this research identified some of the tools that young adults on ongoing daily medication plans currently use or desire, as well as strengths and weaknesses of these tools. A total of 12 interviews were conducted with individuals who fit the target demographic; therefore, due to their personal experiences, the participants are experts in this domain.

\subsection{Recruitment}

The recruitment methods used in this study were snowballing and convenience sampling. Recruitment occurred online, on Carleton University's campus and by word of mouth. Recruitment material was posted on social media, including Facebook, Linked-In and Twitter, on the researcher's account as well as various public pages; a sample of the social media invitation can be found in Appendix A.1. An email was sent out through Carleton's School of Industrial Design mailing list to its current students; a sample of the email invitation can be found in Appendix A.2. Recruitment posters were placed in various locations at Carleton University's campus; a sample of the poster can be found in Appendix A.3. Participants and friends of the researcher were also encouraged to share the invitation.

To participate in the study, individuals had to be between the ages of 18 and 30 , comfortable speaking English and currently or previously have been on an ongoing treatment plan prescribed by a medical professional lasting at least six months. 


\subsection{Screener}

Prior to the session, participants were asked two balancing screener questions. This included their age as well as the gender they identify as; a sample of the screener can be found in Appendix A.4. This information was gathered to ensure that there was a relatively even distribution of ages and genders in the population sampled.

\subsection{Interview Questions}

Participants were asked six questions plus probes and follow-ups; the interview script can be found in Appendix A.5. Participants were initially asked what form they take the medication in, what amount they are required to take daily and how many times a day they have to take the medication. This was all of the information the researcher asked about a participant's specific medication regimen. Participants were then asked about what factors positively and negatively influence their adherence to the medication plan. They were also asked to describe how they organize their medication and what tools they use, if any, to adhere to their medication regimen. As a follow up, they were asked what they like, dislike or would want to change about these tools. Finally, participants were asked what they would like to have in order to improve their adherence.

\subsection{Setup}

Interviews were conducted either in-person or remotely. In-person sessions were conducted in a room at Carleton University where only the researcher and the participant were present. Remote sessions were held on a conferencing tool called GoToMeeting where only the researcher and participant were on the conference. For these sessions, participants could call in either by phone or dial in on their computer. 
Participants were all required to sign a consent form prior to the start of the session; a sample of the consent form can be found in Appendix A.6. For remote sessions, participants received the consent form via email and were required to sign it and send a copy back to the researcher. For in-person sessions, participants were given a copy of the consent form to sign. Once the consent was signed, the session began.

Interviews lasted up to 30 minutes each. They were all audio-recorded and transcribed. As a thank you for their time, participants received a $\$ 5$ gift card to either Starbucks or Tim Hortons.

\subsection{Participant Demographics}

All of the participants were prescribed a daily medication plan for at least six months. Ten participants stated that they took one pill a day and two stated that they take two pills once a day. All participants were required to take their pills orally at the same time every day.

Five of the participants were male and seven were female. All of them were between the ages of 18-30; see Table 3 for a breakdown of participant ages, though it was not mandatory for participants to provide their exact age.

\begin{tabular}{|l|l|l|l|l|l|l|l|l|l|l|l|l|l|}
\hline Age & 18 & 19 & 20 & 21 & 22 & 23 & 24 & 25 & 26 & 27 & 28 & 29 & 30 \\
\hline Number of Participants & 2 & 0 & 0 & 0 & 0 & 2 & 1 & 0 & 1 & 1 & 1 & 2 & 0 \\
& & & & & & & & & & & & & \\
\hline
\end{tabular}

Table 3 Distribution of participant ages for study one. Two participants did not provide an age.

\subsection{Analysis}

Saldaña's (2016) method of cyclical coding was used to analyse the data. In the first round of coding, holistic coding was used. Tabletop categorization was then used to group like codes and data sets. For the second coding cycle, Pattern coding was used. 


\section{Chapter: Study 1 Results}

The results from Study one were grouped into 13 categories. These were: personal motivation, information, time of day, social support, carrying medication, cost, travel, memory, container, storage, tools, negative aspects of tools, good to have in a tool and other desires.

\subsection{Personal Motivation}

Of the 12 participants interviewed, 11 of them stated that the one of the biggest factors for them to take their medication was just their personal motivation to treat the issue. They stated that the benefits of the medication outweighed any of the negative factors.

Nine participants mentioned that taking their medication was not difficult. Six of them said that it had become a routine, three said that their regimen was easy, one said that they had adapted to the side effects, one said it was easy to access and another mentioned that in their case, it was easy because there were no stigmas attached. Three participants mentioned that only having to take one pill positively impacted their adherence.

Five participants mentioned that the side effects of their medication negatively impacted their adherence. In one case, a participant mentioned that they would avoid or delay taking their medication if the side effects would interfere with an event or obligation.

One participant mentioned that they stopped taking their medication because they realized it would limit other areas of their life, for example it would stop them from joining the military or flying a plane. 
One participant mentioned that the stigma around their condition negatively impacted their adherence. Another mentioned that medication could serve as a psychological reminder of their condition.

Table 4 shows the distribution of each of the personal motivation comments between participants as well as the total number of times each comment was mentioned.

\begin{tabular}{|c|c|c|c|c|c|c|c|c|c|c|c|c|c|}
\hline Comment & P1 & P2 & P3 & P4 & P5 & P6 & P7 & P8 & P9 & P10 & P11 & P12 & Total \\
\hline $\begin{array}{l}\text { Personal motivation was one of the biggest } \\
\text { factors }\end{array}$ & $\checkmark$ & $\checkmark$ & $\checkmark$ & $\checkmark$ & $\checkmark$ & $\checkmark$ & & $\checkmark$ & $\checkmark$ & $\checkmark$ & $\checkmark$ & $\checkmark$ & 11 \\
\hline Benefits outweigh the negatives & $\checkmark$ & $\checkmark$ & $\checkmark$ & $\checkmark$ & $\checkmark$ & $\checkmark$ & & $\checkmark$ & & & $\checkmark$ & $\checkmark$ & 9 \\
\hline Taking medication was not difficult & $\checkmark$ & $\checkmark$ & $\checkmark$ & $\checkmark$ & $\checkmark$ & $\checkmark$ & & $\checkmark$ & & $\checkmark$ & $\checkmark$ & & 9 \\
\hline Taking medication has become routine & & & & $\checkmark$ & $\checkmark$ & $\checkmark$ & & $\checkmark$ & & $\checkmark$ & $\checkmark$ & & 6 \\
\hline Treatment plan was easy & $\checkmark$ & $\checkmark$ & & $\checkmark$ & & & & & & & & & 3 \\
\hline Adapted to the side effects & & & & & & $\checkmark$ & & & & & & & 1 \\
\hline Easy to access their medication & & & $\checkmark$ & & & & & & & & & & 1 \\
\hline No stigma attached to their condition & & & & & $\checkmark$ & & & & & & & & 1 \\
\hline $\begin{array}{l}\text { Only taking one pill a day improved } \\
\text { adherence }\end{array}$ & $\checkmark$ & & & $\checkmark$ & & $\checkmark$ & & & & & & & 3 \\
\hline $\begin{array}{l}\text { Side effects of the medication negatively } \\
\text { impacted adherence }\end{array}$ & & & & & $\checkmark$ & $\checkmark$ & & $\checkmark$ & & & $\checkmark$ & $\checkmark$ & 5 \\
\hline $\begin{array}{l}\text { Side effects would cause them to } \\
\text { avoid/delay taking their medication }\end{array}$ & & & & & & & & & & & & $\checkmark$ & 1 \\
\hline $\begin{array}{l}\text { Stopped taking medication because it was } \\
\text { impacting other aspects of their life }\end{array}$ & & & & & & & & & & & $\checkmark$ & & 1 \\
\hline $\begin{array}{l}\text { Stigma around their condition negatively } \\
\text { impacted adherence }\end{array}$ & & & & & & $\checkmark$ & & & & & & & 1 \\
\hline $\begin{array}{l}\text { Medication could be a psychological } \\
\text { reminder of their condition }\end{array}$ & & $\checkmark$ & & & & & & & & & & & 1 \\
\hline
\end{tabular}

Table 4 Personal motivation comments distribution.

\subsection{Information}

Two participants complained that the instructions that came with medication were difficult to follow. One participant mentioned that misinformation about an illness could 
negatively impact adherence. They mentioned that incorrect information was often easy to find online and there were not many credible sources of information written in layman's terms. Another participant mentioned that they had a family member with the same condition as them and that this was a good source of information for them about their medication. Table 5 shows the number of times each comment was made by each participant as well as the total number of times it was mentioned.

\begin{tabular}{|c|c|c|c|c|c|c|c|c|c|c|c|c|c|}
\hline Comment & P1 & $\mathrm{P} 2$ & P3 & P4 & P5 & P6 & P7 & P8 & P9 & P10 & P11 & P12 & Total \\
\hline $\begin{array}{l}\text { Instructions that came with medication were } \\
\text { difficult to go through }\end{array}$ & & $\checkmark$ & & & & & & & & $\checkmark$ & & & 2 \\
\hline $\begin{array}{l}\text { Misinformation about an illness could } \\
\text { negatively impact adherence }\end{array}$ & & $\checkmark$ & & & & & & & & & & & 1 \\
\hline $\begin{array}{l}\text { There is a lot of misinformation online that is } \\
\text { easy to reach and understand but not a lot of } \\
\text { scientific information written in layman's } \\
\text { terms }\end{array}$ & & $\checkmark$ & & & & & & & & & & & 1 \\
\hline $\begin{array}{l}\text { Have family with the same condition that was a } \\
\text { good source of information }\end{array}$ & & & $\checkmark$ & & & & & & & & & & 1 \\
\hline
\end{tabular}

Table 5 Information comment distribution.

\subsection{Time of day}

Eight participants mentioned that they linked taking their medication to an event in their day. Four mentioned that they took it in the morning when they woke up, two mentioned that they took it at noon with lunch and one mentioned that they took it at night around when they went to bed. One participant mentioned that they would take it either before bed or when they woke up. Five participants mentioned that finding a good time to take it had a big impact on their adherence. Three participants mentioned that they had to find a time that they were not too busy. One participant mentioned that they were a University student and therefore had an inconsistent schedule. This made it difficult to find a time that would work well every day. One participant mentioned that they would delay taking 
their medication if they thought others would notice them leave to take it. Table 6 visually shows the number of times each of these comments were made, as well as which participants mentioned them.

\begin{tabular}{|l|l|l|l|l|l|l|l|l|l|l|l|l|c|}
\hline Comment & P1 & P2 & P3 & P4 & P5 & P6 & P7 & P8 & P9 & P10 & P11 & P12 & Total \\
\hline $\begin{array}{l}\text { Participants linked taking their medication to } \\
\text { an event in their day }\end{array}$ & $\checkmark$ & & & $\checkmark$ & $\checkmark$ & $\checkmark$ & & $\checkmark$ & & $\checkmark$ & $\checkmark$ & $\checkmark$ & 8 \\
\hline $\begin{array}{l}\text { Took their medication in the morning when } \\
\text { they woke up }\end{array}$ & $\checkmark$ & & & $\checkmark$ & $\checkmark$ & $\checkmark$ & & & & & $\checkmark$ & & 5 \\
\hline $\begin{array}{l}\text { Took their medication around noon with their } \\
\text { lunch }\end{array}$ & & & & & & & & & & $\checkmark$ & & $\checkmark$ & 2 \\
\hline $\begin{array}{l}\text { Took their medication at night around when } \\
\text { they went to bed }\end{array}$ & & & & & & & & $\checkmark$ & & & & & \\
\hline $\begin{array}{l}\text { Finding a good time to take their medication } \\
\text { had a big impact on their adherence }\end{array}$ & & & & & & & & $\checkmark$ & $\checkmark$ & $\checkmark$ & & & 3 \\
\hline $\begin{array}{l}\text { Having an inconsistent schedule negatively } \\
\text { impacted adherence }\end{array}$ & & & & & & & & & & & & & \\
\hline $\begin{array}{l}\text { Would delay medication taking if they believed } \\
\text { that others would notice them leaving to take it }\end{array}$
\end{tabular}

Table 6 Time of day comment distribution.

\subsection{Social support}

Two participants interviewed had joined youth groups. One of those individuals mentioned that the youth group was supportive, providing a place to talk about the illness, stigma as well as get information; however, they mentioned that this was not particularly helpful when it came to adherence. The other individual involved in a youth group mentioned that the employees working with the group were unprofessional and created a toxic environment in what was meant to be a support system.

Three participants mentioned that they had supportive family environments, however two of these participants mentioned that it did not impact their adherence. One participant mentioned that they did not have a supportive family environment, which negatively impacted their adherence. This individual mentioned that they had support 
from friends, which was a positive factor. Another participant mentioned that when their social interactions with peers increased, so did their adherence, regardless of whether peers knew they were taking medication.

Table 7 shows the number of times each comment was made about social support as well as the participants who mentioned them.

\begin{tabular}{|l|l|l|l|l|l|l|l|l|l|l|l|c|c|}
\hline Comment & P1 & P2 & P3 & P4 & P5 & P6 & P7 & P8 & P9 & P10 & P11 & P12 & Total \\
\hline Participated in youth groups & & $\checkmark$ & & & & $\checkmark$ & & & & & & & 2 \\
\hline $\begin{array}{l}\text { Find youth groups supportive and a place to } \\
\text { discuss illness, stigma and gather information }\end{array}$ & & $\checkmark$ & & & & & & & & & & & \\
\hline Believe youth group did not impact adherence & & $\checkmark$ & & & & & & & & & & & 1 \\
\hline $\begin{array}{l}\text { Support staff at the youth group were } \\
\text { unprofessional and created a toxic } \\
\text { environment }\end{array}$ & & & & & & & & & & & & & \\
\hline $\begin{array}{l}\text { Supportive family environment } \\
\text { Family environment did not impact adherence }\end{array}$ & $\checkmark$ & & & & $\checkmark$ & & & & & & & & 2 \\
\hline $\begin{array}{l}\text { Family was not supportive which negatively } \\
\text { impacted adherence }\end{array}$ & & & & & & & & & & & & $\checkmark$ & 1 \\
\hline Support from friends & & & & & & & & & & & & $\checkmark$ & 1 \\
\hline \begin{tabular}{l} 
More social interactions increases adherence \\
\hline
\end{tabular}
\end{tabular}

Table 7 Social support comment distribution.

\subsection{Carrying medication}

Three participants mentioned that they were worried that others could tell when they were carrying their medications. Two mentioned that they felt their pill bottles were making noise as they carried them and the other mentioned that they felt people could see it when they opened their purse. See Table 8 for a visual representation of which participants said each comment as well as the total number of times each comment was made. 


\begin{tabular}{|l|c|c|c|c|c|c|c|c|c|c|c|c|c|}
\hline Comment & P1 & P2 & P3 & P4 & P5 & P6 & P7 & P8 & P9 & P10 & P11 & P12 & Total \\
\hline $\begin{array}{l}\text { Worried that others could tell when they had } \\
\text { medication on them }\end{array}$ & $\checkmark$ & & & & & $\checkmark$ & & & & $\checkmark$ & & & 3 \\
\hline $\begin{array}{l}\text { Worried pill bottles made noise when they } \\
\text { carried them }\end{array}$ & $\checkmark$ & & & & & $\checkmark$ & & & & & & & 2 \\
\hline $\begin{array}{l}\text { Worried people could see their medication } \\
\text { when they opened their purse }\end{array}$ & & & & & & & & & & $\checkmark$ & & & 1 \\
\hline
\end{tabular}

Table 8 Carrying medication comment distribution.

\subsection{Cost}

Two participants mentioned that the cost of medication negatively impacted their adherence. Another participant mentioned that one of the positive influences on their adherence was the fact that their medication was inexpensive. Two of the individuals interviewed mentioned that they were receiving financial aid for their medication. Another participant mentioned that they could not receive financial aid for all their medications. One of the participants receiving financial assistance mentioned that the application process for it was difficult. They were not told about resources such as financial aid at the doctor's office and when they knew about it, they had issues filling out the necessary forms before receiving financial assistance. Table 9 shows the number of times each comment was made by each participant.

\begin{tabular}{|l|c|c|c|c|c|c|c|c|c|c|c|c|c|}
\hline Comment & P1 & P2 & P3 & P4 & P5 & P6 & P7 & P8 & P9 & P10 & P11 & P12 & Total \\
\hline $\begin{array}{l}\text { Cost of medication negatively impacted } \\
\text { adherence }\end{array}$ & & $\checkmark$ & & & & $\checkmark$ & & & & & & & 2 \\
\hline $\begin{array}{l}\text { Medication was inexpensive, improving } \\
\text { adherence }\end{array}$ & & & $\checkmark$ & & & & & & & & & & 1 \\
\hline Receiving financial assistance for medication & & $\checkmark$ & & & & & & $\checkmark$ & & & & & 2 \\
\hline $\begin{array}{l}\text { Not all medications were covered by financial } \\
\text { assistance }\end{array}$ & & & & & & $\checkmark$ & & & & & & & 1 \\
\hline $\begin{array}{l}\text { Application process for financial assistance was } \\
\text { difficult }\end{array}$ & & $\checkmark$ & & & & & & & & & & & 1 \\
\hline
\end{tabular}

Table 9 Cost comment distribution. 


\subsection{Travel}

One of the factors that came up as a negative influence to adherence was not being home. Four participants mentioned that traveling caused issues with adherence to medication. Some of the issues related to traveling included: forgetting to bring their medication; changes in their normal routine, including changing the location of their pill bottle; not knowing how to adjust for changes in time zones; as well as having to stock up on medications for longer trips.

Two participants mentioned that sleepovers were an issue, either because it was difficult to set up their medication the way they would at home or because they could have forgotten it.

Three participants mentioned that not being home at the time their medication had to be taken could cause them to miss or delay a dose. Participants mentioned that this could be because they forgot to take their medication with them.

Two participants mentioned that they had travel packs so they could take a certain number of doses with them if they were going on a short trip. One participant mentioned that they would use a zip-lock bag to carry a specific amount of medication if they knew they would not be home to take their medication. Other participants mentioned that they would just bring their entire pill bottle.

Two participants mentioned that they have, at times, had multiple bottles of their medication which they would store in different locations. They mentioned that they would keep one at home, one on their person and in some cases, one at another location they would spend a lot of time in. 
Table 10 shows the information gathered on travel, showing how many times each comment was made and by which participants.

\begin{tabular}{|l|l|l|l|l|l|l|l|l|l|l|l|c|c|}
\hline Comment & P1 & P2 & P3 & P4 & P5 & P6 & P7 & P8 & P9 & P10 & P11 & P12 & Total \\
\hline Traveling caused issues with adherence & $\checkmark$ & $\checkmark$ & & $\checkmark$ & & & & & & $\checkmark$ & & & 4 \\
\hline Would forget to bring their pill bottle on trips & & & & & & & & & & $\checkmark$ & & & 1 \\
\hline $\begin{array}{l}\text { Traveling caused a change in their normal } \\
\text { routine which negatively impacted adherence }\end{array}$ & & & & $\checkmark$ & & & & & & & & & 1 \\
\hline $\begin{array}{l}\text { Change in the location of their pill bottle } \\
\text { negatively impacted adherence }\end{array}$ & $\checkmark$ & & & & & & & & & & & & \\
\hline $\begin{array}{l}\text { Unsure of how to adjust medication taking for } \\
\text { changes in time zones }\end{array}$ & & & & $\checkmark$ & & & & & & $\checkmark$ & & & \\
\hline Have to stock up on medications on long trips & & & & & & & & & & $\checkmark$ & & \\
\hline Difficult to adhere during sleepovers & $\checkmark$ & $\checkmark$ & & & & & & & & & & & 2 \\
\hline Miss/delay medication when not home & $\checkmark$ & & & & & & & & $\checkmark$ & $\checkmark$ & & & 2 \\
\hline Had a travel pack for short trips & & $\checkmark$ & & & & & & $\checkmark$ & & & & & 2 \\
\hline $\begin{array}{l}\text { Use a zip lock bag to carry medication when } \\
\text { they wouldn't be home to take it }\end{array}$ & & & & & $\checkmark$ & & & & & & & & \\
\hline Had multiple bottles in different locations & & & & & & $\checkmark$ & $\checkmark$ & & & & \\
\hline
\end{tabular}

Table 10 Travel comment distribution.

\subsection{Memory}

Five participants mentioned that they sometimes forget to take their pill because they are bad at remembering to take it. Two participants mentioned that they sometimes forget whether the pill was taken or not. They mentioned that if they forget whether or not they took the pill, they would just take it again.

Three participants mentioned that physically being able to see their medication was used as their reminder to take it.

Table 11 shows how many times each comment was made about memory as well as which participants mentioned it. 


\begin{tabular}{|l|c|c|c|c|c|c|c|c|c|c|c|c|c|}
\hline Comment & P1 & P2 & P3 & P4 & P5 & P6 & P7 & P8 & P9 & P10 & P11 & P12 & Total \\
\hline Forget to take their pill because of memory & & & $\checkmark$ & $\checkmark$ & $\checkmark$ & & & & & & $\checkmark$ & $\checkmark$ & 5 \\
\hline Sometimes forget whether the pill was taken & $\checkmark$ & $\checkmark$ & & & & & & & & & & & 2 \\
\hline Take pill twice if unsure whether it was taken & $\checkmark$ & $\checkmark$ & & & & & & & & & & & 2 \\
\hline Used seeing the pill bottle as a reminder & $\checkmark$ & & & $\checkmark$ & & & & & & & & $\checkmark$ & 3 \\
\hline
\end{tabular}

Table 11 Memory comment distribution.

\subsection{Container}

Everyone interviewed mentioned that they kept their medication in whatever container

they received it in. Two participants mentioned that they used to use a pillbox but stopped because they did not have time or would forget to fill the pillbox. One of these individuals mentioned that the pillbox served as a good visual reminder of whether they had taken their medication or not. One participant mentioned that they did not believe a pillbox was necessary or useful for them since they only took one pill a day.

\begin{tabular}{|l|l|l|l|l|l|l|l|l|l|l|l|l|l|}
\hline Comment & P1 & P2 & P3 & P4 & P5 & P6 & P7 & P8 & P9 & P10 & P11 & P12 & Total \\
\hline $\begin{array}{l}\text { Kept their medication in the container it came } \\
\text { in }\end{array}$ & $\checkmark$ & $\checkmark$ & $\checkmark$ & $\checkmark$ & $\checkmark$ & $\checkmark$ & $\checkmark$ & $\checkmark$ & $\checkmark$ & $\checkmark$ & $\checkmark$ & $\checkmark$ & 12 \\
\hline Used to use a pill box & & $\checkmark$ & & & & & & $\checkmark$ & & & & & 2 \\
\hline $\begin{array}{l}\text { Stopped using a pill box because they would } \\
\text { forget or not have time to fill it }\end{array}$ & & $\checkmark$ & & & & & & $\checkmark$ & & & & & 2 \\
\hline $\begin{array}{l}\text { Believe a pill box is a good visual reminder of } \\
\text { whether the pill was taken or not }\end{array}$ & & $\checkmark$ & & & & & & & & & & & 1 \\
\hline $\begin{array}{l}\text { Believe that a pillbox is unnecessary since they } \\
\text { have the same one pill that they take daily }\end{array}$ & $\checkmark$ & & & & & & & & & & & & 1 \\
\hline $\begin{array}{l}\text { Receive medication in blister packs } \\
\text { Like that the medication is laid out to show } \\
\text { what day each pill should be taken }\end{array}$ & & & $\checkmark$ & & & & & & $\checkmark$ & $\checkmark$ & & & 3 \\
\hline $\begin{array}{l}\text { Liked that their blister pack came with a sleeve } \\
\text { because it made it more discreet }\end{array}$ & & & & & & & & & $\checkmark$ & $\checkmark$ & & & 2 \\
\hline
\end{tabular}

Table 12 Container comment distribution. 
Three participants mentioned that they receive their medications in blister packs. They mentioned that they liked the way the medication was laid out and that it indicated the days each pill should be taken. Two of these participants mentioned that their blister packs came with sleeves, which they liked because it made it more discreet.

Table 12 visually shows the comments made about the container.

\subsection{Storage}

Seven participants mentioned that they kept their medication at home. Of these participants, two placed it next to their bed, two put it on their bathroom counter, one kept it in a lock box since they had a child in the house and one said that they kept it in a cupboard. Four participants mentioned that they carry their medication with them. Two of them mentioned that they carry it in a backpack and one said they keep it in their purse.

Table 13 shows which participants mentioned these comments as well as the total number of times each was mentioned.

\begin{tabular}{|l|l|l|l|l|l|l|l|l|l|l|l|l|l|}
\hline Comment & P1 & P2 & P3 & P4 & P5 & P6 & P7 & P8 & P9 & P10 & P11 & P12 & Total \\
\hline Keep medication at home & $\checkmark$ & & $\checkmark$ & $\checkmark$ & $\checkmark$ & & $\checkmark$ & $\checkmark$ & & & $\checkmark$ & & 7 \\
\hline Keep medication next to their bed & & & $\checkmark$ & $\checkmark$ & & & & & & & & & 2 \\
\hline Keep medication on their bathroom counter & $\checkmark$ & & & & $\checkmark$ & & & & & & & & 2 \\
\hline $\begin{array}{l}\text { Keep medication in a lockbox to keep it away } \\
\text { from children }\end{array}$ & & & & & & & & $\checkmark$ & & & & & 1 \\
\hline Keep medication in a cupboard & & & & & & & & & & & $\checkmark$ & & 1 \\
\hline Carry their medication with them everywhere & & & & & & $\checkmark$ & & & $\checkmark$ & $\checkmark$ & & $\checkmark$ & 4 \\
\hline Keep medication in a backpack & & & & & & $\checkmark$ & & & & & & $\checkmark$ & 2 \\
\hline Keep medication in a wallet & & & & & & & & & & $\checkmark$ & & & 1 \\
\hline
\end{tabular}

Table 13 Storage comment distribution. 


\subsection{Tools}

Half of the participants mentioned that they mainly rely on their own memory to take their medication. Six participants mentioned that they used a phone application to help them remember their medication. Of these individuals, three used the reminder in the calendar application on their phone, two set alarms and one downloaded applications designed for medication adherence. One participant mentioned that they used the application to help remember if they took their medication, though it was not ideal since it relied on them to identify when the medication was taken. One participant mentioned that they recorded whether they had taken their medication or not in a daily log. See Table 14 for a visual representation of which participants mentioned each comment and how many times each was mentioned.

\begin{tabular}{|c|c|c|c|c|c|c|c|c|c|c|c|c|c|}
\hline Comment & P1 & P2 & P3 & P4 & P5 & P6 & P7 & P8 & P9 & $\mathrm{P} 10$ & P11 & $\mathrm{P} 12$ & Total \\
\hline $\begin{array}{l}\text { Rely on their own memory to take their } \\
\text { medication }\end{array}$ & $\checkmark$ & $\checkmark$ & & & & & $\checkmark$ & & $\checkmark$ & $\checkmark$ & $\checkmark$ & & 6 \\
\hline $\begin{array}{l}\text { Use a phone application to help them } \\
\text { remember }\end{array}$ & & $\checkmark$ & $\checkmark$ & & & $\checkmark$ & & $\checkmark$ & $\checkmark$ & & & $\checkmark$ & 6 \\
\hline $\begin{array}{l}\text { Use the reminder in the calendar application on } \\
\text { their phone }\end{array}$ & & & $\checkmark$ & & & & & & $\checkmark$ & & & $\checkmark$ & 3 \\
\hline Set alarms on their phone & & & & & & $\checkmark$ & & $\checkmark$ & & & & & 2 \\
\hline $\begin{array}{l}\text { Downloaded applications designed for } \\
\text { medication adherence }\end{array}$ & & $\checkmark$ & & & & & & & & & & & 1 \\
\hline $\begin{array}{l}\text { Use an app to remember if medication was } \\
\text { taken though it relies on them to manually } \\
\text { input when medication is taken }\end{array}$ & & $\checkmark$ & & & & & & & & & & & 1 \\
\hline $\begin{array}{l}\text { Recorded whether medication was taken in a } \\
\text { daily log }\end{array}$ & & & & & $\checkmark$ & & & & & & & & 1 \\
\hline
\end{tabular}

Table 14 Tools comment distribution.

\subsection{Negative aspects of tools}

Four participants mentioned that sound was an issue with their alarms. Audible sound was noted as being too public, disruptive and annoying. Two participants mentioned that 
their reminders were too easy to dismiss/ignore. Another two individuals mentioned that their applications were not reliable, often not even presenting the notification. Two participants disliked that their applications did not track whether the pill was taken. One participant mentioned that the application they had came with too many features, most of which were not relevant or useful for them. Table 15 shows the number of times each comment was made about negative aspects of tools and which participants mentioned them.

\begin{tabular}{|l|c|c|c|c|c|c|c|c|c|c|c|c|c|}
\hline Comment & P1 & P2 & P3 & P4 & P5 & P6 & P7 & P8 & P9 & P10 & P11 & P12 & Total \\
\hline Sound of alarms is an issue & & & $\checkmark$ & & & & & $\checkmark$ & & $\checkmark$ & & $\checkmark$ & 4 \\
\hline Reminders are too easy to dismiss/ignore & & $\checkmark$ & & & & & & & & & & $\checkmark$ & 2 \\
\hline $\begin{array}{l}\text { Applications are not reliable and often do not } \\
\text { present the notification }\end{array}$ & $\checkmark$ & & & & & & & & $\checkmark$ & & & & 2 \\
\hline $\begin{array}{l}\text { Applications did not track whether the pill was } \\
\text { taken }\end{array}$ & $\checkmark$ & $\checkmark$ & & & & & & & & & & & 2 \\
\hline $\begin{array}{l}\text { Application had too many features, a lot of } \\
\text { which did not apply to them }\end{array}$ & & $\checkmark$ & & & & & & & & & & & \\
\hline
\end{tabular}

Table 15 Negative aspects of tools comment distribution.

\subsection{Good to have in a tool}

Two participants mentioned that if there is a tool with a reminder, the reminder should be difficult to dismiss/ignore. This included having the reminder/alert present until the pill is taken or having a notification that they would have to respond to. Three participants mentioned that any reminder had to be silent and discreet. This included avoiding vibrations and buzzing.

Three participants mentioned that they did not want a tool on their phone or another device that they would have to carry around.

Four participants mentioned wanting a tool to track whether or not their medication was taken. This could include tracking whether it was taken, what time it was 
taken, showing adherence over time, tracking progress on treatment and a visual representation of pills taken/left.

One participant mentioned that they wanted a solution tailored specifically to their medication plan.

One participant mentioned that they wanted a solution that would be responsive to their situation. For example, something that would allow them to defer a notification if they were in a situation where they could not take their medication.

Two participants mentioned that they wanted a tool that was both simple to use and to set up.

Table 16 shows the number of times each comment was made about what is nice to have in a tool and which participants mentioned them.

\begin{tabular}{|c|c|c|c|c|c|c|c|c|c|c|c|c|c|}
\hline Comment & P1 & P2 & P3 & P4 & P5 & P6 & P7 & P8 & P9 & P10 & P11 & $\mathrm{P} 12$ & Total \\
\hline $\begin{array}{l}\text { Reminders should be difficult to } \\
\text { dismiss/ignore }\end{array}$ & & $\checkmark$ & & & & & & & & & & $\checkmark$ & 2 \\
\hline $\begin{array}{l}\text { Have the notification present until the pill is } \\
\text { taken or have them respond to it }\end{array}$ & & $\checkmark$ & & & & & & & & & & $\checkmark$ & 2 \\
\hline Has to be silent and discreet & & $\checkmark$ & $\checkmark$ & & & & & & & & & $\checkmark$ & 3 \\
\hline $\begin{array}{l}\text { Do not want a tool on their phone or another } \\
\text { device that they would have to carry around }\end{array}$ & $\checkmark$ & $\checkmark$ & & & & & & & $\checkmark$ & & & & 3 \\
\hline $\begin{array}{l}\text { A tool to track whether the medication was } \\
\text { taken }\end{array}$ & $\checkmark$ & $\checkmark$ & & & $\checkmark$ & & $\checkmark$ & & & & & & 4 \\
\hline Track whether medication was taken & $\checkmark$ & $\checkmark$ & & & & & $\checkmark$ & & & & & & 3 \\
\hline Track when medication was taken & & $\checkmark$ & & & & & $\checkmark$ & & & & & & 2 \\
\hline $\begin{array}{l}\text { Show adherence over time and progress on } \\
\text { treatment }\end{array}$ & & & & & & & $\checkmark$ & & & & & & 1 \\
\hline Visually represent pills taken/left & & $\checkmark$ & & & & & & & & & & & 1 \\
\hline $\begin{array}{l}\text { Want a solution tailored to their medication } \\
\text { plan }\end{array}$ & & $\checkmark$ & & & & & & & & & & & 1 \\
\hline $\begin{array}{l}\text { Want a solution that is responsive to their } \\
\text { situation }\end{array}$ & & & & & & & & & & & & $\checkmark$ & 1 \\
\hline Want a tool that is simple and easy to set up & & $\checkmark$ & $\checkmark$ & & & & & & & & & & 2 \\
\hline
\end{tabular}

Table 16 Good to have in a tool comment distribution. 


\subsection{Other desires}

Three participants mentioned that the medication should be portable, making it easy to carry around or take on trips.

Two participants mentioned that they wanted more access to support systems. This included counseling, one-on-one information sessions about the medication/illness and referrals to help when transitioning out of certain systems (e.g. leaving university).

Two participants mentioned that they wanted to receive better, simpler instructions with their medication. Two participants mentioned that they wanted more education around taking medication or the impact it could have in their life.

Two participants mentioned that they wanted more immediate access to their medication. This included ways of deferring the medication cost or having their medication accessible at all drug stores. One participant mentioned that removing the stigma around taking medication would help adherence. One participant mentioned that they wanted a more attractive pill bottle.

Table 17 shows the comments for other desires as well as which participants mentioned them and the total number of times each comment was made.

\begin{tabular}{|l|l|l|l|l|l|l|l|l|l|l|l|l|l|}
\hline Comment & P1 & P2 & P3 & P4 & P5 & P6 & P7 & P8 & P9 & P10 & P11 & P12 & Total \\
\hline Medication should be portable & $\checkmark$ & $\checkmark$ & & & & & & & & & $\checkmark$ & & 3 \\
\hline More access to support systems & & $\checkmark$ & & & $\checkmark$ & & & & & & & & 2 \\
\hline Better, simpler instructions with medication & & $\checkmark$ & & & & & & & & $\checkmark$ & & & 2 \\
\hline More education around medication & & $\checkmark$ & & & & & & & & & $\checkmark$ & & 2 \\
\hline More immediate access to medication & & $\checkmark$ & & & & $\checkmark$ & & & & & & & 2 \\
\hline Removing stigma around medication & & & & & & $\checkmark$ & & & & & & & 1 \\
\hline Should be a more attractive pill bottle & & $\checkmark$ & & & & & & & & & & & 1 \\
\hline
\end{tabular}

Table 17 Other desires comment distribution. 


\section{Chapter: Study 1 Discussion}

Many of the findings from this study were similar to those found in the literature review. As mentioned in Matsui (2007) and Butz (2006), almost all participants in this study mentioned that they had set up routines to take their medication and that these helped with adherence. This often included linking their medication to an event in their day as well as placing their medication in a location that would remind them to take it.

As mentioned by Matsui (2007), participants would align their doses to minimise the disruptiveness to their day as well as avoid taking medications in social situations. This issue of taking medication in social situations was brought up in the interviews as well, where some participants believed taking medication was personal and did not want others to know. Some of the concerns raised were about people seeing or hearing their medication if they were carrying it on them or that their reminders were too public. A couple of participants also mentioned that they would delay taking their medication so that it would not be disruptive or interfere with a specific event. This included school or social situations, as noted in Osterberg \& Blaschke (2005). Unlike the findings of Osterberg \& Blaschke (2005), not many participants mentioned purposely skipping a dose. On the other hand, variations in the routine that they had set up were often noted as causes for missed or delayed doses. These variations included social situations or other obligations. The effect that variations on routine had on adherence was also mentioned in the literature by Nair et al. (2011).

Traveling or being away from home in general was repeated as one of the causes for missed/delayed doses in this study. Five of the twelve participants brought it up as an issue, and strategies of dealing with traveling while on medication was mentioned in 
another four sessions. In this study, traveling refers to going on vacations, weekend trips, sleepovers or day trips, for example to school. Traveling as an issue was also addressed in the literature by Nair et al. (2011) and Hanghøj \& Boisen (2014). Missed doses relating to traveling were often because individuals would forget their pills at home, have alterations in their routine or be in social situations where taking medication would be awkward. Some participants also mentioned that they were not sure of how to adjust medications when switching time zones.

Forgetfulness was also brought up as an area of concern by eight participants. This included forgetting to take their medication, forgetting to carry it on them as well as forgetting whether or not the medication was taken. These could lead to missed doses, delayed doses or doubling up on doses. This finding is similar to the literature, where forgetfulness was commonly mentioned as one of the reasons participants missed a dose of their medication (Osterberg \& Blaschke, 2005; Matsui, 2007; Nair et al., 2011; Hanghøj \& Boisen, 2014). Some participants in this study noted that the simplicity of a medication plan improved their ability to adhere to it. This was also found in Osterberg \& Blaschke (2005), Matsui (2007) and Butz (2006).

Access to medication, as noted by Osterberg \& Blaschke (2005) and Hanghøj \& Boisen (2014), was mentioned as an issue by some participants, though it was not a common problem. Osterberg \& Blaschke (2005), Matsui (2007) and Butz (2006) mentioned education as a barrier to adherence. This was also found in the interviews, although it was only mentioned by a couple of participants. In the interviews, some individuals had mentioned a need for more patient education in interactions with the doctor, the instructions provided with medication and with ongoing support. 
Social stigma, mentioned by Rao et al. (2007) as well as poor communication between patients and their healthcare team, mentioned by Matsui (2007) and Butz (2006) were each mentioned once during the interviews but were not a common concern among participants in the interviews.

Some differences were also found between information in the literature and the interviews conducted. The literature mentioned that adherence declines for long-term treatments, specifically after 6 months (Osterberg \& Blaschke, 2005; DiMatteo, 2003); though in the interviews, almost all the participants said that adherence was not difficult. Half of the participants said that the length of the medication plan allowed them to adapt to taking the medication, making it a routine. Matsui (2007) also mentioned that patients avoid dosing in the middle of the day, though in the interviews, two participants mentioned that noon was the ideal time for them to take their medication.

In the literature review, the transition from youth services was mentioned as an issue (Annunziato et al., 2007) as well as using games to improve adherence (Kato et al., 2008; Nikkila et al., 2012). Neither of these points were mentioned in the interviews. In the interviews, eleven participants mentioned they were personally motivated to take their medication and that it was easy for them, though this was not found in the literature review. These participants mentioned that their personal motivations stemmed from wanting the benefits. These included treating the illness, maintaining one's health and avoiding feeling sick. It was mentioned that these benefits often outweigh the cons of taking the medication, such as dealing with side effects.

The packaging/container of their medication was something that was often discussed by participants, but did not seem to appear in the literature; though some of the 
solutions on the market are medication containers. None of the participants switched their medication out of the container in which it came. This could be an issue with the products on the market since of the four containers identified, three of them seem to require the user to switch medication out of its original package. In the interviews, two participants mentioned that they used to use pillboxes but stopped due to the time they took to fill. With the market solutions found, two were pillboxes; one required participants to manually fill it while the other offered pre-packaged refills to address this issue.

Participants who were happy with the packaging of their medication were all receiving blister packs, which marked off which pills were meant to be taken on any given day. Participants generally liked/wanted this type of packaging because it served as a visual reminder as to whether their medication had been taken or not. Of the tools found on market, only one of the three pharmacies advertised offering medication in blister packs.

As a note, some of the differences between the literature and the interviews could potentially be explained by differences between medication regimens or specific illnesses. Another factor could be differences in the sample of participants recruited since most of the recruitment for this study was conducted in a university setting.

\subsection{Next step}

In the interviews and literature, creating routines to manage medication was a major theme (Matsui, 2007; Butz, 2006). In both the literature and the interviews, travelling was noted as one of the major barriers to this, in part due to the impact it would have on an individual's planned routine (Nair et al., 2011; Hanghøj \& Boisen, 2014). Due to the prevalence of this theme, the co-design sessions could focus on medication adherence 
while traveling for this demographic, where traveling includes vacations, weekend trips, sleepovers and day trips. Though travelling will be the main theme, other key issues may also be discussed. 


\section{Chapter: Study 2 Methods}

Three co-design sessions were conducted, consisting of a total of four groups. Each group had either two or three participants. A total of ten participants took part in the study. Each group had at least one designer and one individual who was either prescribed a daily medication plan by a medical professional or worked closely with an individual on an ongoing daily medication plan. Participants were presented with information found in Study 1 in the form of personas; the personas can be found in Appendix B.1. They were asked to design a solution that improves medication adherence in young adults who are traveling and on ongoing, daily medication plans. The goal of this study was for the participants to develop concepts that aim to assist young adults in adhering to ongoing medication regimens. In addition, this process and the solutions could help provide additional insights into the issues which impact adherence and what is needed in a tool that improves medication adherence in the target demographic.

\subsection{Personas}

Personas are profiles of potential users that are based on common behavioral characteristics. These profiles should be based on information collected from real users (Martin \& Hanington, 2012). According to Martin \& Hanington (2012), personas can be used as a point of reference during the design process to develop, discuss or present concepts. In this study, personas were created from the data gathered in the interviews and were meant to help groups discuss and explore potential solutions to medication adherence in young adults. Though the personas were provided to help facilitate discussion on the topic as well as frame the problem space, participants were encouraged to share and include personal experiences or knowledge. In this case, personas could also 
allow participants to project their opinions and experiences onto someone else if they were uncomfortable discussing their personal life in a group setting.

\subsection{Recruitment}

The recruitment methods for this study were snowballing and convenience sampling. Recruitment was done on Carleton University's campus, online and by word of mouth. Posters were put up around Carleton University's campus; a sample of the poster can be found in Appendix B.2. Email invitations were distributed through Carleton University's department of Industrial Design mailing list as well as to participants who had expressed interest in the first study. A sample of the email invitations can be found in Appendix B.3. Social media invitations were posted to various group pages on Facebook as well as the researcher's Facebook, LinkedIn and Twitter profile. The social media invitation can be found in Appendix B.4. Participants as well as friends of the researcher were encouraged to share the recruitment material. In order to participate, an individual had to be comfortable speaking English, and identify with at least one of the following groups:

- Have been prescribed a daily medication plan by a medical professional

- Worked closely with an individual who has been prescribed a daily medication plan

- Be a designer

\subsection{Screener}

Participants who expressed interest were sent a screener prior to the session. The screener included three demographic questions. Two were balancing questions, including age and gender identified as. One was a differentiating question that asked which group(s) they identified with. A sample of the screener can be found in Appendix B.5. 


\subsection{Setup}

Three sessions were conducted; two of these sessions each had one group participating and one session had two groups running simultaneously. All sessions were conducted inperson, in a private room located on Carleton University's campus. Sessions lasted approximately two hours and were video recorded by a volunteer videographer. Various materials were provided during each session to allow participants to create models, which would help them develop or communicate ideas. The materials provided are shown in

Figure 10.

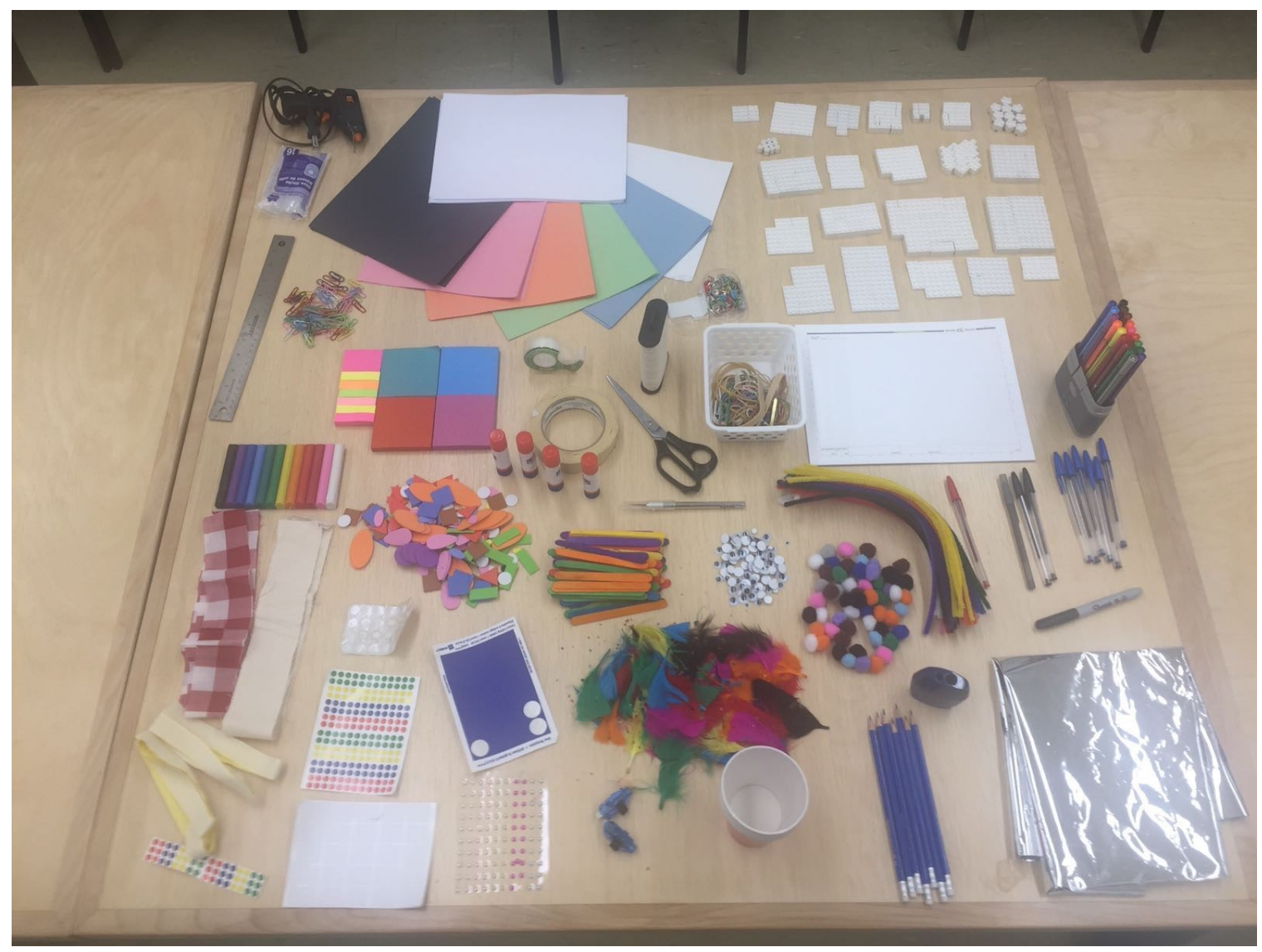

Figure 10 Materials provided to participants during the co-design sessions.

At the start of each session, all participants were required to sign a consent form; a sample of the consent form can be found in Appendix B.6. Once the consent form was 
signed, participants received a copy of the personas as well as an agenda for the session. A copy of the agenda can be found in Appendix B.7. The first 15 minutes of each session was allocated to allowing participants to arrive and sign the consent form. During this time, participants could also review the personas on their own.

Once all the participants had arrived and the consent forms were signed, the study began. Fifteen minutes were spent going through the introduction, during which the facilitator described the study, the plan for the session and went over the personas as a group. Instructions for the session were kept vague, but participants were told to develop a solution for young adults taking medication while on trips. A copy of the Introduction script can be found in Appendix B.8.

Participants then had one hour to discuss, develop solutions and plan a presentation for those solutions. Groups were able to develop and present as many solutions as they wanted. They were also told that the solutions could be 'blue-sky,' therefore they did not have to be restricted by cost, ease of manufacturing or current technology.

After that hour, participants were asked to present their ideas to the researcher. In the session with two groups, the groups were asked to present to each other. After the presentations, the designs were discussed as a group. Twenty-five minutes were allocated to completing this activity.

Finally, participants were given a feedback form where they could provide their personal insight on each of the solutions presented. The feedback forms included four questions asking participants to rank each of the solutions presented and asked for explanations for the ratings they provided. These questions included: 
1. I believe the solution(s) presented today effectively solve the problems presented in the persona.

2. I believe the solution(s) presented today are feasible.

3. I believe the solution(s) presented today would improve how closely young adults adhere to their medication plans.

4. If more than one idea was presented today, please rank them from most suitable to least suitable.

Questions one to three were presented on a Likert Scale from one to five, where one corresponded to strongly disagree and five corresponded to strongly agree. The participants could give each of the solutions its own ranking for questions one to three and were asked to rank them in the fourth question. Prior to handing out the feedback form, all of the solutions were numbered so the participants' data could easily be compared. A copy of the feedback form can be found in Appendix B.9.

As a thank you to all the participants, refreshments were provided during the sessions.

\subsection{Participant Demographics}

Ten individuals took part in the study; of these ten, seven identified as female, two identified as male and one participant did not respond. Participants' ages ranged from 2034 years old; an exact distribution of ages can be found in Table 18.

\begin{tabular}{|l|l|l|l|l|l|l|l|}
\hline Age & 20 & 23 & 25 & 27 & 28 & 29 & 34 \\
\hline Number of Participants & 1 & 2 & 1 & 1 & 1 & 2 & 1 \\
\hline
\end{tabular}

Table 18 Distribution of participant ages for study two. One participant did not provide their age.

Three participants identified as having been prescribed an ongoing daily medication plan, three participants mentioned that they worked closely with an individual who took medication daily and seven identified as designers. Some participants identified 
with more than one of the categories; this can be seen in Table 19 that shows the participant responses.

\begin{tabular}{|l|c|l|c|}
\hline $\begin{array}{l}\text { Participant } \\
\text { Number }\end{array}$ & $\begin{array}{l}\text { Prescribed an ongoing daily } \\
\text { medication plan }\end{array}$ & $\begin{array}{l}\text { Works closely with an individual prescribed } \\
\text { an ongoing daily medication plan }\end{array}$ & Designer \\
\hline 1 & $\checkmark$ & & $\checkmark$ \\
\hline 2 & & $\checkmark$ & $\checkmark$ \\
\hline 3 & $\checkmark$ & $\checkmark$ & $\checkmark$ \\
\hline 4 & & $\checkmark$ & $\checkmark$ \\
\hline 5 & & & $\checkmark$ \\
\hline 6 & $\checkmark$ & & $\checkmark$ \\
\hline 7 & & & $\checkmark$ \\
\hline 8 & & & $\checkmark$ \\
\hline 9 & & & $\checkmark$ \\
\hline 10 & & & $\checkmark$ \\
\hline
\end{tabular}

Table 19 Distribution of participant expertise for study two. One participant did not respond.

\subsection{Analysis Method}

The cyclical coding method presented by Saldaña (2016) was used again for the analysis of data from the second study. In the first cycle, holistic coding and tabletop categorization were used. For the second cycle, pattern coding was used to draw meaning from the data and create considerations presented in the discussion. 


\section{Chapter: Study 2 Results}

Below, the results of the co-design sessions will be discussed. This will be split into three sections, including: comments made during the session, the solutions they presented and the individual comments given in the feedback forms. For the comments made during the session and the solutions presented, data will be presented by the number of times it arose in each group. This is due to the fact that group members influenced one another; therefore, it would be difficult to accurately reflect on the views of each individual member. Individual comments will be noted in the section for the feedback forms.

\subsection{Comments during session}

The following section identifies the various comments made during the one-hour ideation portion of the co-design session.

\subsubsection{Accommodate different medication}

Three of the four groups mentioned that the solution created would need to accommodate medication of different sizes, types and methods of ingestion. One of those groups emphasized the need for it to accommodate insulin, not just pills. Table 20 shows the comments made on this topic and which groups it was mentioned in.

\begin{tabular}{|l|l|l|l|l|l|}
\hline Comment & $\begin{array}{l}\text { Group } \\
1\end{array}$ & $\begin{array}{l}\text { Group } \\
2\end{array}$ & $\begin{array}{l}\text { Group } \\
3\end{array}$ & $\begin{array}{l}\text { Group } \\
4\end{array}$ & Total \\
\hline $\begin{array}{l}\text { Accommodate medication of different sizes, types and methods of } \\
\text { ingestion }\end{array}$ & $\checkmark$ & $\checkmark$ & & $\checkmark$ & 3 \\
\hline Should accommodate insulin, not just pills & & $\checkmark$ & & & 1 \\
\hline
\end{tabular}

Table 20 Accommodate different medications comments during development phase of co-design.

\subsubsection{Carrying medication}

All four groups mentioned a need for medication to always be on the individuals' person. Two were concerned that even if a device can carry medication for multiple days, the 
individual can forget to take it with them. One group mentioned that the issue with some devices is that you can lose them.

All four groups also mentioned a need to reduce the noise created while carrying pills. All four of them recommended muffling the sound of the container with cotton or rubber, which they mentioned they had seen done before. Three of the groups mentioned that individual packaging of pills would still create noise.

Three groups mentioned that the device had to be easy to carry; it should not be too large or heavy. One participant mentioned it "doesn't have to be that big because on average, people don't take that much.”

All four groups mentioned that the solution should store medication for more than one day, however you also should not have to carry all the medication with you. One group mentioned that this was because if it only carried medication for a day you would have to remember to refill it. Two groups mentioned that the solution should be small for day-to-day use but have the ability to expend for longer trips. One participant stated that "if I were to think of my own purse... I would want something slim because my purse is slim." Groups one and three discussed carrying seven days worth of medication and groups two and three discussed carrying three days worth of medication. Group three also mentioned that you could have a spare pill with you in case one of them is dropped.

See Table 21 for a visual of the comments during the development phase of the co-design sessions about carrying medication and which of the groups mentioned each of the comments. 


\begin{tabular}{|c|c|c|c|c|c|}
\hline Comment & $\begin{array}{l}\text { Group } \\
1\end{array}$ & $\begin{array}{l}\text { Group } \\
2\end{array}$ & $\begin{array}{l}\text { Group } \\
3\end{array}$ & $\begin{array}{l}\text { Group } \\
4\end{array}$ & Total \\
\hline Always be on the individuals' person & $\checkmark$ & $\checkmark$ & $\checkmark$ & $\checkmark$ & 4 \\
\hline $\begin{array}{l}\text { Even if it carries pills for multiple days, people may forget to take it with } \\
\text { them }\end{array}$ & & $\checkmark$ & $\checkmark$ & & 2 \\
\hline Reduce the noise created while carrying pill & $\checkmark$ & $\checkmark$ & $\checkmark$ & $\checkmark$ & 4 \\
\hline $\begin{array}{l}\text { Muffle the sound of the container with cotton or rubber, which they have } \\
\text { seen before }\end{array}$ & $\checkmark$ & $\checkmark$ & $\checkmark$ & $\checkmark$ & 4 \\
\hline Individual packaging of pills would still create noise & $\checkmark$ & & $\checkmark$ & $\checkmark$ & 3 \\
\hline Has to be easy to carry, not to large or heavy & $\checkmark$ & $\checkmark$ & $\checkmark$ & & 3 \\
\hline Store medication for more than one day & $\checkmark$ & $\checkmark$ & $\checkmark$ & $\checkmark$ & 4 \\
\hline Should not have to carry all the medication with you & $\checkmark$ & $\checkmark$ & $\checkmark$ & $\checkmark$ & 4 \\
\hline Can forget to refill the device if it only stores for one day & $\checkmark$ & & & & 1 \\
\hline Small for day to day use but have the ability to expend for longer trips & & $\checkmark$ & & $\checkmark$ & 2 \\
\hline Hold 3 days of pills & & $\checkmark$ & $\checkmark$ & & 2 \\
\hline Hold 7 days of pills & $\checkmark$ & & $\checkmark$ & & 2 \\
\hline Spare in case a pill is dropped & & & $\checkmark$ & & 1 \\
\hline
\end{tabular}

Table 21 Carrying medication comment during development phase of co-design.

\subsubsection{Customizable/personalizable}

Three groups decided that their solutions needed to be able to be customized to a specific medication regimen, based on the number of pills or the type of medication. Two groups believed that users should be able to personalize it, for example decorate it so it matches their own personal taste. One group mentioned that it should be able to be customized based on what an individual normally carries everyday. Table 22 shows this information and which groups mentioned it.

\begin{tabular}{|l|l|l|l|l|l|}
\hline Comment & Group 1 & Group 2 & Group 3 & Group 4 & Total \\
\hline Needed to be able to be customized to a specific medication regimen & $\checkmark$ & $\checkmark$ & & $\checkmark$ & 3 \\
\hline Users should be able to personalize it & $\checkmark$ & & & $\checkmark$ & 2 \\
\hline Customized based on what an individual normally carries everyday & $\checkmark$ & & & & 1 \\
\hline
\end{tabular}

Table 22 Customizability and personalization comments during development phase of co-design. 


\subsubsection{Device used}

In terms of the device that would be used, all four groups mentioned that it could be embedded into a wearable, and they all mentioned integrating it into a smart watch. One group did raise a concern that not all users may have a smart watch. One group discussed creating a new device specifically for medication but they also mentioned that that would run the risk of the user forgetting to take it with them. They then recommended allowing users to integrate the solution into whatever they already carry with them on a typical day. Groups one, two and four all mentioned building a solution which integrates pills into water bottle or cup since pills are typically taken with water and this would allow the act of taking the pill to be discrete. Two groups discussed the use of implants as reminder devices. See Table 23, which illustrates the comments made on this topic.

\begin{tabular}{|c|c|c|c|c|c|}
\hline Comment & $\begin{array}{l}\text { Group } \\
1\end{array}$ & $\begin{array}{l}\text { Group } \\
2\end{array}$ & $\begin{array}{l}\text { Group } \\
3\end{array}$ & $\begin{array}{l}\text { Group } \\
4\end{array}$ & Total \\
\hline Embedded into a wearable & $\checkmark$ & $\checkmark$ & $\checkmark$ & $\checkmark$ & 4 \\
\hline Integrated into a smart watch & $\checkmark$ & $\checkmark$ & $\checkmark$ & $\checkmark$ & 4 \\
\hline Not all users may have a smart watch & & & & $\checkmark$ & 1 \\
\hline Create a new device specifically for medication & $\checkmark$ & & & & 1 \\
\hline If solution is part of a new device, users may forget to take it with them & $\checkmark$ & & & & 1 \\
\hline $\begin{array}{l}\text { Integrate the solution into whatever users already carry with them on a } \\
\text { typical day }\end{array}$ & $\checkmark$ & & & & 1 \\
\hline $\begin{array}{l}\text { Built into a water bottle or cup to allow you to discreetly take the pill while } \\
\text { drinking water, since water is typically taken with pills }\end{array}$ & $\checkmark$ & $\checkmark$ & & $\checkmark$ & 3 \\
\hline Implant a reminder device & $\checkmark$ & & & $\checkmark$ & 2 \\
\hline
\end{tabular}

Table 23 Types of devices comment during development phase of co-design.

\subsubsection{Integrate into life}

Group two discussed having the device prompt users to take their medication based on their daily patterns. This could help them integrate taking the medication into their schedule and tie it into their routine, which was also mentioned by group three. Group 
three mentioned that the solution had to be "simple, but it has to fit into your everyday life. It can't be complicated." Group three wanted the device to accommodate users if they were unable or unwilling to take medication at a certain time by delaying the notification. They stated that "when [an individual] delays [taking their medication], it should know that it delayed so that it probes them again because you can't create a solution that forces [someone] to take her medication." Table 24 shows the comments made about product integration into the users life as well as which groups mentioned it.

\begin{tabular}{|l|l|l|l|l|l|}
\hline Comment & $\begin{array}{l}\text { Group } \\
1\end{array}$ & $\begin{array}{l}\text { Group } \\
2\end{array}$ & $\begin{array}{l}\text { Group } \\
3\end{array}$ & $\begin{array}{l}\text { Group } \\
4\end{array}$ & Total \\
\hline $\begin{array}{l}\text { Having the device prompt users to take their medication based on their daily } \\
\text { patterns }\end{array}$ & & $\checkmark$ & & & 1 \\
\hline $\begin{array}{l}\text { Integrate taking the medication into their schedule and tie it into their } \\
\text { routine }\end{array}$ & & $\checkmark$ & $\checkmark$ & & 2 \\
\hline $\begin{array}{l}\text { Accommodate users if they were unable or unwilling to take medication at a } \\
\text { certain time by delaying the notification }\end{array}$ & & & $\checkmark$ & & 1 \\
\hline
\end{tabular}

Table 24 Integrate into life comment during development phase of co-design.

\subsubsection{Change the medication}

Group four recommended changing the medication itself. They suggested making it look like an everyday object, such as gum or placing the medicine in food. They mentioned that there was an issue with that idea since someone could ask for gum if that is what the medication looked like. They also recommended making it look like something interesting, such as emojis so people would be more willing to take it in public. Table 25 summarizes the comments made on this topic and which groups mentioned it.

\begin{tabular}{|c|c|c|c|c|c|}
\hline Comment & Group 1 & Group 2 & Group 3 & Group 4 & Total \\
\hline Make the medicine look like an everyday object, e.g. Like gum & & & & $\checkmark$ & 1 \\
\hline If it looks like an everyday object, e.g. Gum, what if someone asks for gum & & & & $\checkmark$ & 1 \\
\hline Make medication look like something interesting, such as emojis & & & & $\checkmark$ & 1 \\
\hline
\end{tabular}

Table 25 Change the medication comment during development phase of co-design. 


\subsubsection{Motivation}

Group four discussed making medication taking fun by gamifying it. They discussed adding extrinsic rewards and feedback when medication is taken, linking it to an online game or having a pet like a tamagotchi. Both groups one and four recommended using the device to help users build a habit. Table 26 displays these results and the specific groups that made each comment.

\begin{tabular}{|l|l|l|l|l|l|}
\hline Comment & Group 1 & Group 2 & Group 3 & Group 4 & Total \\
\hline Gamify medication taking & & & & $\checkmark$ & 1 \\
\hline Add extrinsic rewards and feedback when medication is taken & & & & $\checkmark$ & 1 \\
\hline Link it to an online game & & & & $\checkmark$ & 1 \\
\hline Have a pet like a tamagotchi & & & & $\checkmark$ & 1 \\
\hline Use the tool to build a habit & $\checkmark$ & & & $\checkmark$ & 2 \\
\hline
\end{tabular}

Table 26 Motivation comment during development phase of co-design.

\subsubsection{Packaging}

Three of the four groups discussed using a blister pack and the other discussed the use of a pillbox. Two of the groups thought it would be helpful to have the medication labeled by day. Group four recommended changing the shape of the pill bottles into something interesting, for example a Pikachu. See Table 27 for a summary of these comments and which groups mentioned them.

\begin{tabular}{|l|l|l|l|l|l|}
\hline Comment & Group 1 & Group 2 & Group 3 & Group 4 & Total \\
\hline Use a blister pack & $\checkmark$ & $\checkmark$ & & $\checkmark$ & 3 \\
\hline Use a pill box & & & $\checkmark$ & & 1 \\
\hline Have the pills labeled by day & $\checkmark$ & & & $\checkmark$ & 2 \\
\hline Change the shape of the pill bottle, e.g. Make it look like a Pikachu & & & & $\checkmark$ & 1 \\
\hline
\end{tabular}

Table 27 Packaging comment during development phase of co-design. 


\subsubsection{Refill}

Three of the groups mentioned that the solution should be quick and easy to fill. The other group suggested including a reminder to refill the device. Two groups mentioned that if the device had to be refilled daily, users could forget. Groups one and two both wanted to use cartridges that would be provided by the pharmacist. Group two wanted the device to automatically refill the travel packs for the user. See Table 28 for a summary of the comments made on this topic.

\begin{tabular}{|l|l|l|l|l|l|}
\hline Comment & Group 1 & Group 2 & Group 3 & Group 4 & Total \\
\hline Quick and easy to fill & $\checkmark$ & $\checkmark$ & $\checkmark$ & & 3 \\
\hline Should remind you to refill the device & & & & $\checkmark$ & 1 \\
\hline If the device has to be refilled daily, users could forget & $\checkmark$ & & $\checkmark$ & & 2 \\
\hline Have a refill cartridge or packets provided by the pharmacist & $\checkmark$ & $\checkmark$ & & & 2 \\
\hline Automatically refill the travel packs for the user & & $\checkmark$ & & & 1 \\
\hline
\end{tabular}

Table 28 Refill comment during development phase of co-design.

\subsubsection{Reminders}

All four groups felt that the notification or reminder to take the medication was an important aspect in any solution. One participant from group three stated, "for me, remembering to take it is the problem." Two groups mentioned that the reminder had to be difficult to ignore. Three groups mentioned that the reminder had to be discreet so that only the individual taking the medication could notice it. One of those three groups stated that it also should not be disruptive. Two groups mentioned that the reminder had to be reliable. One group mentioned that there should be multiple methods of reminders used, for example a phone and something else.

Phones were discussed as a medium to provide the reminder but groups generally had a negative outlook on using a phone for this. Three groups stated that phones were 
not reliable. One group mentioned that phones do not always work when you are traveling since you may not carry it with you or it can run out of batteries. One group stated that phone alarms are easy to ignore. Another group mentioned that "there's a lot of people that just don't like having apps or relying on the phone." Group one mentioned using an app but they brought up that currently, when using their calendar reminder, they do not remember to check it. In group two, it was mentioned that the screen of a phone might be too visible. They stated that a smart watch screen might be more discrete.

In terms of the notification style, only group four mentioned the potential of using an auditory alarm in the form of a soothing noise; however, both group four and two mentioned that auditory notifications could be disturbing and attract attention. Groups one, three and four discussed using visual reminders. Two groups discussed using colour or light, one suggested dancing panda, one recommended using happy/sad faces as indicators and one suggested a notification on the phone screen. Two groups mentioned using a physical object that the user associated with medication as a reminder. All three groups that considered visual reminders also stated that visual reminders only work if they are in your line of sight and could be missed if you are not looking at it at the right time. They stated that this could happen if the object was left in their bag or if they were asleep. All four groups mentioned using a tactile notification, and all four of them mentioned vibration. Other tactile reminders that were mentioned include temperature changes that was mentioned by two groups, pain which was mentioned by one group and one group mentioned a slimy slug crawling on your skin as a reminder. Three groups discussed using multimodal reminders, usually including tactile and visual. 
Three participants wanted to visually see when pills had been taken so they would not accidentally take them twice. It was recommended to visually showing something emptying. One group mentioned only unlocking one pill at a time so that users could not take more than one. Two groups also mentioned wanting to visually see what pills are left.

See Table 29 for a summary of all the comments made about reminders in this section of the co-design sessions.

\begin{tabular}{|c|c|c|c|c|c|}
\hline Comment & $\begin{array}{l}\text { Group } \\
1\end{array}$ & $\begin{array}{l}\text { Group } \\
2\end{array}$ & $\begin{array}{l}\text { Group } \\
3\end{array}$ & $\begin{array}{l}\text { Group } \\
4\end{array}$ & Total \\
\hline Reminder to take the medication was an important aspect & $\checkmark$ & $\checkmark$ & $\checkmark$ & $\checkmark$ & 4 \\
\hline Should be difficult to ignore & & $\checkmark$ & & $\checkmark$ & 2 \\
\hline Should be discreet so that only the individual taking the medication notices & & $\checkmark$ & $\checkmark$ & $\checkmark$ & 3 \\
\hline Should not be disruptive & & $\checkmark$ & & & 1 \\
\hline Has to be reliable & $\checkmark$ & & & $\checkmark$ & 2 \\
\hline Multiple methods of reminders should be used & $\checkmark$ & & & & 1 \\
\hline Phone is not reliable & $\checkmark$ & $\checkmark$ & & $\checkmark$ & 3 \\
\hline $\begin{array}{l}\text { Phone does not always work with travel since they can out of batteries or not } \\
\text { carried }\end{array}$ & $\checkmark$ & & & & 1 \\
\hline Phone alarms are easy to ignore & & & & $\checkmark$ & 1 \\
\hline Some people don't like having apps or relying on the phone & & & & $\checkmark$ & 1 \\
\hline $\begin{array}{l}\text { The reminder could use an app, but currently when they use their calendar, } \\
\text { they forget to check it }\end{array}$ & $\checkmark$ & & & & 1 \\
\hline Screen of phone is too visible, a smart watch screen may be more discrete & & $\checkmark$ & & & 1 \\
\hline Auditory alarm as a soothing noise & & & & $\checkmark$ & 1 \\
\hline Can be disturbing and attracts attention & & $\checkmark$ & & $\checkmark$ & 2 \\
\hline Use a visual reminder & $\checkmark$ & & $\checkmark$ & $\checkmark$ & 3 \\
\hline Visual reminder as colour or light & & & $\checkmark$ & $\checkmark$ & 2 \\
\hline Visual reminder as a dancing panda pet & & & & $\checkmark$ & 1 \\
\hline Visual reminder as a happy or sad face & & & $\checkmark$ & & 1 \\
\hline
\end{tabular}




\begin{tabular}{|c|c|c|c|c|c|}
\hline Visual reminder as a notification on a phone screen & $\checkmark$ & & & & 1 \\
\hline Visual reminder as a physical object that users will associate with medication & $\checkmark$ & & & $\checkmark$ & 2 \\
\hline $\begin{array}{l}\text { Visual reminders only work if they are in your line of sight and could be } \\
\text { missed if you are not looking at it at the right time }\end{array}$ & $\checkmark$ & & $\checkmark$ & $\checkmark$ & 3 \\
\hline Use a tactile notification & $\checkmark$ & $\checkmark$ & $\checkmark$ & $\checkmark$ & 4 \\
\hline Vibration as a tactile reminder & $\checkmark$ & $\checkmark$ & $\checkmark$ & $\checkmark$ & 4 \\
\hline Temperature as a tactile reminder & $\checkmark$ & & & $\checkmark$ & 2 \\
\hline Pain as a tactile reminder & & & & $\checkmark$ & 1 \\
\hline Slimy slug crawling onto your skin as a tactile reminder & & & & $\checkmark$ & 1 \\
\hline Use a multimodal notification & $\checkmark$ & & $\checkmark$ & $\checkmark$ & 3 \\
\hline Visually show what pills have been taken to ensure pills are not taken twice & $\checkmark$ & & $\checkmark$ & $\checkmark$ & 3 \\
\hline Unlock one pill at a time & & & & $\checkmark$ & 1 \\
\hline Visually see what pills you have left & $\checkmark$ & & & $\checkmark$ & 2 \\
\hline
\end{tabular}

Table 29 Reminders comment during development phase of co-design.

\subsubsection{Keeping medication taking a secret}

Three groups mentioned that the device needs to look discrete. It should be small and not look like a medication packet. Three groups stated that it should make taking the medication discrete. One group recommended doing this by allowing the user to take the medication quickly. One of the participants in group one mentioned that they personally did not feel hiding medication was important. They stated, "why do people want to hide medication? ... I don't care if people know... I would rather not forget it rather then hide it." Table 30 visually shows the information gathered on this topic.

\begin{tabular}{|l|l|l|l|l|l|}
\hline Comment & Group 1 & Group 2 & Group 3 & Group 4 & Total \\
\hline Needs to look discrete, not like a medication package & $\checkmark$ & & $\checkmark$ & $\checkmark$ & 3 \\
\hline Should make taking the medication discrete & $\checkmark$ & $\checkmark$ & & $\checkmark$ & 3 \\
\hline Allow the user to take the medication quickly so others do not see & $\checkmark$ & & & & 1 \\
\hline Hiding fact that taking medication is not important & & & $\checkmark$ & & 1 \\
\hline
\end{tabular}

Table 30 Keeping medication taking a secret comments during development phase of co-design. 


\subsubsection{Smart system}

All four groups wanted devices that were part of a connected system. Three of them wanted to sync the device used to take the pills with a reminder device. One group mentioned connecting their device to the users phone. Another group mentioned that the device should be able to sync with the users calendar to help them plan when they take their medication and how much they should carry. One mentioned having a device that could connect to an online game so as you are taking medication, you are taking care of and adding to a virtual pet. All four groups mentioned that the device had to be smart. This included it knowing when it is full, when the users medication had to be taken, what the users medication regimen is and what their schedule is. Three groups mentioned that the device should have the users location information so that it can automatically correct for a change in time zones.

Two groups mentioned that the device should be able to monitor whether medication was taken or not. Two groups mentioned that it should be able to also track a users health and proactively combat health issues. For example, with diabetics, it could tell them when their insulin is low and tell than that they need to take a dose.

One group mentioned that the system should connect with the healthcare team and potentially the users family if needed. This could be to allow the healthcare team to monitor their health, so someone will know if something happens to the individual or to automatically refill their prescription when needed.

See Table 31 for summary of the comments made on this topic and which groups mentioned them. 


\begin{tabular}{|c|c|c|c|c|c|}
\hline Comment & $\begin{array}{l}\text { Group } \\
1\end{array}$ & $\begin{array}{l}\text { Group } \\
2\end{array}$ & $\begin{array}{l}\text { Group } \\
3\end{array}$ & $\begin{array}{l}\text { Group } \\
4\end{array}$ & Total \\
\hline Should be a connected system & $\checkmark$ & $\checkmark$ & $\checkmark$ & $\checkmark$ & 4 \\
\hline Sink the device you use to take the pills with a reminder device & $\checkmark$ & $\checkmark$ & & $\checkmark$ & 3 \\
\hline Device connected to the user's phone & $\checkmark$ & & & & 1 \\
\hline $\begin{array}{l}\text { Connects to the user's calendar to help plan when to take the pill and how } \\
\text { many pills are needed }\end{array}$ & & $\checkmark$ & & & 1 \\
\hline $\begin{array}{l}\text { Connected to an online game so as users take medication, you take care of } \\
\text { and add to a virtual pet }\end{array}$ & & & & $\checkmark$ & 1 \\
\hline $\begin{array}{l}\text { Has to be smart: know when it is full, when medication should be taken and } \\
\text { what the user's schedule is }\end{array}$ & $\checkmark$ & $\checkmark$ & $\checkmark$ & $\checkmark$ & 4 \\
\hline $\begin{array}{l}\text { Have access to the user's location so it can automatically correct for time } \\
\text { zones }\end{array}$ & $\checkmark$ & $\checkmark$ & & $\checkmark$ & 3 \\
\hline Should be able to monitor whether medication was taken or not & & & $\checkmark$ & $\checkmark$ & 2 \\
\hline Track a users health and proactively combat health issues & & $\checkmark$ & & $\checkmark$ & 2 \\
\hline $\begin{array}{l}\text { Connect to the users healthcare team to allow them to monitor a patient's } \\
\text { health and potentially automatically refill prescriptions }\end{array}$ & & $\checkmark$ & & & 1 \\
\hline Potentially connect to the users family & & $\checkmark$ & & & 1 \\
\hline
\end{tabular}

Table 31 smart system comments during development phase of co-design.

\subsubsection{Stigma}

Groups two, three and four all discussed that the device should remove the stigma of taking medication. Group four recommended doing this by adding cool names, using brand names or using interesting shapes. One of the participants in that group stated that a packet "is easy to produce, functional but boring... make taking pills cool." See Table 32 for a summary of comments made about stigma.

\begin{tabular}{|l|l|l|l|l|l|}
\hline Comment & $\begin{array}{l}\text { Group } \\
1\end{array}$ & $\begin{array}{l}\text { Group } \\
2\end{array}$ & $\begin{array}{l}\text { Group } \\
3\end{array}$ & $\begin{array}{l}\text { Group } \\
4\end{array}$ & Total \\
\hline Should remove the stigma of taking medication & & $\checkmark$ & $\checkmark$ & $\checkmark$ & 3 \\
\hline $\begin{array}{l}\text { Make taking medication cool by adding cool names, interesting shapes or } \\
\text { brand names }\end{array}$ & & & & $\checkmark$ & 1 \\
\hline
\end{tabular}

Table 32 Stigma comment during development phase of co-design. 


\subsubsection{Time of medication}

Groups one, three and four all mentioned that the device should account for the time of day and adjust when medication should be taken. Group four mentioned that a shift in schedule based on a change in time zones could mean that a pill would have to be taken when the user is asleep, or that medication that would have to be taken with food would no longer have to be taken at meal time. One of the participants stated that with a time difference, the user "has to take it at 5:00 in the morning and 9:00 in the morning... that's tough... she is probably not awake at 5:00 in the morning." See Table 33 for a summary of the comments made on this topic.

\begin{tabular}{|l|l|l|l|l|l|}
\hline Comment & $\begin{array}{l}\text { Group } \\
1\end{array}$ & $\begin{array}{l}\text { Group } \\
2\end{array}$ & $\begin{array}{l}\text { Group } \\
3\end{array}$ & $\begin{array}{l}\text { Group } \\
4\end{array}$ & Total \\
\hline $\begin{array}{l}\text { Should account for the time of day and adjust when medication should be } \\
\text { taken }\end{array}$ & $\checkmark$ & & $\checkmark$ & $\checkmark$ & 3 \\
\hline $\begin{array}{l}\text { Shift in schedule based on a change in time zones could affect how they take } \\
\text { their medication, they may be asleep or no longer have it with lunch }\end{array}$ & & & & $\checkmark$ & 1 \\
\hline
\end{tabular}

Table 33 Time of medication comment during development phase of co-design.

\subsubsection{General device needs}

Three groups mentioned that the solution should be unisex. Three groups also mentioned that the solution would need to be mobile. Two stated that it should be easy to use. The same two groups also mentioned that the device would need to be sanitary; including it being easy to clean, antibacterial and antifungal. Groups one and two mentioned that the cost of the device would need to be kept low. Group three mentioned that the solution should be ergonomic. They also mentioned that it should be environmentally friendly by reducing the waste that could come from one-time use packages. Table 34 shows the general device needs mentioned and which groups discussed them. 


\begin{tabular}{|c|c|c|c|c|c|}
\hline Comment & $\begin{array}{l}\text { Group } \\
1\end{array}$ & $\begin{array}{l}\text { Group } \\
2\end{array}$ & $\begin{array}{l}\text { Group } \\
3\end{array}$ & $\begin{array}{l}\text { Group } \\
4\end{array}$ & Total \\
\hline Should be unisex & $\checkmark$ & & $\checkmark$ & $\checkmark$ & 3 \\
\hline Needs to be mobile & $\checkmark$ & $\checkmark$ & & $\checkmark$ & 3 \\
\hline Should be easy to use & $\checkmark$ & & & $\checkmark$ & 2 \\
\hline Needs to be sanitary: easy to maintain/clean and antibacterial/antifungal & $\checkmark$ & & & $\checkmark$ & 2 \\
\hline Cost should be kept low & $\checkmark$ & $\checkmark$ & & & 2 \\
\hline Needs to be ergonomic & & $\checkmark$ & & & 1 \\
\hline $\begin{array}{l}\text { Environmentally friendly, e.g. By reducing waste from one time use } \\
\text { packaging }\end{array}$ & & $\checkmark$ & & & 1 \\
\hline
\end{tabular}

Table 34 General device needs comment during development phase of co-design.

\subsection{Solutions created}

A total of nine solutions were developed and presented by all of the groups. Group one had three solutions; a cup/bottle with a refillable cartridge, a wearable notification device and a combination of the two. When asked to rank their ideas from best to worst, this group ranked the combination of the two solutions higher, followed by the wearable device (see Figure 11 for the exact rankings). Group two developed a pill-dispensing machine. Group three had three solutions, including a necklace, a bracelet and a phone attachment. Group two and three were in the same session so they presented their ideas to each other and included an evaluation of one-another's ideas in the feedback forms.

When asked to rank the solutions presented in the session, groups two and three rated the bracelet and pill dispensing machine higher than the necklace and phone attachment (see Figure 12 for the exact rankings). Finally, group four developed two ideas; a panda companion and a water bottle with integrated pill storage. When asked to rank the solutions, group four preferred the panda companion over the water bottle with integrated storage (see Figure 13 for the exact rankings). Below is a description of what was 
presented by each group in regards to their ideas as well as how those ideas were ranked in the feedback form.

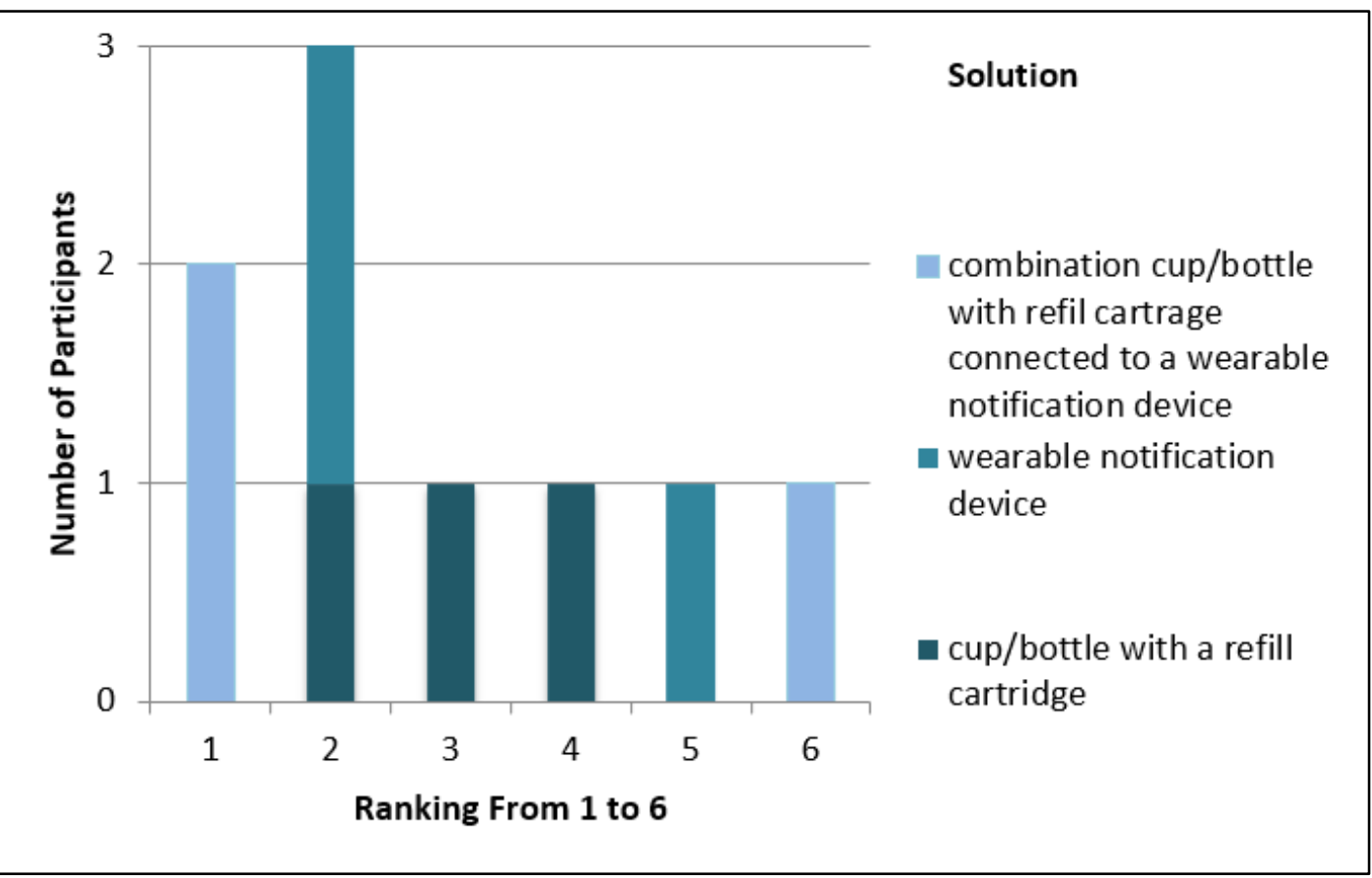

Figure 11 Solution rankings from session one.

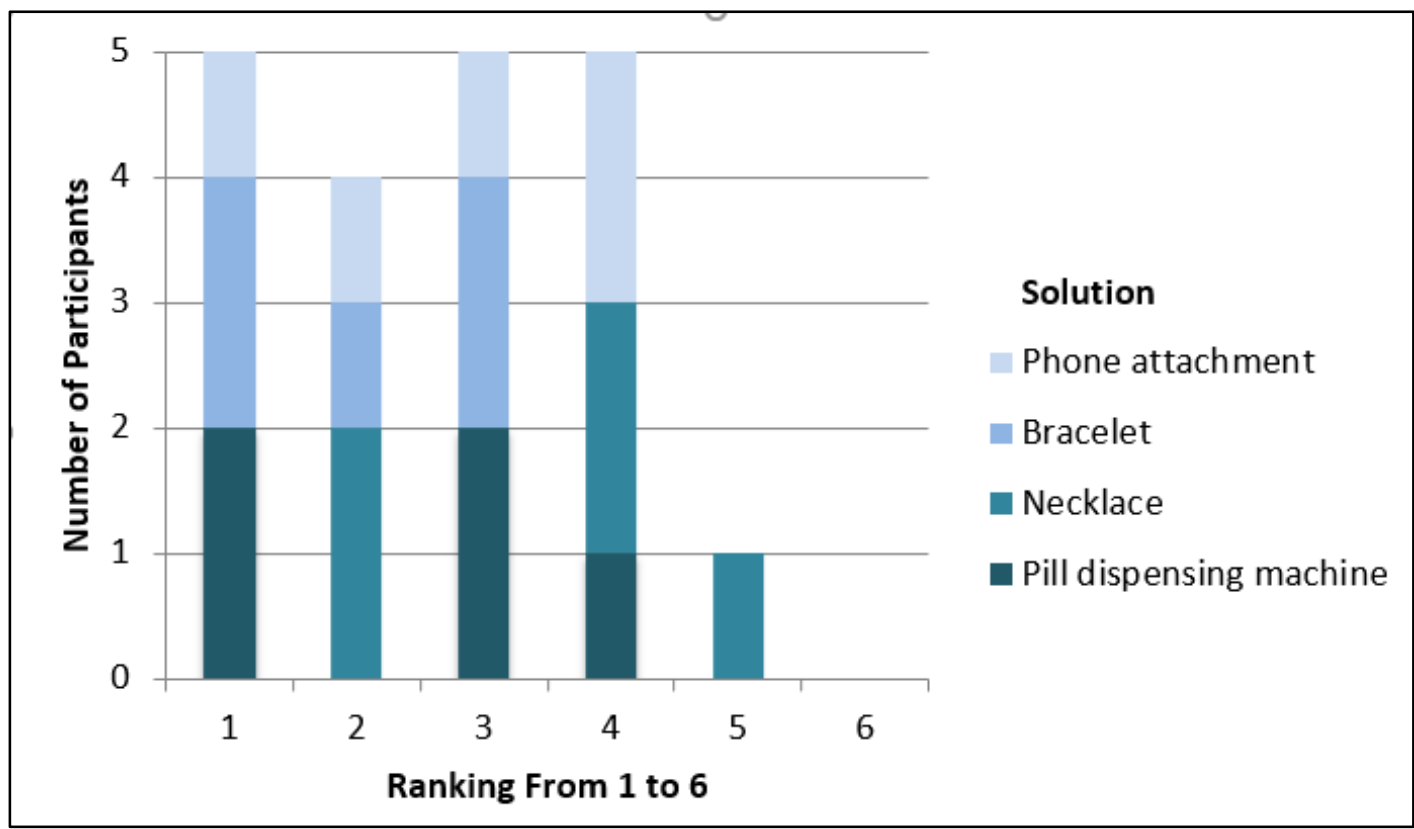

Figure 12 Solution rankings from session two. 


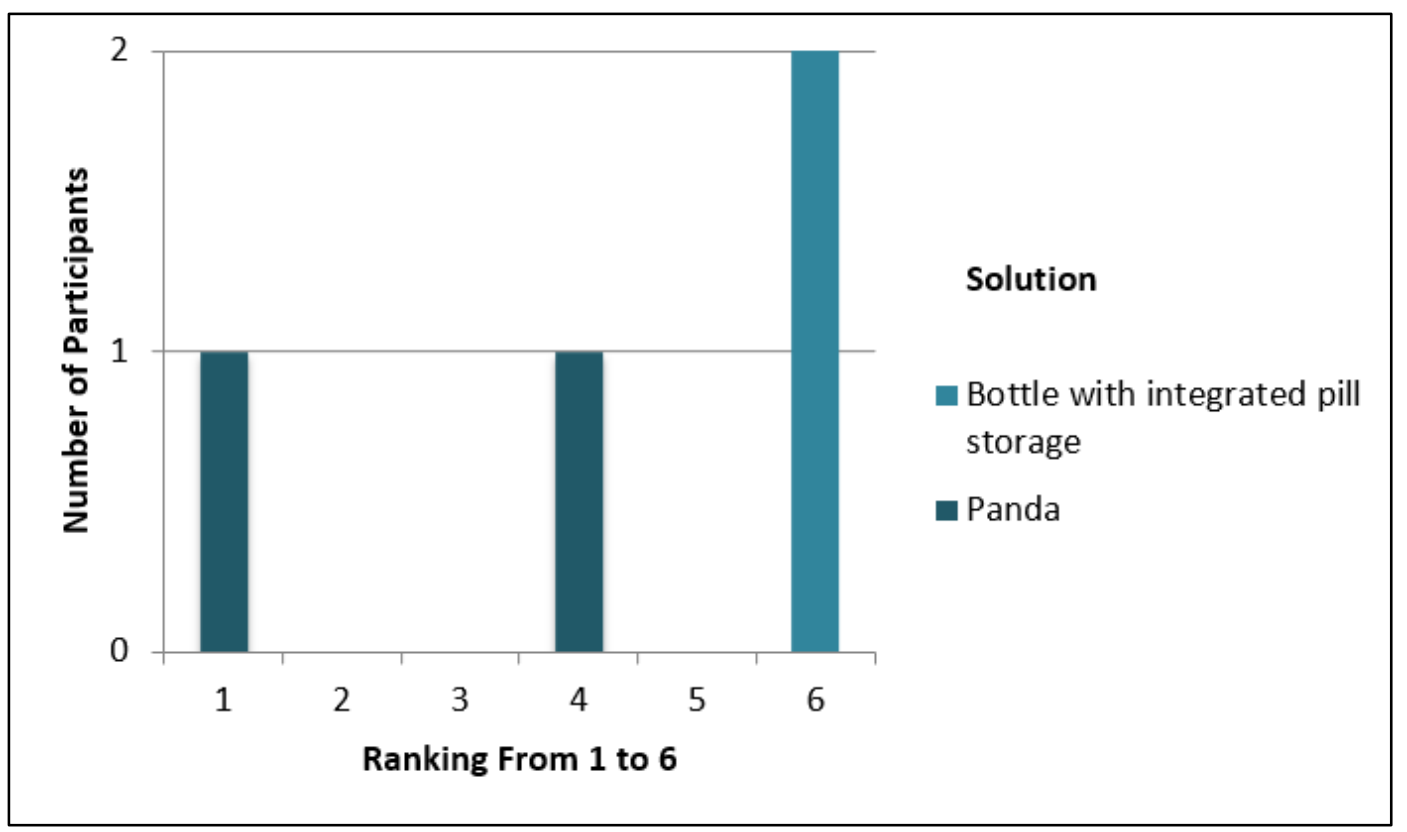

Figure 13 Solution rankings from session three.

\subsubsection{Cup/bottle with a refillable cartridge - Group 1}

For this solution, the group mentioned that users would have an option to choose whether they wanted to use a water bottle or a cup to allow it to be somewhat customizable. Using a water bottle/cup would make taking the medication discrete since it would just look like drinking water, and others would not see a pill bottle. The device would be feasible to carry around yet big enough to accommodate holding different types of medication. It would also provide a visual reminder for users to take their medication. The bottle would use refill cartridges that can be bought at the pharmacy so users would just have to insert a cartridge instead of filling each pill. On the individual feedback forms, participants rated this device as a four in terms of its of its effectiveness and impact on adherence, whereas they all had different opinions on its feasibility. Figure 14 shows the rankings given to this solution in the feedback form and Figure 15 shows the model of the device. 


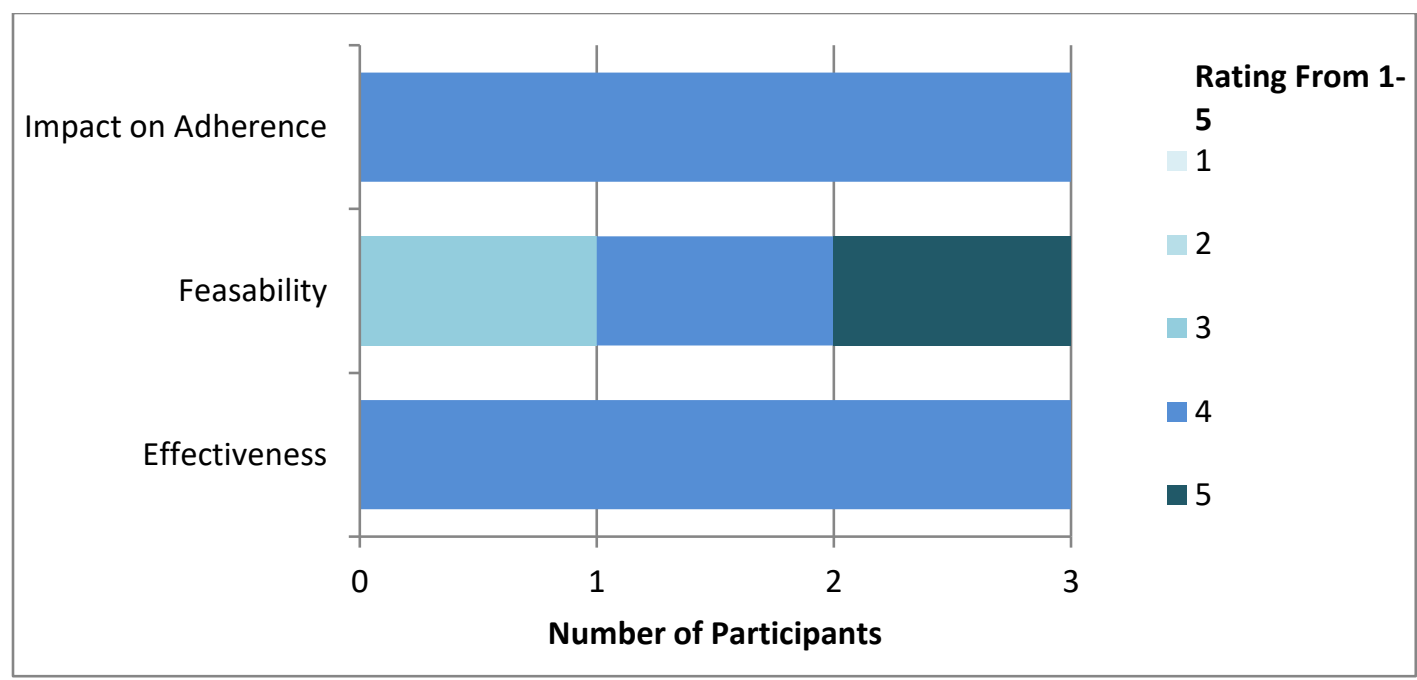

Figure 14 Solution ratings for the cup/bottle with a refillable cartridge from session one.

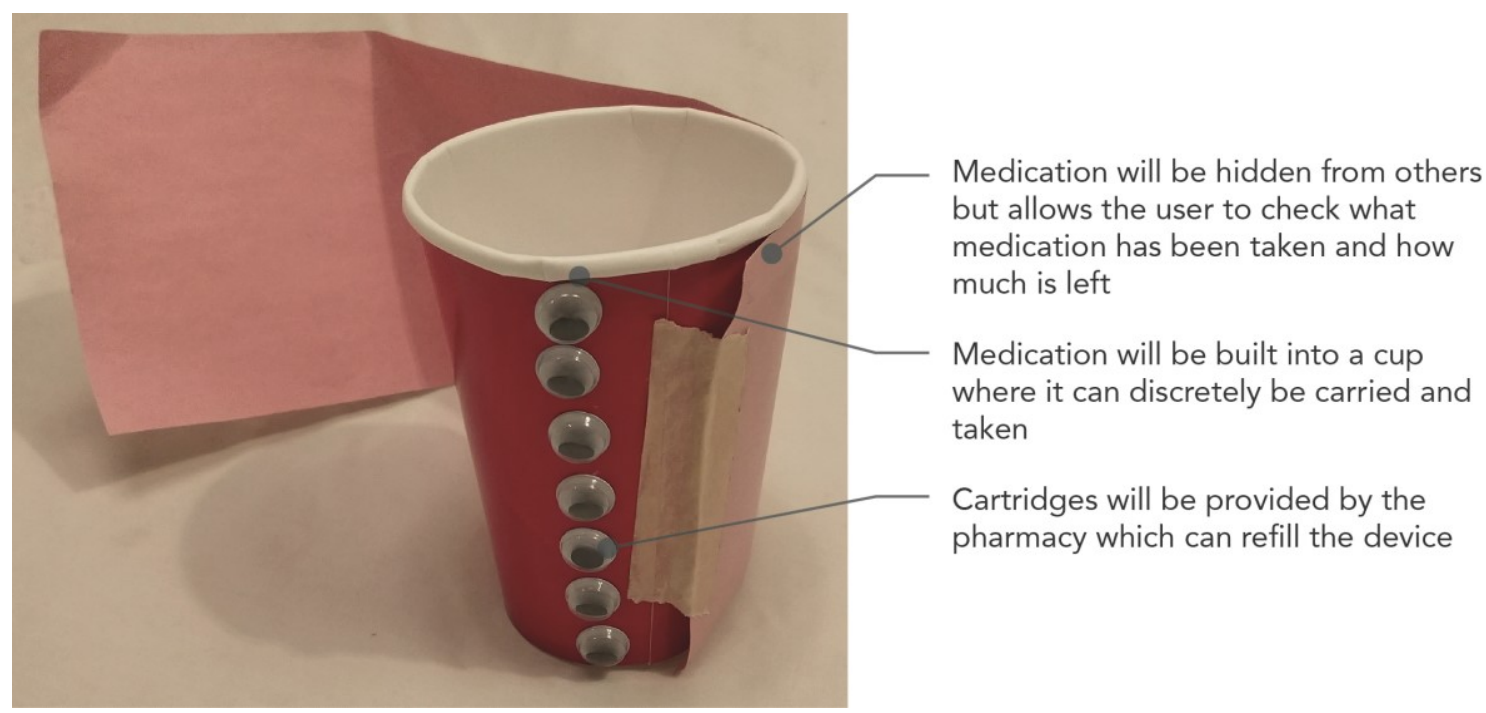

Figure 15 The model created by group one for the cup/bottle with a refillable cartridge.

\subsubsection{A wearable notification device - Group 1}

Group one also developed a notification device. This is a device that the user can customize and add to anything they wear or carry normally. This device could connect to a users smartphone or watch if they wanted it to or it could work as a stand-alone device.

On the individual feedback forms, this device was rated highly on all three rating scales, 
which were effectiveness, feasibility and impact on adherence. Feedback form ratings for this solution can be found in Figure 16. No model was created for this solution.

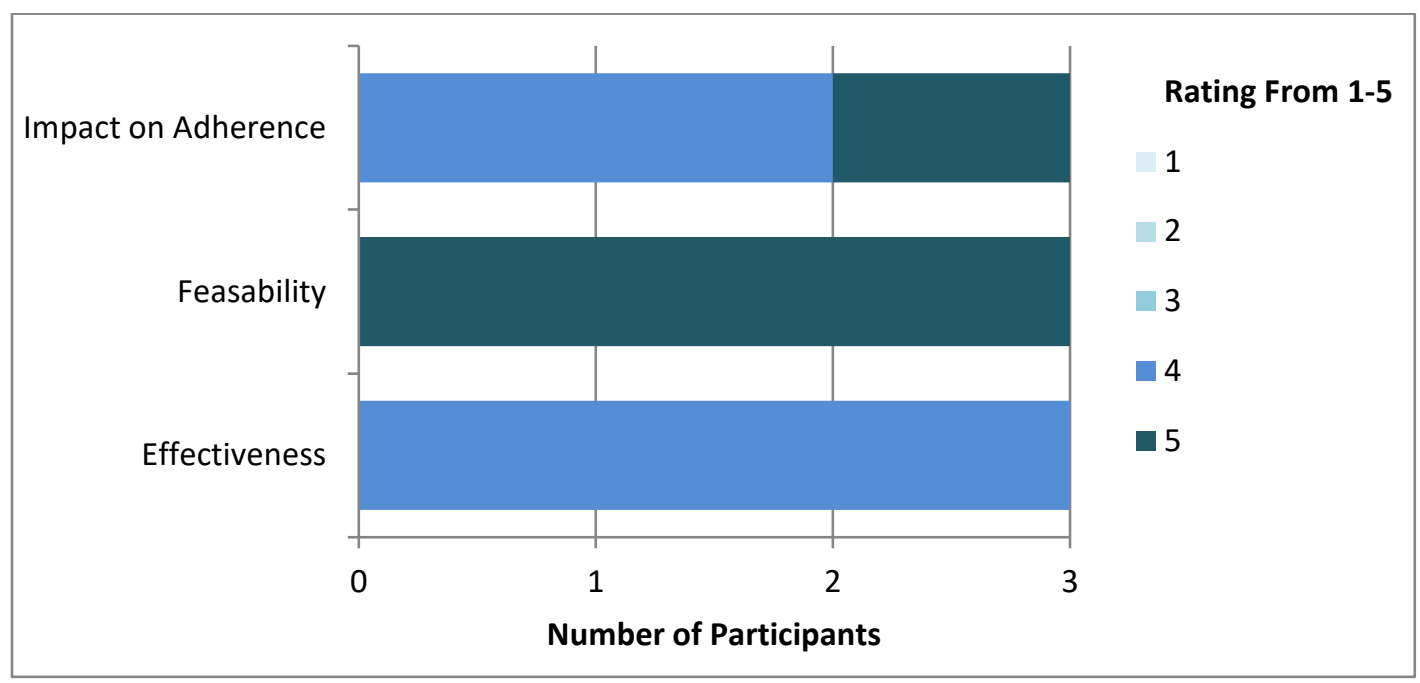

Figure 16 Solution ratings for the wearable notification device from session one.

\subsubsection{Cup/bottle with refillable cartridge connected to wearable device - Group 1}

For this solution, the group combined their to other ideas, so users would have a reminder device as well as a tool to carry and take their medication discreetly. They believed that the combination of the two devices would solve all the users problems, but they should each be able to be used individually as well. On the individual feedback forms, participants rated the device highly in terms of feasibility, effectiveness and impact on adherence. Each scale received two ratings of five and one four. Figure 17 shows group one's rankings of this solution in the feedback form. 


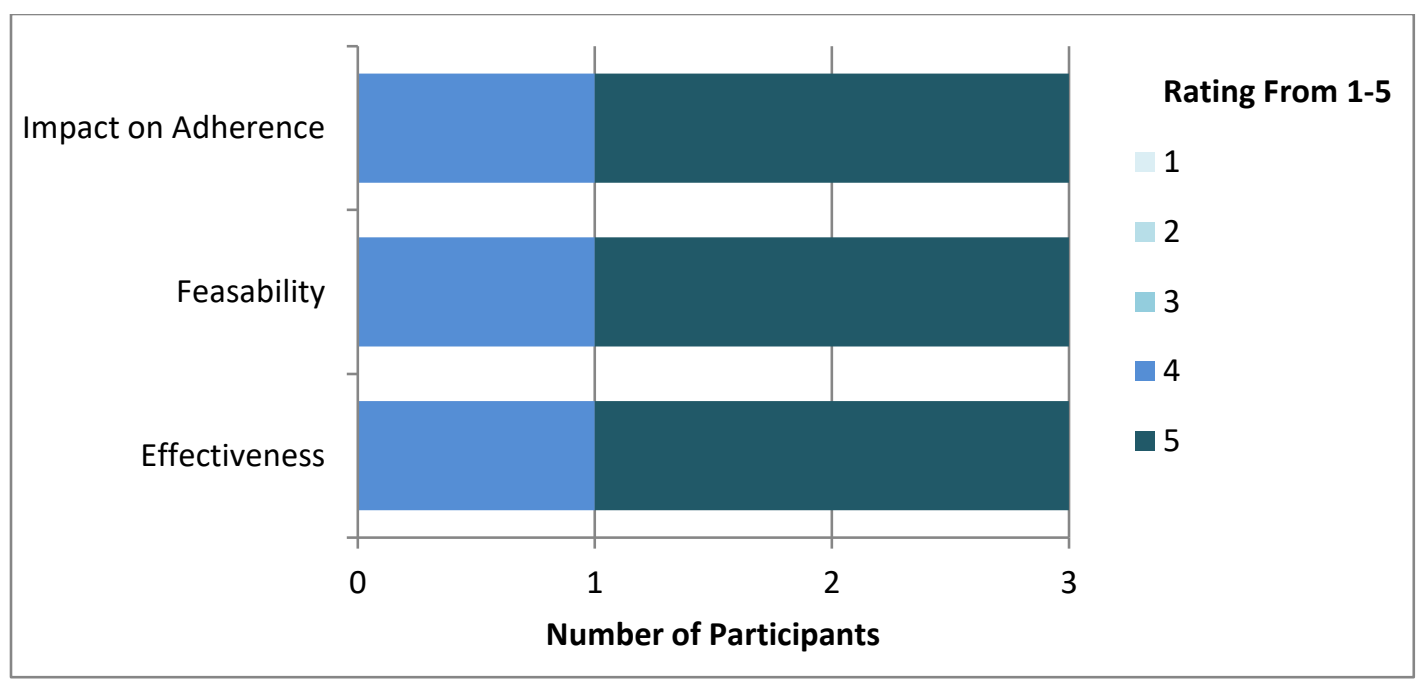

Figure 17 Solution ratings for the combination of the cup/water bottle with a refillable cartridge and the wearable notification device from session one.

\subsection{Pill dispensing machine - Group 2}

Group two developed a machine that would dispense pills for the user. It consisted of an intelligent unit users could keep at home that would automatically create and dispense packets that the user can take with then when they go out. The device would connect to the user's calendar to know how long they would be gone. This way it would know if they were going on a vacation and needed a lot of pills or if they were going away for the day. It would also be able to use other devices, such as the user's smart watch, to monitor their overall health and behavioral patterns. With this information it could recommend times for them to take their medication, which are the least busy in their day. It would also know where the user is to automatically adjust for time zones. It could also proactively monitor their health and let them know if they needed to take their medication. The example for this was that for diabetics, the device could detect if their insulin levels were high and recommend that they take a dose. This monitoring could also notify their healthcare team and/or family if needed, though this would be an optional 
setting for the user. The device would accommodate different forms of medication by dispensing blister packs for individuals taking pills, and syringes for individuals who needed it. The device could also connect to a wearable device, such as a smart watch to notify the user when it is time to take their medication. They also specified that this notification would be tactile to keep it discrete. It would also connect to the healthcare team and pharmacy to auto refill prescriptions when the user runs out. The refill packages would be cartridges made specifically for the machine that would be given to the user by the pharmacist. The cartridges used and packets dispensed by the machine would all be reusable to be more environmentally friendly. When rating this solution on the feedback form, four of the five participants rated it positively on all three scales, whereas one rated it as neutral on all three factors. Figure 18 shows the ratings given to this device in the feedback forms from groups two and three. An image of this solutions model can be found in Image 19.

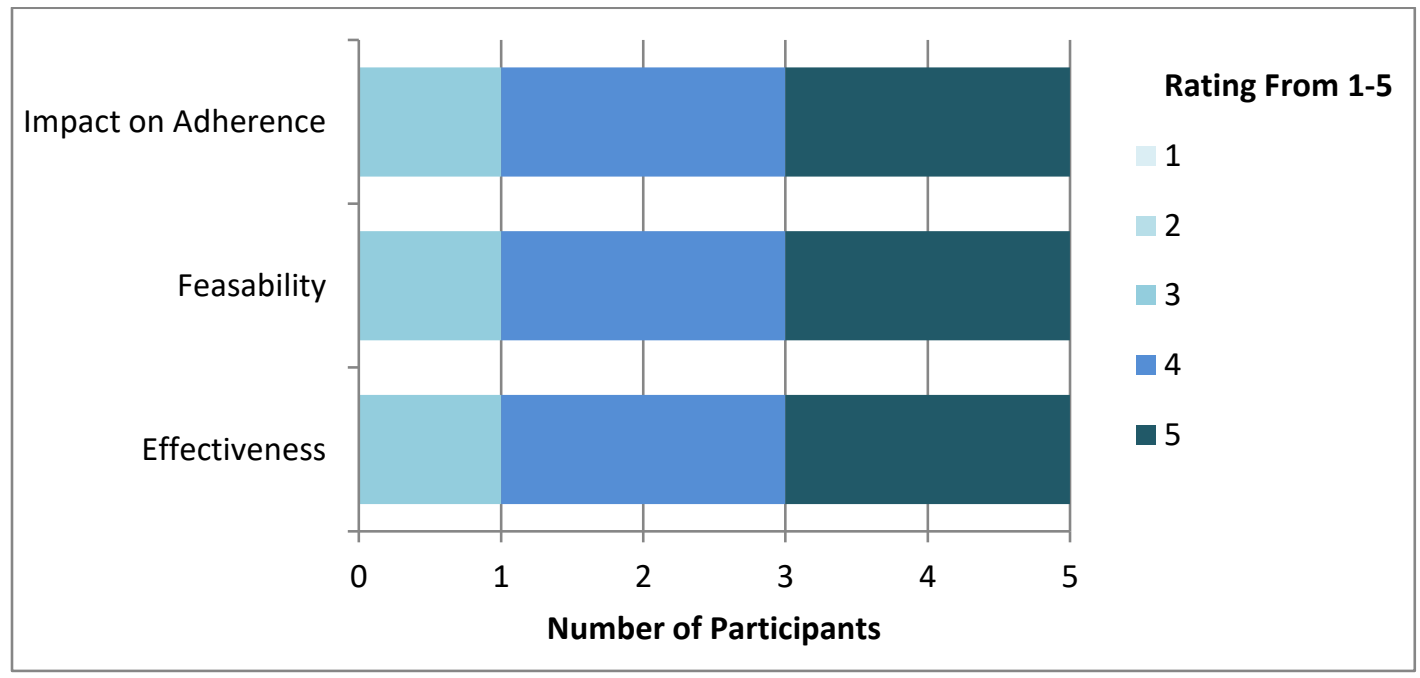

Figure 18 Solution ratings for the pill-dispensing machine from session two. 


\section{Add-onside}

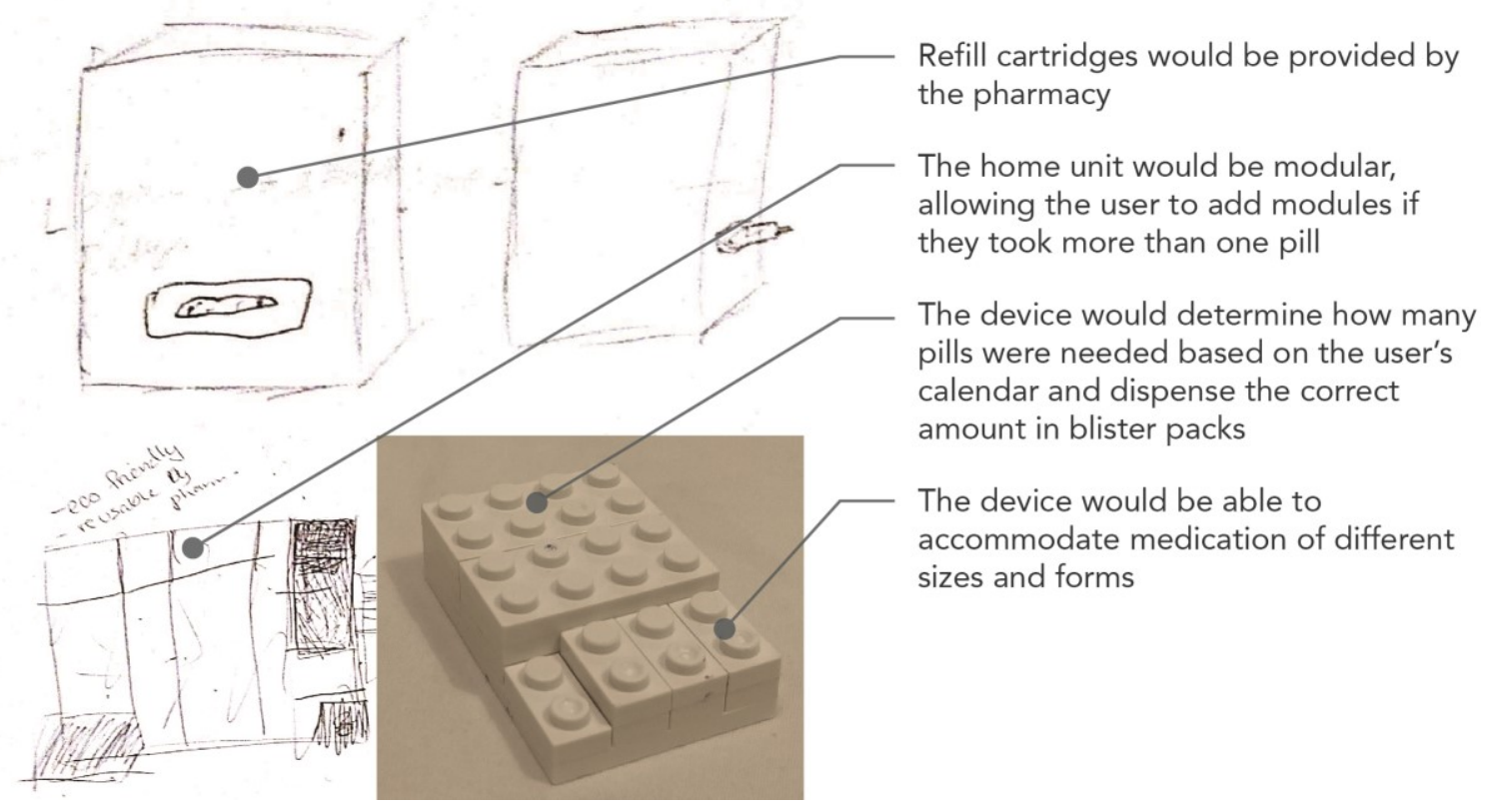

Figure 19 Model and sketches of the pill dispensing machine created by group two.

\subsubsection{Necklace - Group 3}

This solution was a necklace that the user could wear. It would contain seven doses of medication so it only had to be refilled once a week if the user only has one type of medication. It would be a smart device which could detect whether it was full or not, and based on that determine if the user had taken that dose of medication. This would be a discreet way of storing the medication and could provide a discrete notification to the user first visually by glowing, then by vibrating. On the individual feedback form, all participants rated this solution highly in terms of feasibility. in terms of its impact on adherence, four participants rated it highly while one was neutral. In terms of its effectiveness at meeting the needs of the target demographic, only two participants rated it highly, while two were neutral and one gave it a negative rating. Figure 20 shows 
ratings for this solution from groups two and three. Figure 21 shows the model created for this solution.

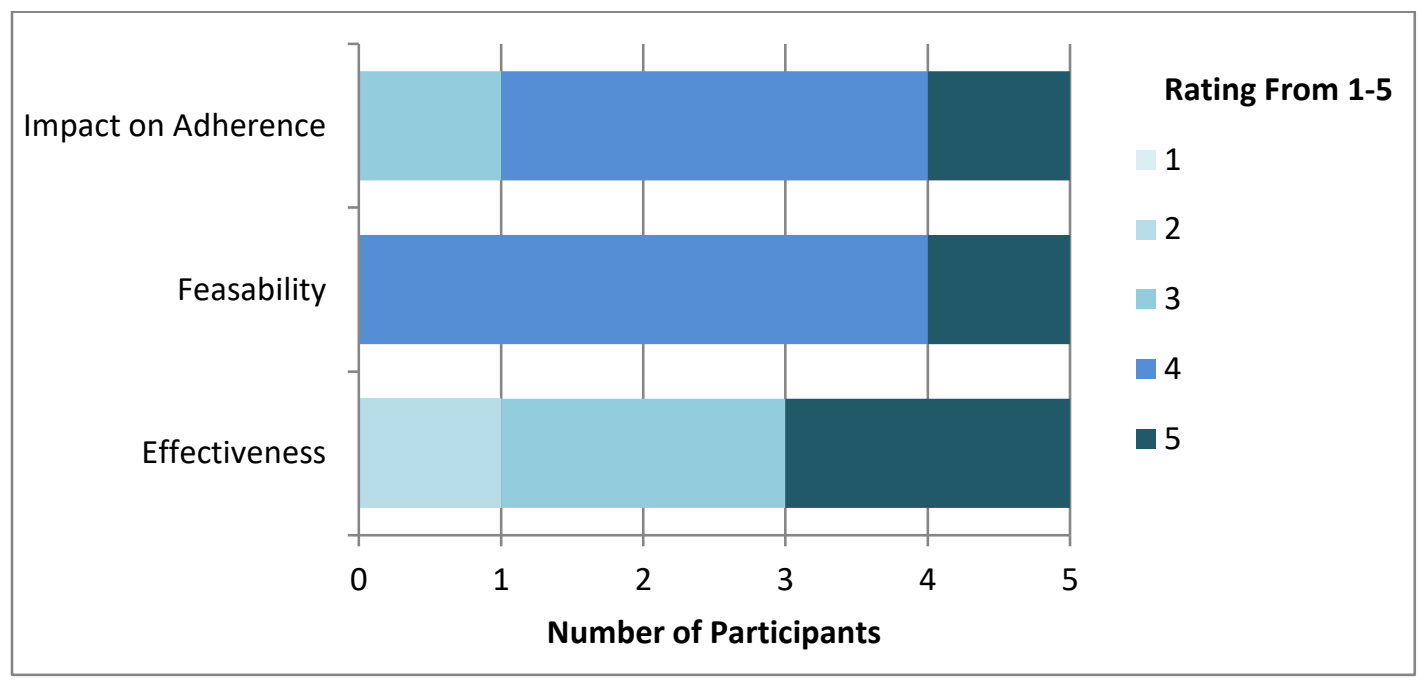

Figure 20 Solution ratings for the necklace from session two.

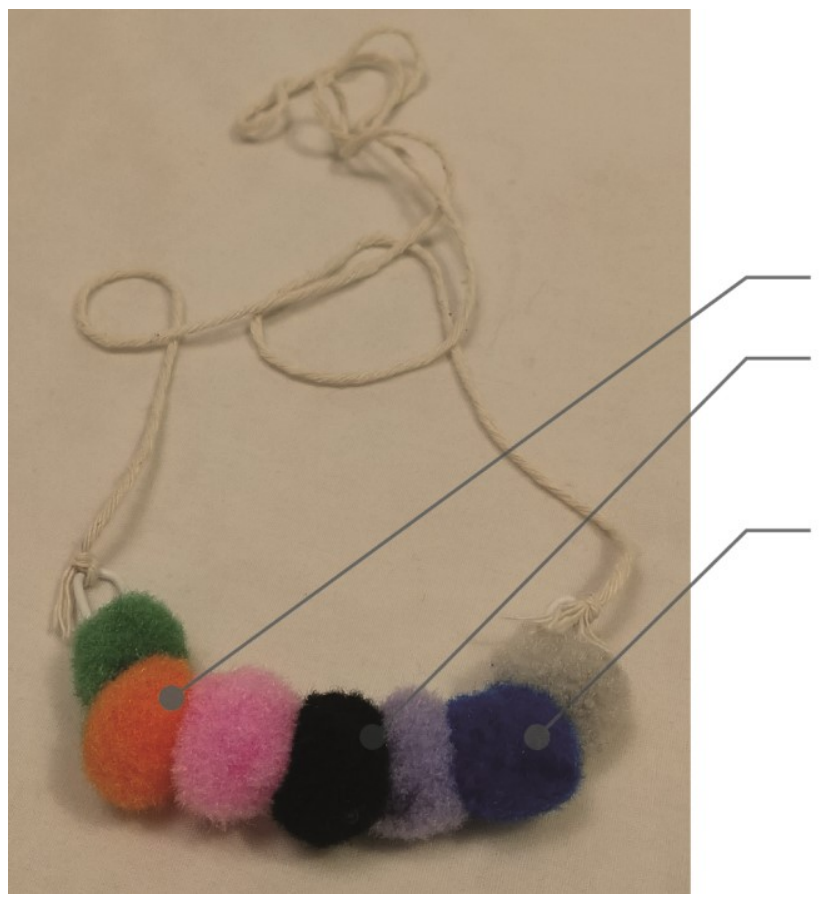

Discretely stores medication

Each bead stores a dose of medication and there is there is room for seven doses

Provides a visual notification by glowing, followed by a vibration if the user does not take the medication

Figure 21 Model created of the necklace solution by group three. 


\subsubsection{Bracelet - Group 3}

This solution is the same as the necklace above, just in a different form. It is a wearable bracelet that would carry multiple days of medication, notify the user and detect whether or not the medication has been taken. In the individual feedback form, this solution was rated highly by all participants in terms of its impact on adherence. In terms of its effectiveness and feasibility, four participants rated it highly while one was neutral.

Ratings given to this device by groups two and three can be found in Figure 22. An image of the model created for this device can be found in Figure 23.

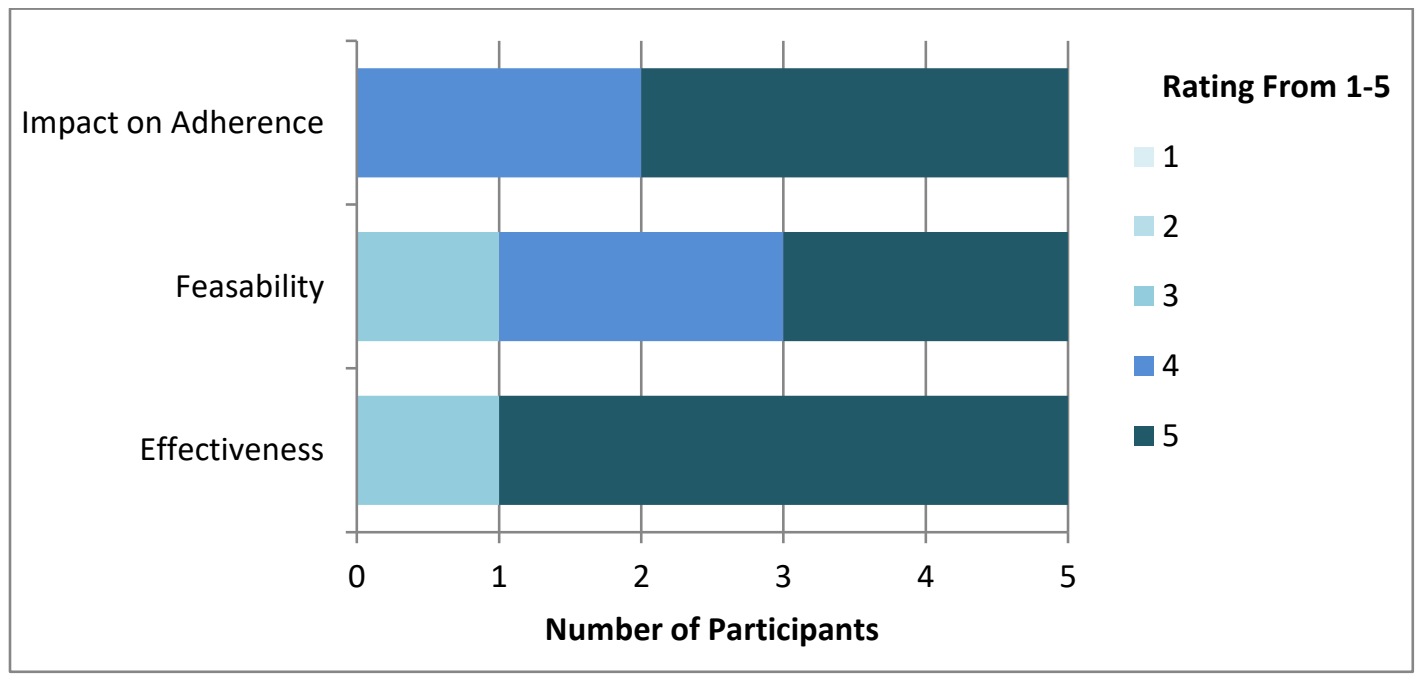

Figure 22 Solution ratings for the bracelet from session two.

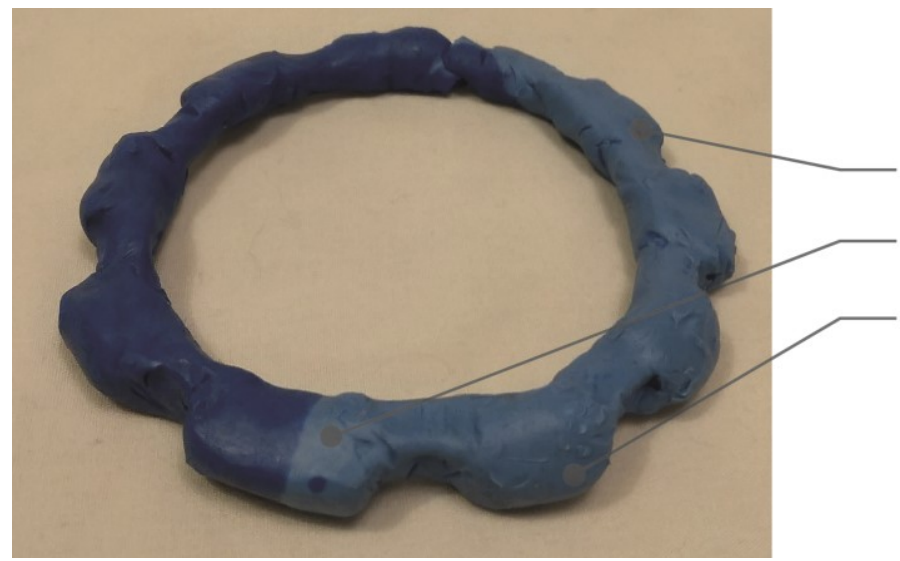

Discretely stores medication

Each bead stores a dose of medication

Provides a visual notification by glowing, followed by a vibration if the user does not take the medication

Figure 23 Model of the bracelet solution created by group three. 


\subsubsection{Phone attachment - Group 3}

Group three came up with a third solution that was similar to the previous two but had a few distinct differences. This device would attach to the back of a users phone and liked similar to attachments that are currently used. This device is linked to a users phone that they believed would be useful since it is a device people already always carry with them. It would still notify the users but this time through an application on their mobile device or by emojis on the device. It would use happy and sad faces to indicate on the device when the user should take their medication. The device would store less medication than the other solutions due to its size but it could still detect when medication had been taken. In the individual feedback form, four participants rated this device highly on all three scales, whereas one was neutral in terms of impact on adherence as well as feasibility and rated it negatively in terms of effectiveness. See Figure 24 for this solutions ratings by groups two and three in the feedback form. Figure 25 shows the model created for this solution.

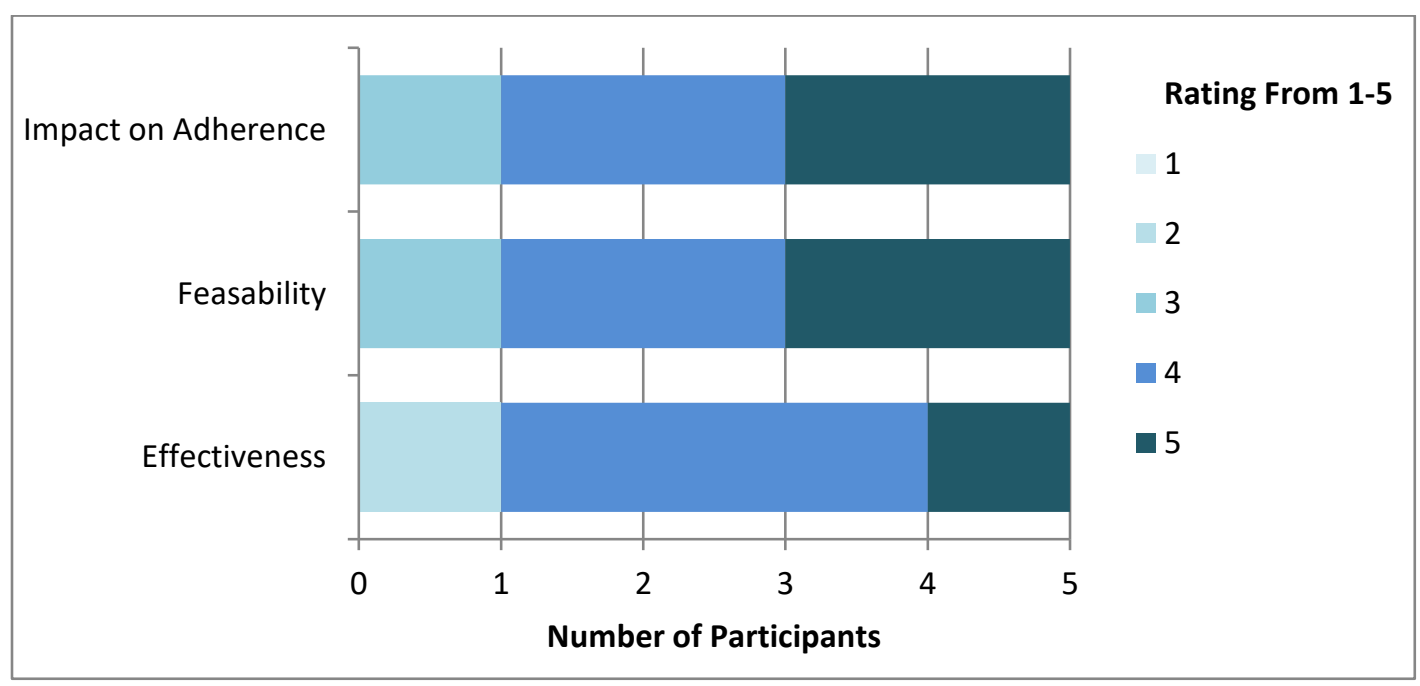

Figure 24 Solution ratings for the phone attachment from session two. 


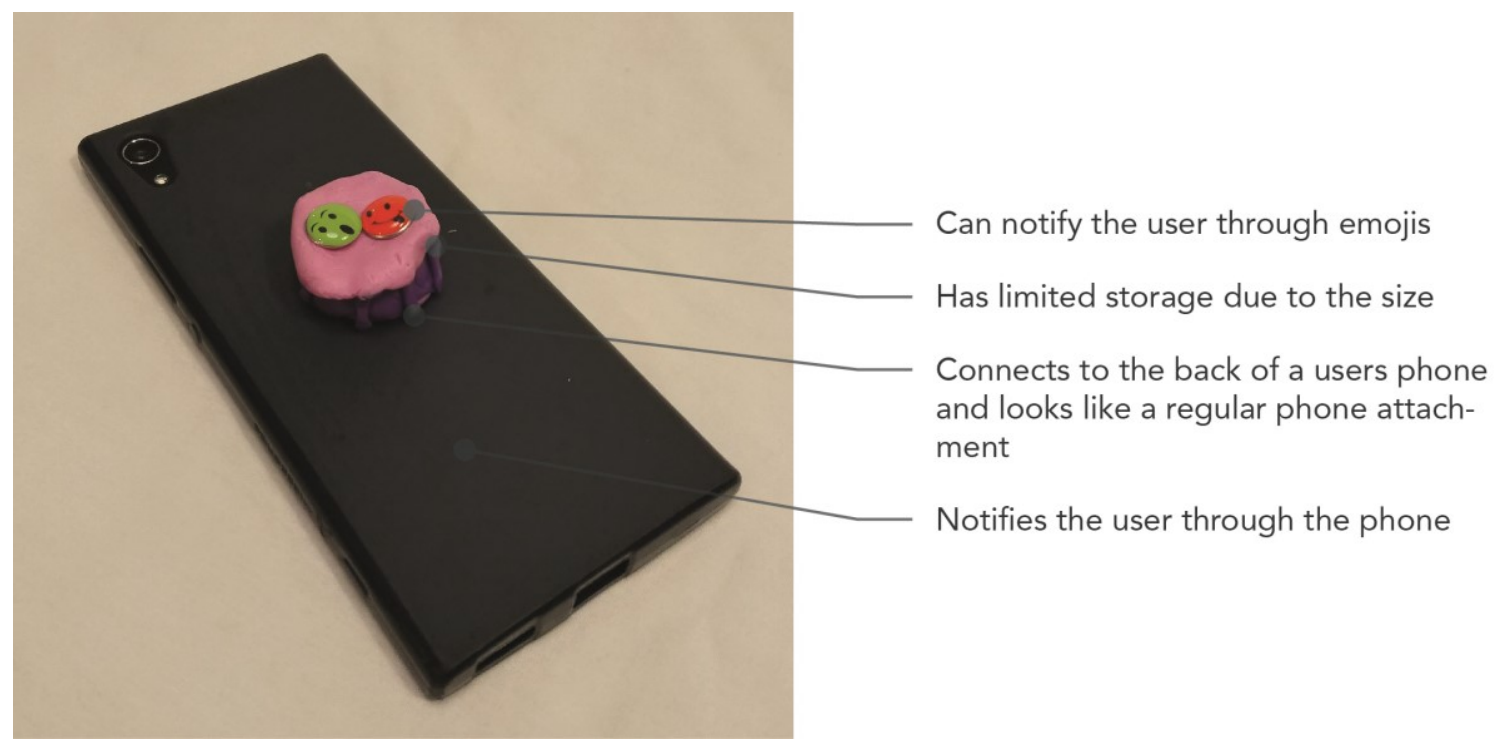

Figure 25 Model created by group three of the phone attachment.

\subsubsection{Panda companion - Group 4}

Group four developed a companion robotic pet that the user could carry around with them. It would be a small, fluffy companion that would connect to the Internet. It could be used as a physical reminder for the user to take their medication as well as notify them when the medication would have to be taken. The pet would notify the user by dancing, jostling them, vibrating or by a soothing alarm. If the user does not take their medication, the panda would change colours and start to look sick. The user could store medication in the panda, and it would have expandable storage if the user was going to go on a trip. This would be done through accessories to the panda, like a backpack. The panda would hand the user the pill and would visually be able to show the user what pills they have taken and how many are left. It would potentially break the stigma around taking medication by making it fun/cool. It would also be able to adjust for time zones if the user were to go on a trip. In the individual feedback form, both participants from session three rated this device highly in terms of impact on adherence and feasibility. On 
effectiveness, one rated it highly while the other was neutral. Figure 26 shows the ratings for this device in the feedback forms and Figure 27 shows the model created.

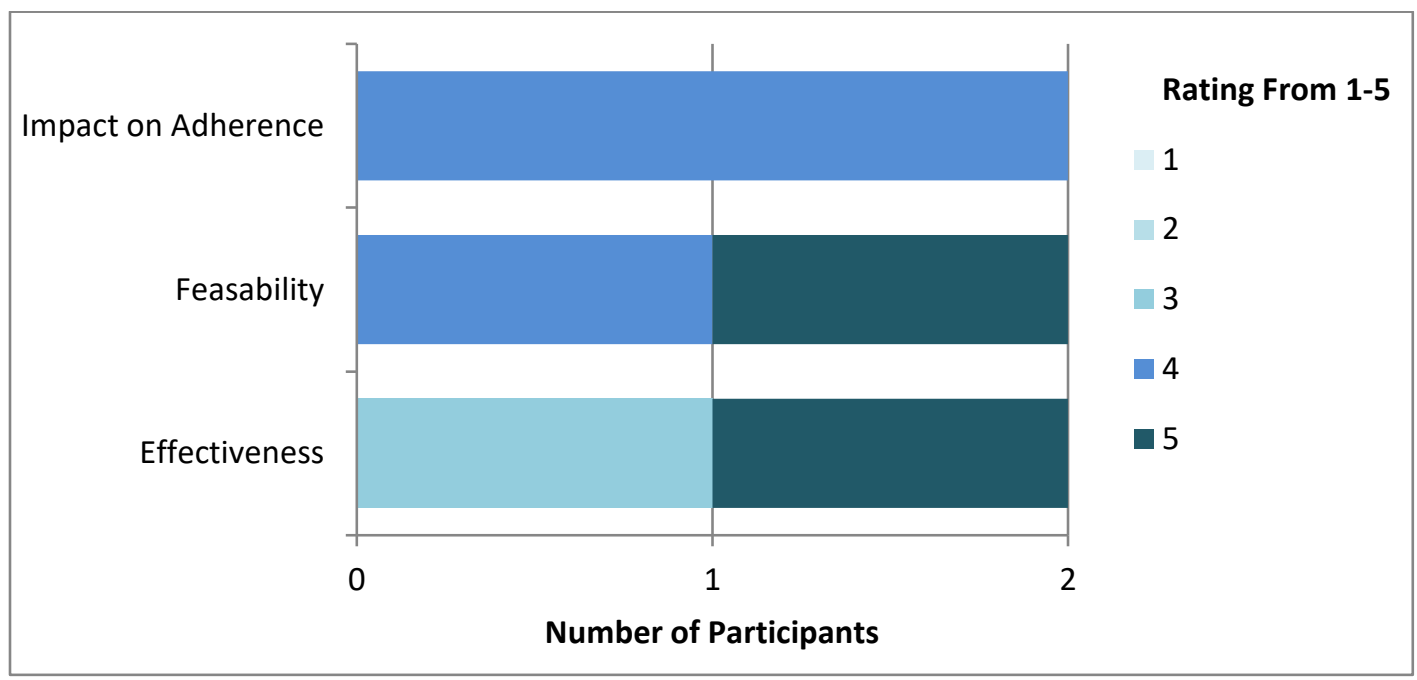

Figure 26 Solution ratings for the panda from session three.

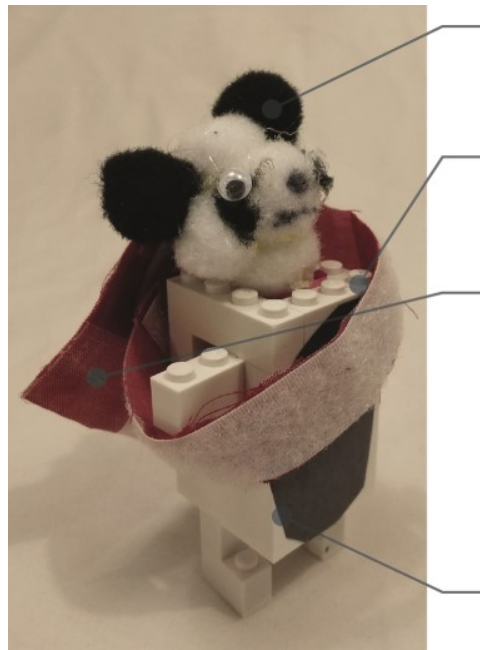

The device would be a cute panda pet that could break stigma around taking medication

As a notification, it could dance, jostle the user, vibrate or have a soothing alarm

It could have accessories for expanded storage

Medication would be stored inside and it would hand it to the user

It would visually display the medication taken and left

The panda would look sick if the user does not take their medication

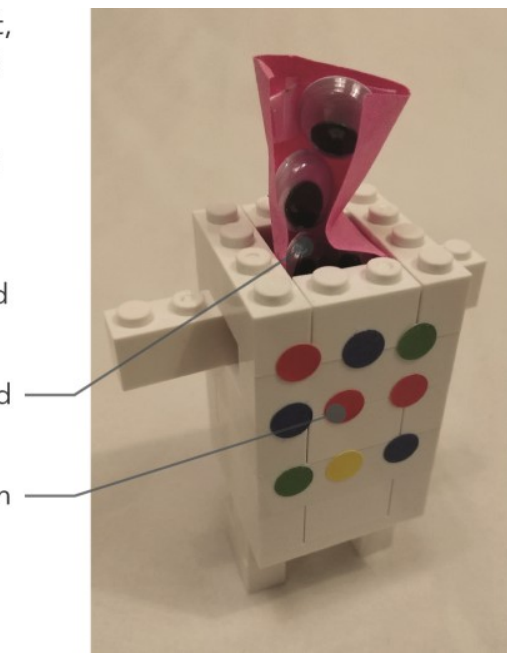

Figure 27 Model of the panda solution created by group four.

\subsubsection{Water bottle with integrated pill storage - Group 4}

This solution involved a bottle cap with a standardized neck so it could fit into multiple bottles. This would allow the bottle to be customizable, the cap would store pills and would be connected to the Internet. It would be able to tell you when you had to refill the 
cap and would change colour if you do not take the pill. It would also only unlock one pill at a time so users could not accidentally take multiple. On the individual rating forms, both participants rated this solution highly on all three scales. Feedback form ratings for this device can be found in Figure 28 and an image of the model is in Figure 29.

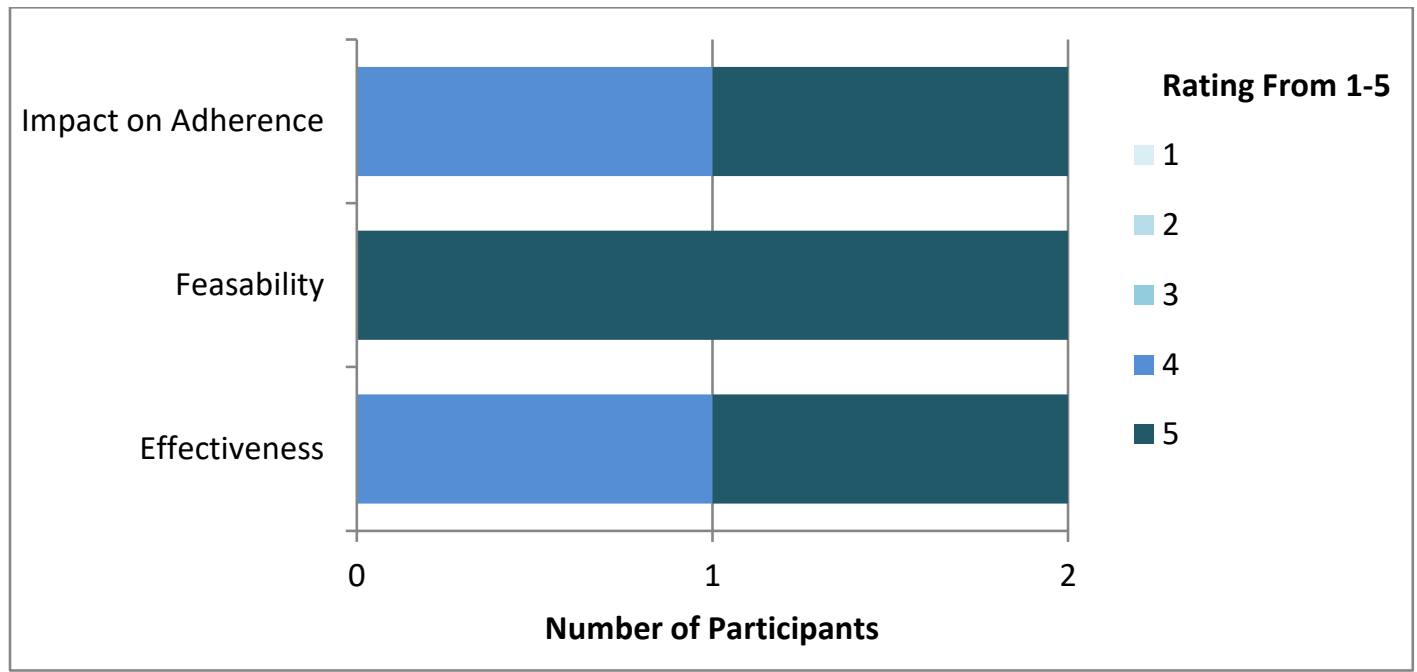

Figure 28 Solution ratings for the bottle with integrated pill storage from session three.

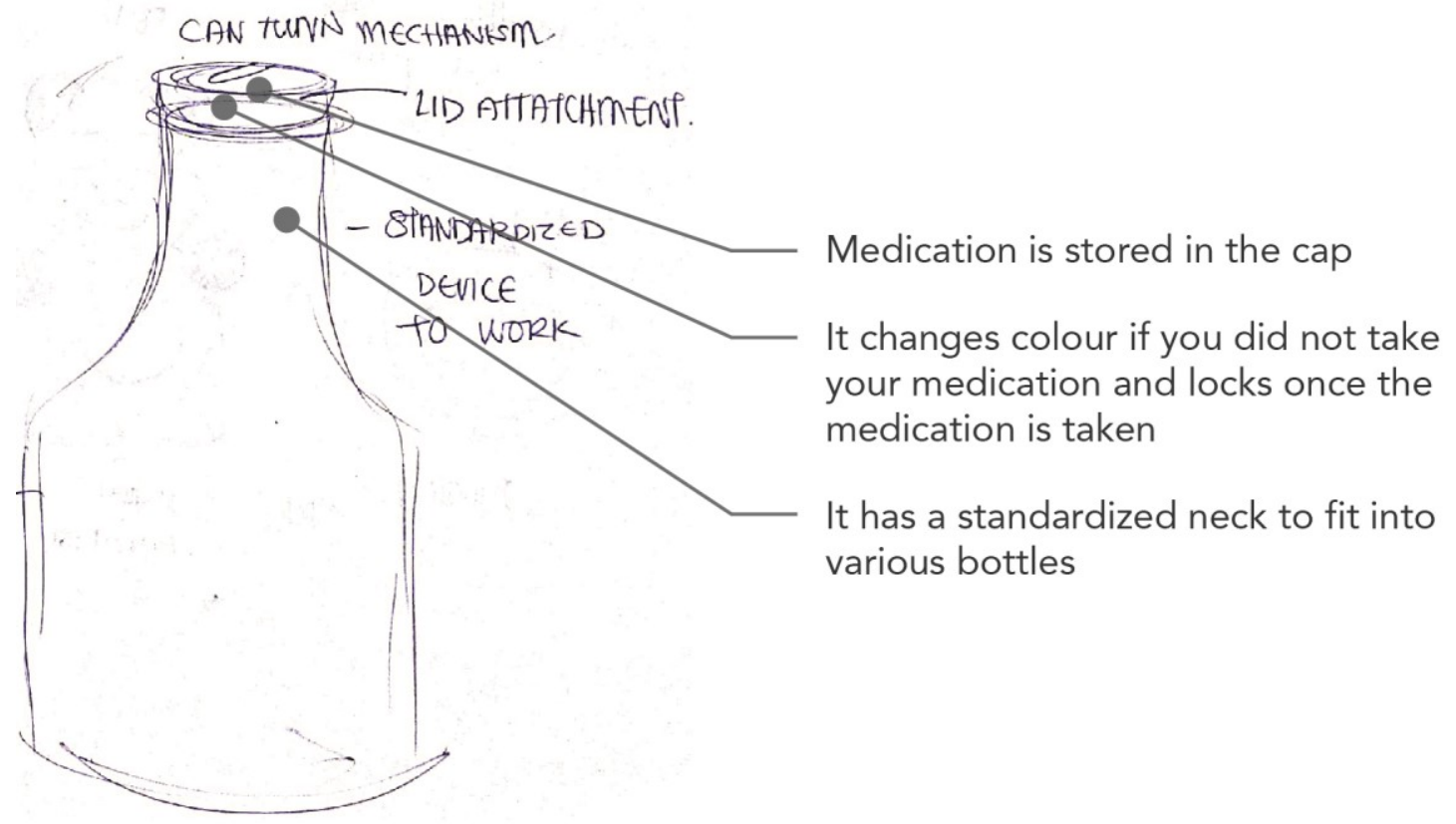

Figure 29 Group four's sketch of the water bottle with integrated pill storage. 


\subsection{Presentation comments comparison}

Below is a comparison of the key points brought up during the presentation section of the co-design session.

\subsubsection{Accommodate different medications}

During the presentation, two groups highlighted that their devices would have to accommodate different types of medication, either in different sizes or forms. See Table 35 for a chart of this data.

\begin{tabular}{|l|l|l|l|l|l|l|l|l|}
\hline \multirow{2}{*}{ Key features } & \multicolumn{2}{|l|}{ Group 1 } & Group 2 & \multicolumn{2}{l|}{ Group 3 } & \multicolumn{2}{l|}{ Group 4 } \\
\cline { 2 - 7 } & $\begin{array}{l}\text { Cup/bottle } \\
\text { with refill } \\
\text { cartridge }\end{array}$ & $\begin{array}{l}\text { Wearable } \\
\text { reminder } \\
\text { device }\end{array}$ & $\begin{array}{l}\text { Bottle with refill } \\
\text { cartridge connected } \\
\text { to wearable device }\end{array}$ & $\begin{array}{l}\text { Pill } \\
\text { dispensing } \\
\text { machine }\end{array}$ & Necklace & Bracelet & $\begin{array}{l}\text { Phone } \\
\text { attachment }\end{array}$ & $\begin{array}{l}\text { Panda } \\
\text { Bottle with } \\
\text { pills } \\
\text { integrated }\end{array}$ \\
\hline $\begin{array}{l}\text { Can accommodate } \\
\text { different types of } \\
\text { medication }\end{array}$ & $\checkmark$ & $\checkmark$ & $\checkmark$ & & & \\
\hline
\end{tabular}

Table 35 Accommodating different medications comments during co-design sessions.

\subsubsection{Carrying the medication}

All four groups commented that the device would have to hold multiple days worth of medication. Groups two and four also mentioned an expandable storage, whereas group three had decided on seven pill slots so that it would only be refilled once a week. Table 36 shows the data collected on this topic.

\begin{tabular}{|c|c|c|c|c|c|c|c|c|c|}
\hline \multirow[t]{2}{*}{ Key features } & \multicolumn{3}{|l|}{ Group 1} & \multirow{2}{*}{$\begin{array}{l}\text { Group } 2 \\
\text { Pill } \\
\text { dispensing } \\
\text { machine }\end{array}$} & \multicolumn{3}{|l|}{ Group 3} & \multicolumn{2}{|c|}{ Group 4} \\
\hline & $\begin{array}{l}\text { Cup/bottle } \\
\text { with refill } \\
\text { cartridge }\end{array}$ & $\begin{array}{l}\text { Wearable } \\
\text { reminder } \\
\text { device }\end{array}$ & $\begin{array}{l}\text { Bottle with refill } \\
\text { cartridge connected } \\
\text { to wearable device }\end{array}$ & & Necklace & Bracelet & $\begin{array}{l}\text { Phone } \\
\text { attachment }\end{array}$ & Panda & $\begin{array}{l}\text { Bottle with } \\
\text { pills } \\
\text { integrated }\end{array}$ \\
\hline $\begin{array}{l}\text { Holds multiple } \\
\text { days of pills }\end{array}$ & $\checkmark$ & & & $\checkmark$ & $\checkmark$ & $\checkmark$ & & & $\checkmark$ \\
\hline $\begin{array}{l}\text { Expandable } \\
\text { storage }\end{array}$ & & & & $\checkmark$ & & & & $\checkmark$ & \\
\hline $\begin{array}{l}\text { Only refilled once a } \\
\text { week ( } 7 \\
\text { medication slots) }\end{array}$ & & & & & $\checkmark$ & $\checkmark$ & & & \\
\hline
\end{tabular}

Table 36 Carrying the medication comments during co-design sessions. 


\subsubsection{Customizable/personalizable}

Group one mentioned that the device should be able to be customized to what the individual carries with them daily. Group two mentioned that individuals should be able to customize it to their medication regimen. Group four mentioned that it should be able to be personalized to the user; e.g. through decoration. See Table 37 for a summary of which presented solutions included these comments.

\begin{tabular}{|l|l|l|l|l|l|l|l|l|l|}
\hline \multirow{2}{*}{ Key features } & \multicolumn{2}{|l|}{ Group 1 } & Group 2 & \multicolumn{2}{l|}{ Group 3 } & \multicolumn{2}{l|}{ Group 4 } \\
\cline { 2 - 8 } & $\begin{array}{l}\text { Cup/bottle } \\
\text { with refill } \\
\text { cartridge }\end{array}$ & $\begin{array}{l}\text { Wearable } \\
\text { reminder } \\
\text { device }\end{array}$ & $\begin{array}{l}\text { Bottle with refill } \\
\text { cartridge } \\
\text { connected to } \\
\text { wearable device }\end{array}$ & $\begin{array}{l}\text { Pill } \\
\text { dispensing } \\
\text { machine }\end{array}$ & Necklace & Bracelet & $\begin{array}{l}\text { Phone } \\
\text { attachment }\end{array}$ & Panda & $\begin{array}{l}\text { Bottle with } \\
\text { pills } \\
\text { integrated }\end{array}$ \\
\hline $\begin{array}{l}\text { Should be customized } \\
\text { based on what an } \\
\text { individual carries or has } \\
\text { regularly }\end{array}$ & $\checkmark$ & $\checkmark$ & $\checkmark$ & & & & & & \\
\hline $\begin{array}{l}\text { Customizable for } \\
\text { medication regimen }\end{array}$ & & & & & $\checkmark$ & & & & \\
\hline $\begin{array}{l}\text { Should be } \\
\text { personalizable; e.g. } \\
\text { Decorated }\end{array}$ & & & & & & & & & $\checkmark$ \\
\hline
\end{tabular}

Table 37 Customizable/personalizable comments during co-design sessions.

\subsubsection{Device used}

Groups one and three came up with devices that were wearable. Groups one, three and four all had at least one solution that would attach to a device users already own or carry around with them. Groups one and three both presented solutions that integrated the medication storage into a water bottle or cup, where they could discreetly take the medication as well. This concept of a bottle/cup with medication was also mentioned by group two during their initial discussion, but was not presented. See Table 38 for a breakdown of which solutions included comments about the type of device that could be used. 


\begin{tabular}{|c|c|c|c|c|c|c|c|c|c|}
\hline \multirow[t]{2}{*}{ Key features } & \multicolumn{3}{|l|}{ Group 1} & \multirow{2}{*}{$\begin{array}{l}\text { Group } 2 \\
\begin{array}{l}\text { Pill } \\
\text { dispensing } \\
\text { machine }\end{array}\end{array}$} & \multicolumn{3}{|l|}{ Group 3} & \multicolumn{2}{|c|}{ Group 4} \\
\hline & $\begin{array}{l}\text { Cup/bottle } \\
\text { with refill } \\
\text { cartridge }\end{array}$ & $\begin{array}{l}\text { Wearable } \\
\text { reminder } \\
\text { device }\end{array}$ & $\begin{array}{l}\text { Bottle with refill } \\
\text { cartridge connected } \\
\text { to wearable device }\end{array}$ & & Necklace & Bracelet & $\begin{array}{l}\text { Phone } \\
\text { attachment }\end{array}$ & Panda & $\begin{array}{l}\text { Bottle with } \\
\text { pills } \\
\text { integrated }\end{array}$ \\
\hline Wearable & & $\checkmark$ & & & $\checkmark$ & $\checkmark$ & $\checkmark$ & & \\
\hline $\begin{array}{l}\text { Linked to a device } \\
\text { people already } \\
\text { carry }\end{array}$ & & $\checkmark$ & & & & & $\checkmark$ & & $\checkmark$ \\
\hline $\begin{array}{l}\text { Integrate } \\
\text { medication into a } \\
\text { cup or a bottle }\end{array}$ & $\checkmark$ & & & & & & & & $\checkmark$ \\
\hline
\end{tabular}

Table 38 Device used comments during co-design sessions.

\subsubsection{Integrated into life}

Groups two and three both highlighted the importance of the device helping integrate medication taking into the individual's daily life. Table 39 shows which solutions highlighted these factors of integrating the solution into a user's daily life.

\begin{tabular}{|c|c|c|c|c|c|c|c|c|c|}
\hline \multirow[t]{2}{*}{ Key features } & \multicolumn{3}{|l|}{ Group 1} & \multirow{2}{*}{$\begin{array}{l}\text { Group } 2 \\
\text { Pill } \\
\text { dispensing } \\
\text { machine }\end{array}$} & \multicolumn{3}{|l|}{ Group 3} & \multicolumn{2}{|c|}{ Group 4} \\
\hline & $\begin{array}{l}\text { Cup/bottle } \\
\text { with refill } \\
\text { cartridge }\end{array}$ & $\begin{array}{l}\text { Wearable } \\
\text { reminder } \\
\text { device }\end{array}$ & $\begin{array}{l}\text { Bottle with refill } \\
\text { cartridge connected } \\
\text { to wearable device }\end{array}$ & & Necklace & Bracelet & $\begin{array}{l}\text { Phone } \\
\text { attachment }\end{array}$ & Panda & $\begin{array}{l}\text { Bottle with } \\
\text { pills } \\
\text { integrated }\end{array}$ \\
\hline $\begin{array}{l}\text { Helps integrate } \\
\text { medication taking } \\
\text { into daily life }\end{array}$ & & & & $\checkmark$ & $\checkmark$ & $\checkmark$ & $\checkmark$ & & \\
\hline
\end{tabular}

Table 39 Integrated into life comments during co-design sessions.

\subsubsection{Keeping medication taking a secret}

Three of the four groups mentioned their solutions would make carrying medication discrete by having the device not look like a pill bottle. One of those groups highlighted that their device also made taking the medication discrete. See Table 40 for a summary of the comments made about keeping medication a secret.

\begin{tabular}{|l|l|l|l|l|l|l|l|l|l|}
\hline \multirow{2}{*}{ Key features } & \multicolumn{2}{|l|}{ Group 1 } & \multicolumn{2}{l|}{ Group 2 } & \multicolumn{2}{l|}{ Group 3 } & \multicolumn{2}{l|}{ Group 4 } \\
\cline { 2 - 9 } & $\begin{array}{l}\text { Cup/bottle } \\
\text { with refill } \\
\text { cartridge }\end{array}$ & $\begin{array}{l}\text { Wearable } \\
\text { reminder } \\
\text { device }\end{array}$ & $\begin{array}{l}\text { Bottle with refill } \\
\text { cartridge } \\
\text { connected to } \\
\text { wearable device }\end{array}$ & $\begin{array}{l}\text { Pill } \\
\text { dispensing } \\
\text { machine }\end{array}$ & Necklace & Bracelet & $\begin{array}{l}\text { Phone } \\
\text { attachment }\end{array}$ & Panda & $\begin{array}{l}\text { Bottle with } \\
\text { pills } \\
\text { integrated }\end{array}$ \\
\hline $\begin{array}{l}\text { Does not look like a } \\
\text { pill bottle - discreat } \\
\text { storage of medication }\end{array}$ & $\checkmark$ & & $\checkmark$ & & $\checkmark$ & $\checkmark$ & $\checkmark$ & $\checkmark$ & $\checkmark$ \\
\hline $\begin{array}{l}\text { Discreet method of } \\
\text { taking pill }\end{array}$ & $\checkmark$ & & $\checkmark$ & & & & & & \\
\hline
\end{tabular}

Table 40 Keeping medication taking a secret comments during co-design sessions. 


\subsubsection{Refill}

Groups one and two both had devices with refill cartridges they could get from a pharmacy. A large part of group two's solution was making it easy to refill a travel package. Group three integrated a reminder to refill the travel package. See Table 41 for a breakdown of which solutions included these factors.

\begin{tabular}{|c|c|c|c|c|c|c|c|c|c|}
\hline \multirow[t]{2}{*}{ Key features } & \multicolumn{3}{|l|}{ Group 1} & \multirow{2}{*}{$\begin{array}{l}\text { Group 2 } \\
\text { Pill } \\
\text { dispensing } \\
\text { machine }\end{array}$} & \multicolumn{3}{|l|}{ Group 3} & \multicolumn{2}{|c|}{ Group 4} \\
\hline & $\begin{array}{l}\text { Cup/bottle } \\
\text { with refill } \\
\text { cartridge }\end{array}$ & $\begin{array}{l}\text { Wearable } \\
\text { reminder } \\
\text { device }\end{array}$ & $\begin{array}{l}\text { Bottle with refill } \\
\text { cartridge connected } \\
\text { to wearable device }\end{array}$ & & Necklace & Bracelet & $\begin{array}{l}\text { Phone } \\
\text { attachment }\end{array}$ & Panda & $\begin{array}{l}\text { Bottle with } \\
\text { pills } \\
\text { integrated }\end{array}$ \\
\hline $\begin{array}{l}\text { Refill cartridges } \\
\text { provided by } \\
\text { pharmacy }\end{array}$ & $\checkmark$ & & $\checkmark$ & $\checkmark$ & & & & & \\
\hline $\begin{array}{l}\text { Makes it easy to } \\
\text { refill travel pack }\end{array}$ & & & & $\checkmark$ & & & & & \\
\hline $\begin{array}{l}\text { Reminder to } \\
\text { refill }\end{array}$ & & $\checkmark$ & & & & & & & $\checkmark$ \\
\hline
\end{tabular}

Table 41 Refill comments during co-design sessions.

\subsubsection{Reminders}

All four groups included some form of notification or reminder to take medication into all of their solutions. Group three highlighted that the notification used was discrete. Visual reminders were used by groups one, three and four. These included the device itself being a physical reminder to take the medication and well as changing lights or colours. Group four also included the pet dancing and looking sick as visual reminders. Groups two, three and four used tactile notification methods; mainly vibration. Only group four used an auditory notification in the form of a soothing alarm. Groups three and four both decided on multimodal alarms. Group three used them as different stages, where it would start out as visual and go to tactile if the alarm was not noticed.

Groups two, three and four highlighted that their device would allow users to know when a pill has been taken as well as visually showing them how many pills are 
left. Group four had one solution that would prevent users from taking another pill if they had already taken one.

Table 42 shows which solutions discussed reminders and what factors were included in each.

\begin{tabular}{|c|c|c|c|c|c|c|c|c|c|}
\hline \multirow[t]{2}{*}{ Key features } & \multicolumn{3}{|l|}{ Group 1} & \multirow{2}{*}{$\begin{array}{l}\text { Group } 2 \\
\begin{array}{l}\text { Pill } \\
\text { dispensing } \\
\text { machine }\end{array}\end{array}$} & \multicolumn{3}{|l|}{ Group 3} & \multicolumn{2}{|c|}{ Group 4} \\
\hline & $\begin{array}{l}\text { Cup/bottle } \\
\text { with refill } \\
\text { cartridge }\end{array}$ & $\begin{array}{l}\text { Wearable } \\
\text { reminder } \\
\text { device }\end{array}$ & $\begin{array}{l}\text { Bottle with refill } \\
\text { cartridge } \\
\text { connected to } \\
\text { wearable device }\end{array}$ & & Necklace & Bracelet & $\begin{array}{l}\text { Phone } \\
\text { attachment }\end{array}$ & Panda & $\begin{array}{l}\text { Bottle with } \\
\text { pills } \\
\text { integrated }\end{array}$ \\
\hline $\begin{array}{l}\text { Has a method of } \\
\text { notification or } \\
\text { reminder to take } \\
\text { medication }\end{array}$ & $\checkmark$ & $\checkmark$ & $\checkmark$ & $\checkmark$ & $\checkmark$ & $\checkmark$ & $\checkmark$ & $\checkmark$ & $\checkmark$ \\
\hline Discreet notification & & & & & $\checkmark$ & $\checkmark$ & $\checkmark$ & & \\
\hline $\begin{array}{l}\text { Device is a visual } \\
\text { reminder to take } \\
\text { medication }\end{array}$ & $\checkmark$ & & $\checkmark$ & & & & & $\checkmark$ & \\
\hline $\begin{array}{l}\text { Visual reminder in } \\
\text { the form of lights or } \\
\text { colour }\end{array}$ & & & & & $\checkmark$ & $\checkmark$ & & $\checkmark$ & $\checkmark$ \\
\hline Dancing & & & & & & & & $\checkmark$ & \\
\hline $\begin{array}{l}\text { Pet looks sick if } \\
\text { medication not taken }\end{array}$ & & & & & & & & $\checkmark$ & \\
\hline Tactile notification & & & & $\checkmark$ & $\checkmark$ & $\checkmark$ & & $\checkmark$ & \\
\hline $\begin{array}{l}\text { Soothing alarm as an } \\
\text { auditory notification }\end{array}$ & & & & & & & & $\checkmark$ & \\
\hline $\begin{array}{l}\text { Multimodal } \\
\text { notification }\end{array}$ & & & & & $\checkmark$ & $\checkmark$ & & $\checkmark$ & \\
\hline $\begin{array}{l}\text { Visually shows pills } \\
\text { taken }\end{array}$ & & & & $\checkmark$ & $\checkmark$ & $\checkmark$ & & $\checkmark$ & \\
\hline $\begin{array}{l}\text { Visually shows pills } \\
\text { left }\end{array}$ & & & & $\checkmark$ & $\checkmark$ & $\checkmark$ & & $\checkmark$ & \\
\hline $\begin{array}{l}\text { Does not allow you to } \\
\text { take more than one } \\
\text { pill by locking them }\end{array}$ & & & & & & & & & $\checkmark$ \\
\hline
\end{tabular}

Table 42 Reminders comments during co-design sessions.

\subsubsection{Smart system}

All four groups created devices that could be used as a connected system. Groups two, three and four highlighted that their solutions were a smart device. Group two and four 
mentioned that the device could know the users location to account for time zones. Group one's device would connect to family and the users healthcare team as well as proactively monitoring their health and refilling their prescriptions. See Table 43 for a summary of the solutions that included a smart system.

\begin{tabular}{|c|c|c|c|c|c|c|c|c|c|}
\hline \multirow[t]{2}{*}{ Key features } & \multicolumn{3}{|l|}{ Group 1} & \multirow{2}{*}{$\begin{array}{l}\text { Group } 2 \\
\text { Pill } \\
\text { dispensing } \\
\text { machine }\end{array}$} & \multicolumn{3}{|l|}{ Group 3} & \multicolumn{2}{|c|}{ Group 4} \\
\hline & $\begin{array}{l}\text { Cup/bottle } \\
\text { with refill } \\
\text { cartridge }\end{array}$ & $\begin{array}{l}\text { Wearable } \\
\text { reminder } \\
\text { device }\end{array}$ & $\begin{array}{l}\text { Bottle with refill } \\
\text { cartridge } \\
\text { connected to } \\
\text { wearable device }\end{array}$ & & Necklace & Bracelet & $\begin{array}{l}\text { Phone } \\
\text { attachment }\end{array}$ & Panda & $\begin{array}{l}\text { Bottle with } \\
\text { pills } \\
\text { integrated }\end{array}$ \\
\hline Connected system & & & $\checkmark$ & $\checkmark$ & & & $\checkmark$ & $\checkmark$ & $\checkmark$ \\
\hline Smart device & & & & $\checkmark$ & $\checkmark$ & $\checkmark$ & $\checkmark$ & & $\checkmark$ \\
\hline $\begin{array}{l}\text { Know the user's } \\
\text { location and adjusts } \\
\text { for time zones }\end{array}$ & & & & $\checkmark$ & & & & $\checkmark$ & \\
\hline $\begin{array}{l}\text { Connected to family } \\
\text { and healthcare team }\end{array}$ & & & & $\checkmark$ & & & & & \\
\hline $\begin{array}{l}\text { Proactively monitors } \\
\text { health }\end{array}$ & & & & $\checkmark$ & & & & & \\
\hline $\begin{array}{l}\text { Automatically refills } \\
\text { prescription }\end{array}$ & & & & $\checkmark$ & & & & & \\
\hline
\end{tabular}

Table 43 Smart System comments during co-design sessions.

\subsubsection{Stigma}

Group four believed their device would help remove the stigma around having medication by making it cool. Table 44 shows which solutions discussed stigma.

\begin{tabular}{|c|c|c|c|c|c|c|c|c|c|}
\hline \multirow[t]{2}{*}{ Key features } & \multicolumn{3}{|l|}{ Group 1} & \multirow{2}{*}{$\begin{array}{l}\text { Group } 2 \\
\begin{array}{l}\text { Pill } \\
\text { dispensing } \\
\text { machine }\end{array}\end{array}$} & \multicolumn{3}{|l|}{ Group 3} & \multicolumn{2}{|c|}{ Group 4} \\
\hline & $\begin{array}{l}\text { Cup/bottle } \\
\text { with refill } \\
\text { cartridge }\end{array}$ & $\begin{array}{l}\text { Wearable } \\
\text { reminder } \\
\text { device }\end{array}$ & $\begin{array}{l}\text { Bottle with refill } \\
\text { cartridge connected } \\
\text { to wearable device }\end{array}$ & & Necklace & Bracelet & $\begin{array}{l}\text { Phone } \\
\text { attachment }\end{array}$ & Panda & $\begin{array}{l}\text { Bottle with } \\
\text { pills } \\
\text { integrated }\end{array}$ \\
\hline $\begin{array}{l}\text { Removes stigma by } \\
\text { making it cool to } \\
\text { take medication }\end{array}$ & & & & & & & & $\checkmark$ & \\
\hline
\end{tabular}

Table 44 Stigma comments during co-design sessions.

\subsubsection{General device needs}

Only group two brought up having reusable packets to be more environmentally friendly.

Table 45 shows the general device needs presented. 


\begin{tabular}{|c|c|c|c|c|c|c|c|c|c|}
\hline \multirow[t]{2}{*}{ Key features } & \multicolumn{3}{|l|}{ Group 1} & \multirow{2}{*}{$\begin{array}{l}\text { Group } 2 \\
\begin{array}{l}\text { Pill } \\
\text { dispensing } \\
\text { machine }\end{array}\end{array}$} & \multicolumn{3}{|l|}{ Group 3} & \multicolumn{2}{|c|}{ Group 4} \\
\hline & $\begin{array}{l}\text { Cup/bottle } \\
\text { with refill } \\
\text { cartridge }\end{array}$ & $\begin{array}{l}\text { Wearable } \\
\text { reminder } \\
\text { device }\end{array}$ & $\begin{array}{l}\text { Bottle with refill } \\
\text { cartridge } \\
\text { connected to } \\
\text { wearable device }\end{array}$ & & Necklace & Bracelet & $\begin{array}{l}\text { Phone } \\
\text { attachment }\end{array}$ & Panda & $\begin{array}{l}\text { Bottle with } \\
\text { pills } \\
\text { integrated }\end{array}$ \\
\hline $\begin{array}{l}\text { Reusable packs - } \\
\text { environmentally } \\
\text { friendly }\end{array}$ & & & & $\checkmark$ & & & & & \\
\hline
\end{tabular}

Table 45 General device needs comments during co-design sessions.

\subsection{Feedback comments}

Below is a description of the key points written by participants in the feedback forms.

\subsubsection{Carrying Medication}

One participant mentioned that it is important to have a device that is close to the user so they do not have to remember to bring it with them. Another participant mentioned that the device should remove the need for the user to carry around their pill bottle. One participant mentioned that with wearable devices, some could fall off and get lost. Table 46 shows which sessions each comment was made in as well as the participant who mentioned it.

\begin{tabular}{|l|l|l|l|l|l|l|l|l|l|l|l|l|l|l|}
\hline & \multicolumn{3}{|l|}{ Session 1 } & \multicolumn{3}{l|}{ Session 2 } & \multicolumn{2}{l|}{$\begin{array}{l}\text { Session } \\
3\end{array}$} & $\begin{array}{l}\text { Number of } \\
\text { participants who } \\
\text { mentioned it }\end{array}$ & $\begin{array}{l}\text { Number of } \\
\text { sessions it was } \\
\text { mentioned in }\end{array}$ \\
\hline Comment & P1 & P2 & P3 & P4 & P5 & P6 & P7 & P8 & P9 & P10 & & \\
\hline $\begin{array}{l}\text { The device should always be } \\
\text { close to the users so they do } \\
\text { not have to remember it }\end{array}$ & & & & & & & $\checkmark$ & & & & 1 & 1 \\
\hline $\begin{array}{l}\text { Removes the need to carry a } \\
\text { pill bottle }\end{array}$ & $\checkmark$ & & & & & & & & & & 1 & 1 \\
\hline $\begin{array}{l}\text { Some wearable devices could } \\
\text { fall off }\end{array}$ & & & & & $\checkmark$ & & & & & & 1 & & 1 \\
\hline
\end{tabular}

Table 46 Carrying medication comments on feedback form.

\subsubsection{Customizable/personalizable}

Two participants mentioned that the solutions could work well for young adults because that demographic is technologically savvy. Another participant mentioned that there is a difference between the needs of young adults, between the individuals in that range that 
are older and those who are younger. It was also mentioned by two participants that the devices success would depend on the user's personality; whether that individual would want to integrate this device into their lives. Table 47 shows the participants who made each of these comments on the feedback form.

\begin{tabular}{|c|c|c|c|c|c|c|c|c|c|c|c|c|}
\hline \multirow[b]{2}{*}{ Comment } & \multicolumn{3}{|c|}{ Session 1} & \multicolumn{5}{|c|}{ Session 2} & \multicolumn{2}{|c|}{$\begin{array}{l}\text { Session } \\
3\end{array}$} & \multirow{2}{*}{$\begin{array}{l}\text { Number of } \\
\text { participants who } \\
\text { mentioned it }\end{array}$} & \multirow{2}{*}{$\begin{array}{l}\text { Number of } \\
\text { sessions it was } \\
\text { mentioned in }\end{array}$} \\
\hline & P1 & P2 & P3 & P4 & P5 & P6 & P7 & P8 & P9 & P10 & & \\
\hline $\begin{array}{l}\text { Solutions work well for young } \\
\text { adults because they are tech } \\
\text { savvy }\end{array}$ & & $\checkmark$ & $\checkmark$ & & & & & & & & 2 & 1 \\
\hline $\begin{array}{l}\text { There is a difference in needs of } \\
\text { young adults on the younger and } \\
\text { older sides of the range }\end{array}$ & & & & & & & & & $\checkmark$ & & 1 & 1 \\
\hline $\begin{array}{l}\text { It depends on the individual's } \\
\text { personality, whether they are } \\
\text { interested in integrating the } \\
\text { device into their lives }\end{array}$ & $\checkmark$ & & $\checkmark$ & & & & & & & & 2 & 1 \\
\hline
\end{tabular}

Table 47 Customizability/personalizability comments on feedback form.

\subsubsection{Device used}

Two participants mentioned that the solution should adapt to different existing items and integrate into what the user already has or would like to have. Table 48 shows which participant made this comment.

\begin{tabular}{|l|l|l|l|l|l|l|l|l|l|l|l|l|}
\hline & \multicolumn{3}{|l|}{ Session 1 } & \multicolumn{3}{l|}{ Session 2 } & \multicolumn{2}{l|}{$\begin{array}{l}\text { Session } \\
3\end{array}$} & $\begin{array}{l}\text { Number of } \\
\text { participants who } \\
\text { mentioned it }\end{array}$ & $\begin{array}{l}\text { Number of sessions } \\
\text { it was mentioned in }\end{array}$ \\
\hline Comment & P1 & P2 & P3 & P4 & P5 & P6 & P7 & P8 & P9 & P10 & & \\
\hline $\begin{array}{l}\text { Can adapt to fit different } \\
\text { existing items and adapt to } \\
\text { what the user has }\end{array}$ & & & & & & & & & & $\checkmark$ & 1 & 1 \\
\hline
\end{tabular}

Table 48 Device used comments on feedback form.

\subsubsection{Integrate into life}

One of the participants in group four mentioned that their water bottle idea would make it easy to integrate medication taking into an individual's life and schedule. Table 49 shows 
which participant commented on the integration of adherence devices into daily life as well as which session they were in.

\begin{tabular}{|l|l|l|l|l|l|l|l|l|l|l|l|l|l|}
\hline & \multicolumn{3}{|l|}{ Session 1 } & \multicolumn{3}{|l|}{ Session 2 } & \multicolumn{3}{l|}{$\begin{array}{l}\text { Session } \\
3\end{array}$} & $\begin{array}{l}\text { Number of participants } \\
\text { who mentioned it }\end{array}$ & $\begin{array}{l}\text { Number of sessions it } \\
\text { was mentioned in }\end{array}$ \\
\cline { 1 - 4 } Comment & P1 & P2 & P3 & P4 & P5 & P6 & P7 & P8 & P9 & P10 & & \\
\cline { 1 - 5 } $\begin{array}{l}\text { Easy to integrate into an } \\
\text { individual's schedule }\end{array}$ & & & & & & & & & & $\checkmark$ & 1 & 1 \\
\hline
\end{tabular}

Table 49 Integrate into life comments on feedback form.

\subsubsection{Motivation}

Four participants, from groups one, three and four believed that their solutions could work well because they were creative and exciting to own. Table 50 shows which participants commented on this in the feedback form.

\begin{tabular}{|l|l|l|l|l|l|l|l|l|l|l|l|l|l|}
\hline & \multicolumn{3}{|l|}{ Session 1 } & \multicolumn{3}{|l|}{ Session 2 } & \multicolumn{2}{l|}{$\begin{array}{l}\text { Session } \\
\text { Number of participants }\end{array}$} & $\begin{array}{l}\text { Number of sessions it } \\
\text { who mentioned it }\end{array}$ \\
\cline { 1 - 4 } Comment & P1 & P2 & P3 & P4 & P5 & P6 & P7 & P8 & P9 & P10 & & \\
\hline $\begin{array}{l}\text { Creative and } \\
\text { exciting to own }\end{array}$ & & & & $\checkmark$ & & & & $\checkmark$ & $\checkmark$ & $\checkmark$ & 4 & 2 \\
\hline
\end{tabular}

Table 50 Motivation comments on feedback form.

\subsubsection{Keeping medication taking secret}

One participant mentioned it was important to keep taking the medication a secret.

Another three participants thought it was important that the device did not look like a medication container and would therefore blend in when in public. Details of which participant made each comment can be seen in Table 51 .

\begin{tabular}{|l|l|l|l|l|l|l|l|l|l|l|l|l|l|}
\hline & \multicolumn{3}{|l|}{ Session 1 } & \multicolumn{3}{l|}{ Session 2 } & \multicolumn{2}{l|}{$\begin{array}{l}\text { Session } \\
3\end{array}$} & $\begin{array}{l}\text { Number of } \\
\text { participants who } \\
\text { mentioned it }\end{array}$ & $\begin{array}{l}\text { Number of sessions it } \\
\text { was mentioned in }\end{array}$ \\
\hline Comment & P1 & P2 & P3 & P4 & P5 & P6 & P7 & P8 & P9 & P10 & \\
\hline $\begin{array}{l}\text { Important to keep } \\
\text { taking the medication } \\
\text { secret }\end{array}$ & $\checkmark$ & & & & & & & & & & 1 & 1 \\
\hline $\begin{array}{l}\text { Does not look like a pill } \\
\text { bottle }\end{array}$ & & $\checkmark$ & & $\checkmark$ & & $\checkmark$ & & & & & 3 & & 2 \\
\hline
\end{tabular}

Table 51 Keeping medication taking secret comments on feedback form. 


\subsubsection{Refill}

Two participants believed that it was important to consider the preparation of the medication. One participant thought it might not be feasible to get pharmacies to produce refill cartridges for a specific device. This information is displayed in Table 52.

\begin{tabular}{|l|l|l|l|l|l|l|l|l|l|l|l|l|l|}
\hline & \multicolumn{3}{l|}{ Session 1 } & \multicolumn{3}{l|}{ Session 2 } & \multicolumn{2}{l|}{$\begin{array}{l}\text { Session } \\
3\end{array}$} & $\begin{array}{l}\text { Number of } \\
\text { participants who } \\
\text { mentioned it }\end{array}$ & $\begin{array}{l}\text { Number of sessions } \\
\text { it was mentioned in }\end{array}$ \\
\hline Comment & P1 & P2 & P3 & P4 & P5 & P6 & P7 & P8 & P9 & P10 & & \\
\hline $\begin{array}{l}\text { Preparation of medication is } \\
\text { important }\end{array}$ & & & & $\checkmark$ & & $\checkmark$ & & & & & 2 & 1 \\
\hline $\begin{array}{l}\text { May not be feasible to have } \\
\text { pharmacies produce refill } \\
\text { cartridges }\end{array}$ & & & & $\checkmark$ & & & & & & & 1 & 1 \\
\hline
\end{tabular}

Table 52 Refill comments on feedback form.

\subsubsection{Reminders}

Two participants highlighted the importance of having an automatic reminder so users do not forget to take their medication. One participant from group four mentioned that in their solution, the device would be a physical reminder. Comments made on the feedback forms about reminders can be seen in Table 53.

\begin{tabular}{|l|l|l|l|l|l|l|l|l|l|l|l|l|l|}
\hline & \multicolumn{3}{|l|}{ Session 1 } & \multicolumn{3}{l|}{ Session 2 } & \multicolumn{2}{l|}{$\begin{array}{l}\text { Session } \\
3\end{array}$} & $\begin{array}{l}\text { Number of } \\
\text { participants who } \\
\text { mentioned it }\end{array}$ & $\begin{array}{l}\text { Number of } \\
\text { sessions it was } \\
\text { mentioned in }\end{array}$ \\
\hline Comment & P1 & P2 & P3 & P4 & P5 & P6 & P7 & P8 & P9 & P10 & & \\
\hline $\begin{array}{l}\text { Needs to be an automatic } \\
\text { reminder so they do not forget } \\
\text { to take their medication }\end{array}$ & $\checkmark$ & & & & & & $\checkmark$ & & & & 2 & 2 \\
\hline $\begin{array}{l}\text { With the water bottle, it will } \\
\text { be there as a physical } \\
\text { reminder }\end{array}$ & & & & & & & & & & $\checkmark$ & 1 & 1 \\
\hline
\end{tabular}

Table 53 Reminders comments on feedback form.

\subsubsection{Smart system}

All of the participants from group one believed that the combination of their two solutions would solve all of the users problems since each focuses on solving a different issue. One participant from group three mentioned that a combination of group three and 
four's solutions would work best. One participant believed the solutions relied more on technology than people and though that having a system that tracks a user may not be feasible. Another two participants thought it would be feasible to track and monitor an individual's health. This information is shown in Table 54.

\begin{tabular}{|c|c|c|c|c|c|c|c|c|c|c|c|c|}
\hline \multirow[b]{2}{*}{ Comment } & \multicolumn{3}{|c|}{ Session 1} & \multicolumn{5}{|c|}{ Session 2} & \multicolumn{2}{|c|}{$\begin{array}{l}\text { Session } \\
3\end{array}$} & \multirow{2}{*}{$\begin{array}{l}\text { Number of } \\
\text { participants who } \\
\text { mentioned it }\end{array}$} & \multirow{2}{*}{$\begin{array}{l}\text { Number of sessions } \\
\text { it was mentioned ir }\end{array}$} \\
\hline & P1 & P2 & P3 & P4 & P5 & P6 & P7 & P8 & P9 & P10 & & \\
\hline $\begin{array}{l}\text { Combining multiple items } \\
\text { would solve all the users } \\
\text { problems }\end{array}$ & $\checkmark$ & $\checkmark$ & $\checkmark$ & & & $\checkmark$ & & & & & 4 & 2 \\
\hline $\begin{array}{l}\text { Solutions rely more on } \\
\text { technology than people }\end{array}$ & & & & & & $\checkmark$ & & & & & 1 & 1 \\
\hline $\begin{array}{l}\text { A system that tracks users } \\
\text { may not be feasible }\end{array}$ & & & & & & $\checkmark$ & & & & & 1 & 1 \\
\hline $\begin{array}{l}\text { Feasible to build a system } \\
\text { that tracks patients health }\end{array}$ & & & & $\checkmark$ & & & $\checkmark$ & & & & 2 & 1 \\
\hline
\end{tabular}

Table 54 Smart system comments on feedback form.

\subsubsection{General device needs}

One participant mentioned that the solutions need to be easy to use. Two participants were concerned that solutions were not necessarily unisex. Table 55 shows which participants made these comments.

\begin{tabular}{|c|c|c|c|c|c|c|c|c|c|c|c|c|}
\hline \multirow[b]{2}{*}{ Comment } & \multicolumn{3}{|c|}{ Session 1} & \multicolumn{5}{|c|}{ Session 2} & \multicolumn{2}{|c|}{$\begin{array}{l}\text { Session } \\
3\end{array}$} & \multirow{2}{*}{$\begin{array}{l}\text { Number of participants } \\
\text { who mentioned it }\end{array}$} & \multirow{2}{*}{$\begin{array}{l}\text { Number of sessions it } \\
\text { was mentioned in }\end{array}$} \\
\hline & P1 & P2 & P3 & P4 & P5 & P6 & P7 & P8 & P9 & P10 & & \\
\hline $\begin{array}{l}\text { Solutions need to } \\
\text { be easy to use }\end{array}$ & & $\checkmark$ & & & & & & & & & 1 & 1 \\
\hline $\begin{array}{l}\text { Not all solutions } \\
\text { are unisex }\end{array}$ & & & & $\checkmark$ & $\checkmark$ & & & & & & 2 & 1 \\
\hline
\end{tabular}

\section{Table 55 General device needs comments on feedback form.}

\subsubsection{Manufacturing}

Participants in group four thought that the bottle idea would be easy to produce but one believed that the panda would be difficult to make. In group one, one participant thought that there is available technology to produce the solutions they came up with. Another 
participant in that group thought that the wearable was easy to produce whereas the water bottle would be difficult. In session two, one participant from group two mentioned that the solutions presented by groups two and three were both possible to produce. This information is shown in Table 56.

\begin{tabular}{|l|l|l|l|l|l|l|l|l|l|l|l|l|}
\hline \multicolumn{2}{|l|}{} & \multicolumn{3}{|l|}{ Session 1 } & \multicolumn{3}{|l|}{ Session 2 } & \multicolumn{2}{l|}{$\begin{array}{l}\text { Session } \\
\text { participants who } \\
\text { mentioned it }\end{array}$} & $\begin{array}{l}\text { Number of } \\
\text { it was mentioned in }\end{array}$ \\
\hline Comment & P1 & P2 & P3 & P4 & P5 & P6 & P7 & P8 & P9 & P10 & & \\
\hline $\begin{array}{l}\text { Hard to } \\
\text { produce/manufacture }\end{array}$ & & & $\checkmark$ & & $\checkmark$ & & & & $\checkmark$ & & 3 & 3 \\
\hline $\begin{array}{l}\text { Possible to } \\
\text { produce/manufacture }\end{array}$ & & $\checkmark$ & $\checkmark$ & & $\checkmark$ & & & & & & 3 & 2 \\
\hline $\begin{array}{l}\text { Easy to } \\
\text { produce/manufacture }\end{array}$ & & & & & & & & & $\checkmark$ & $\checkmark$ & 2 & 1 \\
\hline
\end{tabular}

Table 56 Manufacturing comments on feedback form. 


\section{Chapter: Discussion}

The following chapter is broken into two sections. The first section, 9.1, describes the design considerations that arose from analysing the two studies and comparing them to the literature. The second section, 9.2, discusses the major contributions of this work.

\subsection{Design Recommendations}

Based on synthesizing the information gathered and reflecting on it in light of the literature review, the following design considerations have been developed. They will help guide individuals looking to develop or assess a tool that assists in improving medication adherence in young adults on ongoing treatment plans. These considerations are grouped into three categories: functional guidelines, experiential considerations and components of the healthcare system. Functional guidelines are the components, attributes or capabilities that need to be integrated into the tool in order for it to be useful. Experiential guidelines highlight users' different needs and behaviors that impact their use of medication and related tools. Finally, there are some factors related to the healthcare system that need to be considered in the way participants interact with their healthcare team and receive their treatment plans. Figure 30 shows the different guidelines and the key topics of considerations in each.

Although travel was used as the theme for the co-design sessions, other issues and aspects of medication adherence were also discussed. Since the results of the literature review, interviews and co-design sessions involved more than just travel, this theme is not central to the design considerations developed. Though it was not the key topic, its influence can be seen in some of the design considerations, mainly in the section on 
carrying medication. It is also a factor in the discussions around discretion of the device and the reminder systems which can be seen in various sections.

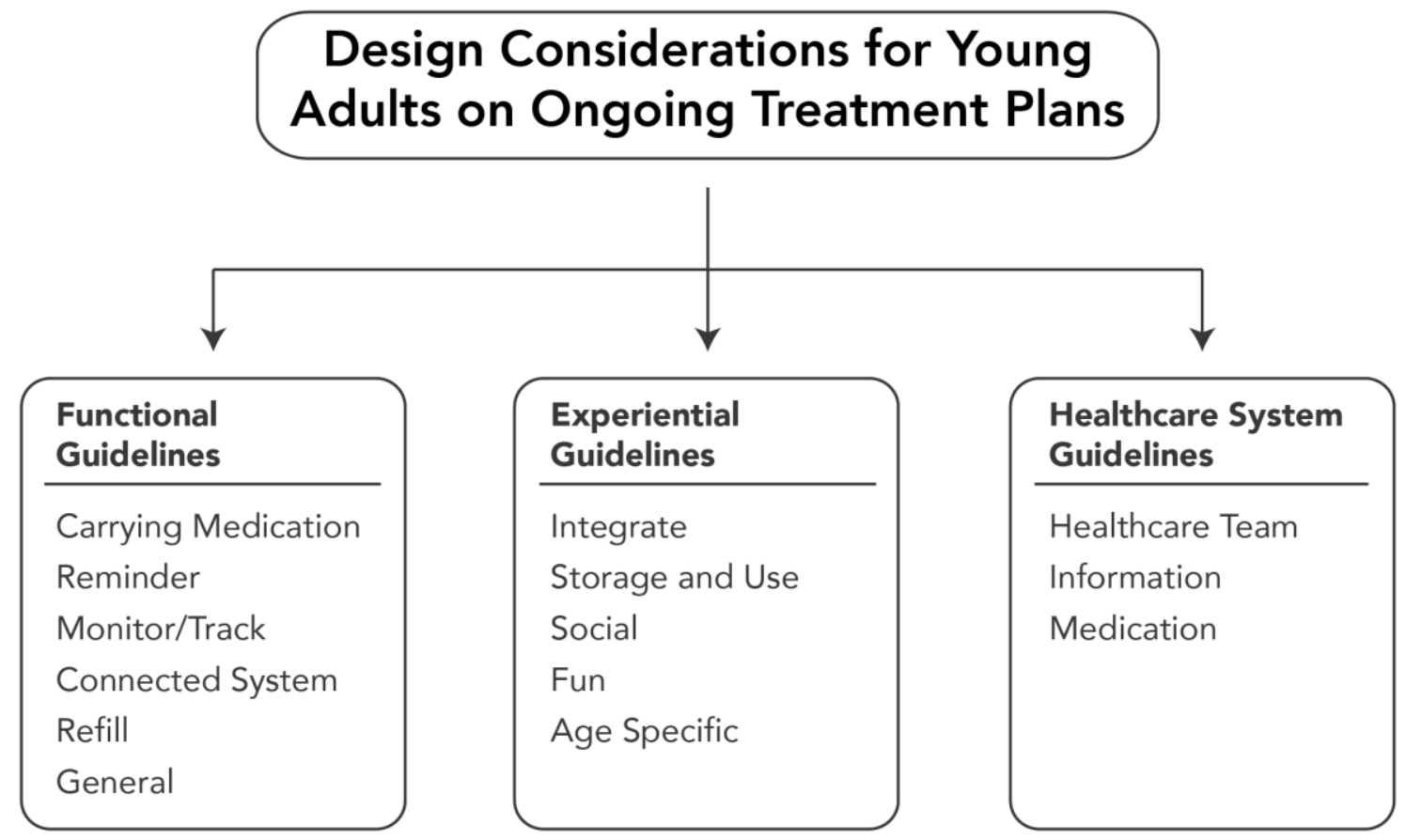

Figure 30 The three guidelines identified as design considerations and their key topics.

\subsubsection{Functional guidelines}

Functional guidelines will help guide what needs to be included in a tool that helps individuals adhere to a medication plan. These include: a way for individuals to carry the required amount of medication; a reminder or notification which allows them to know when medication should be taken; a tool that helps them track whether they have taken their medication and potentially monitors their health; a way of integrating a medication device with other devices or objects they use on a daily basis; a method for them to easily refill the device; as well as general needs such as having something that they can easily use and is affordable. See Figure 31 for an illustration of the key functional guidelines and the factors described in each. 


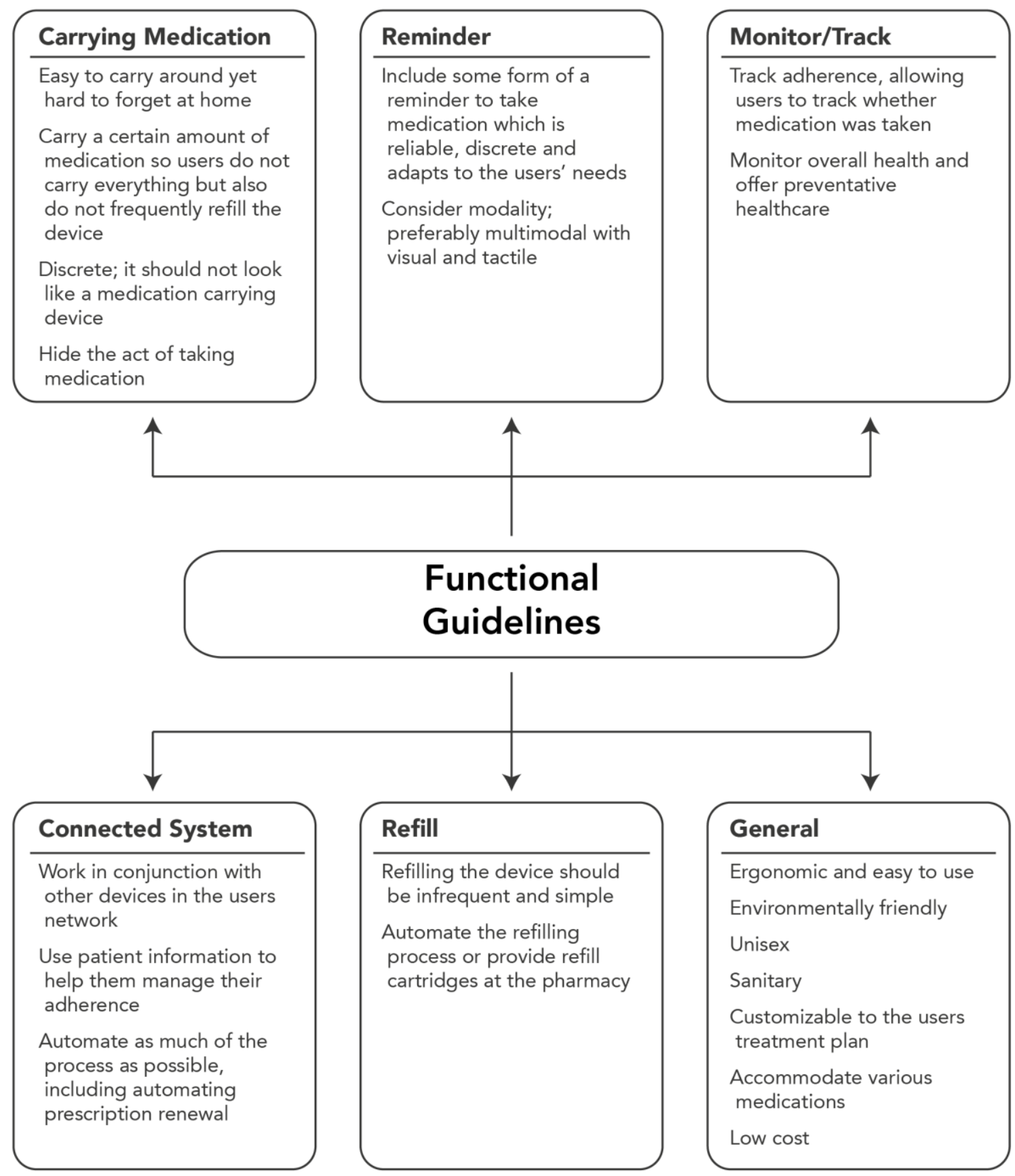

Figure 31 An outline of the functional guidelines and the key factors identified in each.

\subsubsection{Carrying medication}

In the interviews, participants mentioned that medication should be easy to carry around.

Since the co-design session focused on traveling while adhering to medication, issues around the portability of medication arose in that study as well. It has to be feasible to 
carry around the device, which participants associated with it being small and light. It was also stated that the device had to either always be kept close to the individual's person, like a smart watch, or it had to be integrated into something that they typically carry with them every time they leave the house, for example keys, a phone or a wallet. This was because participants were concerned that a new, stand-alone object would be easy to forget at home.

In the co-design session, all groups agreed that it was important to have the device carry multiple days' worth of pills so that they would not have to constantly refill it. On the other hand, participants also mentioned that they did not want to have to carry all of their medication with them. In the co-design session, storage spaces ranged from three to seven days' worth of pills. Although that seemed to be an ideal number to carry around, in the interviews it was identified that individuals would often abandon using pillboxes because they would forget or did not want to refill them once a week.

Participants in the interviews were also concerned about others hearing or seeing their medication, either when they were carrying it or when they were taking the pills. This topic was reflected and commonly discussed in the co-design sessions as well. In terms of the object's appearance, all groups discussed solutions in which the device carrying the medication did not look like a traditional pill bottle. This included hiding medication in jewellery, phone accessories and cups/bottles. Making medication look like everyday objects, such as gum, was another idea that came up but was dismissed since it ran the risk of others asking or taking medication thinking it is gum. To reduce the sound of medication rattling in a package, it was recommended to individually wrap medication and/or muffle the sound by using cotton fillers and rubber packaging. In the co-design 
session, an alternative to discrete packaging that was mentioned was making packaging that was fashionable and therefore would remove aspects of stigma surrounding carrying the medication.

Another issue was hiding the act of taking the medication. This was something that was also often built into the medication-carrying device. A common idea in the codesign session was integrating the medication into a pill bottle or cup so patients could easily carry it around and discreetly take their medication without it being noticed.

\subsubsection{Reminder}

The literature, interviews and co-design sessions all highlighted the importance of having a reminder system built into a solution that tries to improve adherence. This was also seen in a lot of the solutions on market that included reminders for their users (MyTherapy, 2018; Medisafe, 2018; AdhereTech, 2018; NantHealth, 2018; MedMinder, 2018;

PILBOX, 2018; HeroHealth, 2017). Matsui (2007) and Osterberg \& Blaschke (2005) both mention that forgetfulness is one of the most common causes of missing doses. Both Matsui (2007) and Butz (2006) mention that people often set reminders. In the interviews, most participants mentioned having some form of a reminder to take their medication, whether that was an alarm or just a physical object associated with taking medication. A lot of participants used a phone application to remind them, though they often disliked this reminder system.

Through the interviews and co-design sessions, the key considerations identified for the reminder system were that it had to be discrete, reliable and difficult to ignore. Participants wanted only the individual taking medication to notice the reminder or know what it meant. For discretion, the modality of the notification was an important factor. 
Participants in the interviews sometimes complained that he reminders they currently used were not reliable and there were occasions where they would either not notice the reminder or it would not go off. In terms of reminders being easy to ignore, participants mentioned that there were times where they would accidentally dismiss the notifications or they would just not respond to them. They also wanted notifications that they could push back if they were unable to take medication at that exact time.

In terms of the alarm's modality, participants generally liked a mixture of tactile and visual but disliked auditory. Auditory alarms were not discrete and could be disturbing. In the co-design session, only one group considered using an auditory reminder, though it was not the only modality they used. Visual reminders were used a lot in the solutions from the co-design sessions and by participants in the interviews. Visual reminders were either notifications on a device, subtle changes in colour, lights or physical objects that individuals would associate with taking medication. One group in the co-design session used happy and sad faces as visual reminders and another had a pet that would look sick when medication was not taken. In terms of tactile notifications, participants mostly used vibration, though two groups in the co-design sessions mentioned temperature. A combination of different reminder devices and modalities were also suggested in the co-design sessions and used by the interviewees. Multimodal alarms were also created by some of the groups in the co-design sessions; these usually involved the use of both visual and tactile notifications.

\subsubsection{Monitor/Track}

In the interviews, a common theme was participants wanting to track whether or not they had taken their medication and have a visual indication of this. Some participants 
mentioned that with blister packs it was easy to visually see whether or not a pill was taken. For participants who used a traditional pill bottle, they mentioned potentially missing or doubling doses because they were unsure of whether they had taken their medication or not. It was mentioned that here were apps that would track whether pills were taken, but they were inaccurate because they relied on users to report when they took their medication. Participants tended to like pill bottles for this because they could see if the pills were taken or not, but they often abandoned this tool because they did not want to manually refill it. In the co-design sessions, participants solved this issue by either adding sensors to the device to detect when the pill was missing or by using something similar to a blister pack, where the pharmacy provides individually packaged medication. One group also mentioned locking the device that dispenses medication after a dose has been taken. A lot of the solutions on the market that were assessed included some form of monitoring or tracking of patient's medication taking behaviour, though a lot of it was through indirect methods (Rexall PharmaPlus, 2018; Shoppers Drug Mart, 2018; Guardian and IDA Pharmacies, 2018; MyTherapy, 2018; Medisafe, 2018; AdhereTech, 2018; NantHealth, 2018; PILBOX, 2018).

In the co-design sessions, one group wanted to monitor both medication adherence and overall health through their device. By connecting it to a smart watch and potentially other devices, they wanted to be able to track a patient's health. This information could be shared with the healthcare team if the patient is willing or it can be used as a warning to get a patient help in emergency situations. By tracking overall health, it could also pre-emptively tell them if they need to take medication. This was 
seen as being useful with some medical conditions, such as diabetes, where patients may not necessarily have to follow a scheduled dosing plan.

\subsubsection{Connected System}

In the co-design sessions, a common theme was creating solutions that worked as part of a connected system. In this, participants expected the device to access their location, their calendar and information on their medication plan. One benefit of having location information was that it could adjust the time medication should be taken to their current time zone. For one group, they wanted the device to access to this information so it could automatically tell them the best time to take their medication. Ideally the device would identify the time when taking medication would be the least disruptive to their daily activities. They also wanted the device to be able to tell them how many pills they should take with them when they left the house so they were not short. These address some of the issues raised in the interviews, where participants mentioned that taking medication on trips can be difficult. Specifically, it addresses the fact that participants were unsure of how to adjust medication taking for time zones. Automatically finding time in their schedule to take the medication can also be a huge help because in both the interviews and the literature, finding a suitable time to take the medication was an important factor that affected adherence (Matsui, 2007; Butz, 2006; Nair et al., 2011).

Participants also wanted the device to connect a reminder device to a device that carried the medication. The device carrying medication had to be smart enough to know when it is full so it can detect whether medication was taken or if it was filled. This information could then be communicated to the reminder device so that it would continue to remind an individual to take medication until it sensed that medication had been taken. 
The carrying device could also potentially send reminders to users when it needed to be refilled. Another potential use of having a connected system was the device to being able to automatically refill prescriptions.

\subsubsection{Refill}

It is also important to consider how an individual will be refilling the device used. In the interviews, to avoid having to constantly refill another device, participants mentioned that they would just keep their medication in whatever package it came in. Solutions that were viewed positively, such as pillboxes would be abandoned because they would either forget or not want to take the time to refill them. In the co-design sessions, participants mentioned that devices should be quick and easy to fill but also should not need to be refilled every day. Two of the solutions removed the need for that participant to refill packages by providing them with cartridges at the pharmacy. One of those solutions used the provided cartridges to crate travel packs for the participant based on their personal schedule. Of the on market solutions that were described in the literature review, one of them had something to help participants with refilling of a device used for adherence (MedMinder, 2018).

\subsubsection{General}

Some general themes that emerged during the research was that the device needed to be easy to use, ergonomic, environmentally friendly and unisex. In the co-design sessions, it was mentioned that the device had to be sanitary, in terms of being easy to clean as well as antibacterial and antifungal. In both the interviews and the co-design sessions, it was stated that the tool should be tailored to a specific medication regimen or be able to easily 
be customized for a specific medication regimen. It should also be able to accommodate non-pill forms of medication and pills of varying sizes.

The issue of cost came up in the literature, interviews and co-design sessions. In Osterberg \& Blaschke (2005) the cost of medication was noted as a barrier to adherence. In the interviews, a few participants mentioned that they were receiving financial assistance to help cover the cost of their medication, and that lower costs helped them improve adherence. In the co-design sessions, it was mentioned by a couple of groups that the cost of the solution would affect participant's willingness to adopt the solution.

\subsubsection{Experiential Considerations}

When designing tools to help improve adherence, experiential needs also have to be considered. These were identified mainly in the interviews and co-design sessions, though some were backed up by the literature. They include: integrating the tool and the behaviour into their lifestyle and daily routine; considering various ways in which individuals will store or use their medication; social factors which may impact their adherence, such as social stigmas and support systems; making medication taking a fun or enjoyable experience; as well as age specific factors which may impact the usefulness or adoption of the tool. See Figure 32 for a visual of the key experiential guidelines and the factors described in each.

\subsubsection{Integrate}

In the interviews, co-design sessions and interviews, the concept of integrating a treatment plan into a patient's life was viewed as having a positive impact on adherence. In the literature, this was discussed by Osterberg \& Blaschke (2005) who discussed the importance of considering a patients lifestyle when prescribing treatment plans and how 
participants may miss doses due to alternate priorities. Matsui (2007) discussed adherence being positively impacted by reducing the disruptiveness of taking medication. In the interviews, some participants mentioned that they would delay or skip doses if they had other obligations or believed that someone may notice them taking their medication.

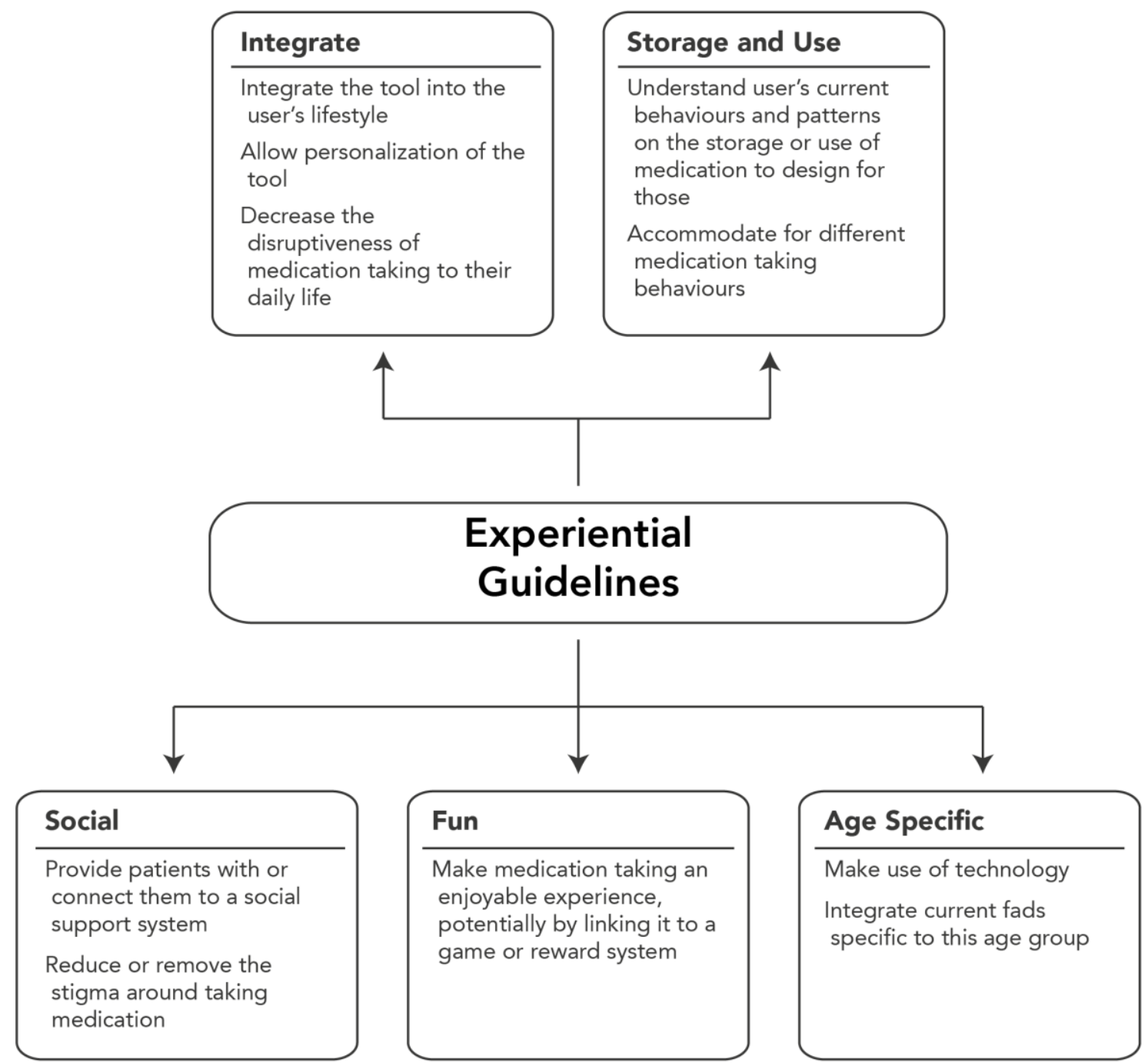

Figure 32 An outline of the experiential guidelines and the key factors identified in each.

In the interviews, almost all of the participants mentioned linking taking their medication to an event in their day, for example going to bed, waking up or eating. Aligning medication doses with daily events was also mentioned by Matsui (2007) and Butz (2006). In one of the solutions developed in the co-design sessions, the group suggested 
having the tool recommend times to take medication and adjust medication doses as necessary depending on daily patterns and scheduled events. In the interviews, one participant also mentioned wanting a solution that was responsive to their schedule.

In the co-design session, personalization of the solution was also a common theme. Participants wanted to be able to integrate the tool into things that hey already had and carried with them. They also wanted the device to aesthetically match their personality. Some groups showed this by saying that their device would be an attachment people could connect to anything or a device that they could decorate.

\subsubsection{Storage and Use}

In the interviews, it was identified that individuals all had different methods of storing their medication. Some would leave medication in their bag, most would leave it at home and some would store it in multiple locations. At home users would mostly store medication either by their bedside or in their bathroom. One participant had mentioned that they would store it in a lockbox to keep it away from children.

Most participants in the interviews mentioned that they would keep it in whatever packaging the medication came in. Those who received medication in a blister pack seemed happy with the packaging since it easily fit in their purse/bag and would visually show them what they had taken as well as what was left. Participants liked a pillbox because it had the same visual indication as a blister pack but often would not use it because refilling it was a hassle. Some individuals mentioned that when leaving the house they would use a zip lock bag to carry their medication while others bought travel packs that could carry one or two doses. 
All of the participants in the interviews linked their medication to a point in their routine, whether it was waking up, going to bed or having lunch. This idea of aligning a medication dose with a daily event was also mentioned by Matsui (2007), Butz (2006), Nair et al. (2011) and Hanghøj \& Boisen (2014). A lot of participants in the interviews, as well as some of the literature, also mentioned that placing their physical pill bottle in a location where they would see it in their routine helped serve as a reminder for them to take it (Nair et al., 2011). Changes in this routine, such as going on a vacation, having a sleepover or going on a day trip were noted to negatively impact adherence. In addition, a participant had mentioned that with a university schedule, there was never much consistency in their daily routine. The impact of traveling on medication adherence was mentioned in the literature as well by Nair et al. (2011) and Hanghøj \& Boisen (2014).

\subsubsection{Social}

During the interviews, participants mentioned that having support from friends and family would positively impact their adherence. It was also mentioned that having friends or family with similar conditions was used as a source of information. On the other hand, an unsupportive family or friend group would decrease adherence by leading to situations where participants would delay or avoid taking medication. Some participants also mentioned joining youth groups for support although opinions of these groups varied. Some participants found support groups to be a good place to discuss the illness and gather information; other participants thought that they were a negative influence because they were poorly run.

Stigmas were an important factor brought up in the literature, co-design sessions and interviews. Rao et al. (2007) and Matsui (2007) both discuss social stigmas as being 
a barrier to adherence. In the interviews, some participants mentioned that stigma would lead to them hiding the fact that they were taking medication, often causing to them missing or delaying doses. In the co-design sessions, stigma was also brought up often and participants wanted solutions that removed the social stigmas from taking medication. One group recommended doing this by making medication more exciting by adding brand names or making them look more interesting.

\subsubsection{Fun}

In both the literature and the co-design session, promoting medication adherence through a game was mentioned (Nikkila et al., 2012; Kato et al., 2008), though it was not a common theme in either. Participants in the co-design session thought of making medication-taking fun by adding rewards and feedback. Another solution was linking medication taking behaviour with caring for a virtual pet, where the pet would reflect the patient's health, e.g. with the panda solution, it would get sick if the patient did not take the medication. This virtual pet idea came from the idea of Tamagotchis.

\subsubsection{Age Specific}

Dean et al. (2010) and Rao et al. (2007) mentioned that the needs of young adults should be specifically targeted, instead of just translating findings from research done on older adults. Some groups confirmed this in the co-design session. Some participants felt that in this age group, people were more technologically savvy and therefore could handle using or may prefer to have tools that rely more on technology. A lot of the solutions created reflected this by making use of devices like phones, smart watches and connected homes in order to create solutions that worked as part a system. The idea of this age 
group being technologically savvy matched with marketing research on their generational cohorts, which are often described as having access to, easily using and wanting to use technology (Smith \& Nichols, 2015; Nichols \& Wright, 2018; Grewal et al., 2011). Another age specific comment brought up in the co-design sessions was the potential of changing the look of pills or pill bottles to fit in with current fads. Participants used the examples of making pill bottles shaped like Pikachu or pills that look like emojis. It was also mentioned in the co-design sessions that young adults might still be too broad of a target demographic, since there are still differences between older young adults and younger ones. This reflects in their level of comfort with technology as well as fads and interests. Based on the literature, currently, older young adults are in a different generational cohort than the younger ones.

\subsubsection{Healthcare System}

Improvements to the healthcare system could help improve adherence overall. Issues relating to the healthcare system were mostly brought up in the literature and by a few participants in the interviews. These considerations include: improving access and communication with the healthcare team; providing simpler instructions and education along with the prescription of the treatment plan; and altering or adjusting treatment plans to better suit the patients needs. See Figure 33 for a visual of the key healthcare system guidelines and the factors described in each. 


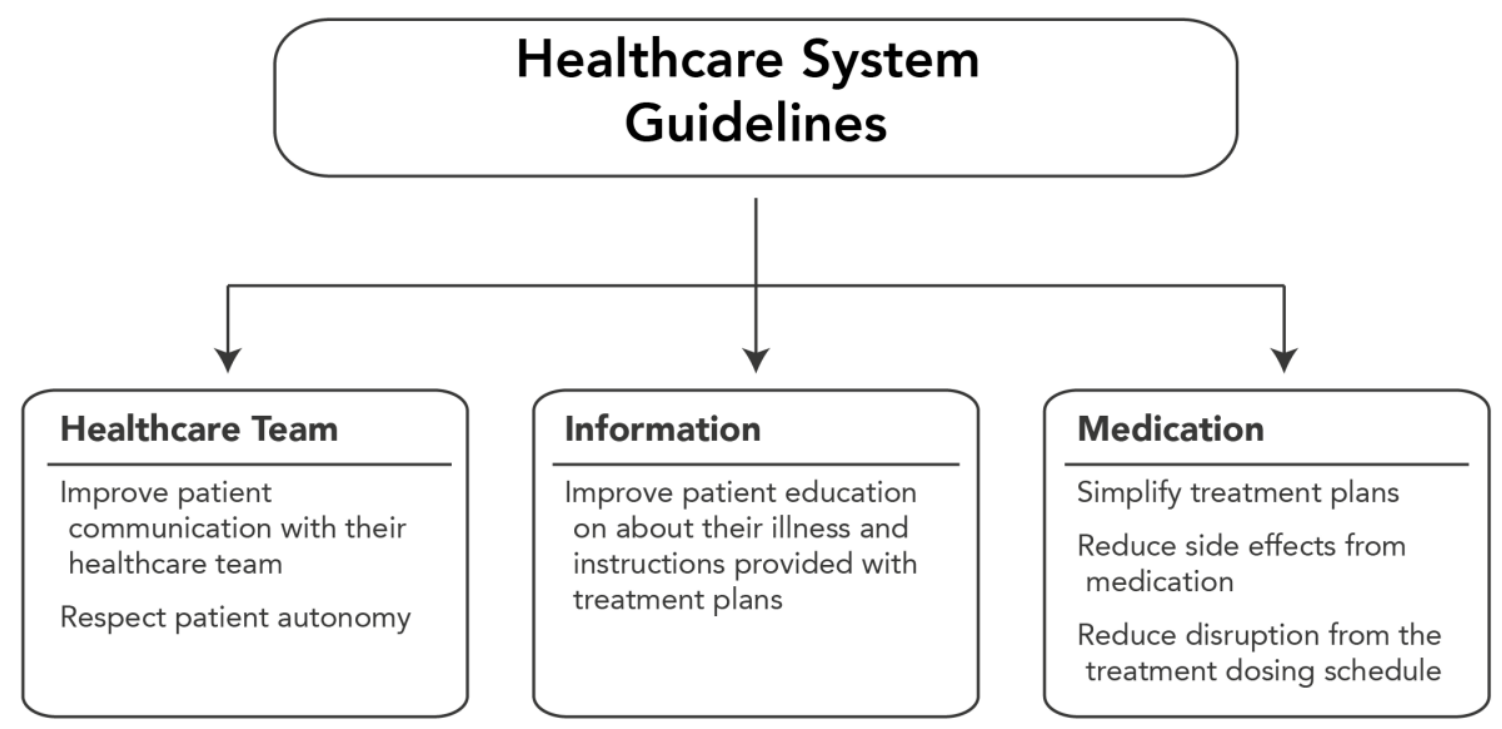

Figure 33 An outline of the healthcare system guidelines and the key factors identified in each.

\subsubsection{Healthcare Team}

The literature highlighted the importance of improving communication between the healthcare team and the patient in order to improve adherence and the effectiveness of the treatment (Osterberg \& Blaschke, 2005; Matsui, 2007; Butz, 2006). Within this idea of communication, some articles brought up the issue of patients inaccurately reporting medical information to their healthcare team (Becker \& Maiman, 1975; DiMatteo, 2004; Matsui, 2007; Rao et al., 2007; Butz, 2006). The idea of communication with the healthcare team was not mentioned as a concern by participants in either of the two studies; however, one group in the co-design session felt that a tool tailored to assisting in medication adherence should have the ability to automatically report findings and communicate with the healthcare team and/or some family members. This was seen as being able to reduce some unnecessary visits to the doctor by automatically refilling prescriptions and preventatively predicting patient health. Having a device automatically reporting on patient behaviour was also seen as a concern in terms of patient autonomy. 
The same group in the co-design session mentioned that the patient should have the ability to make decisions in their healthcare; therefore, they should be able to decide what is or is not shared without worrying about a device telling on them if they fail to follow their plan. In six of the in market solutions analyzed, there was some information that the devices would communicate to healthcare providers (MyTherapy, 2018; Medisafe, 2018; AdhereTech, 2018; NantHealth, 2018; MedMinder, 2018; HeroHealth, 2017). In the literature, Rao et al. (2007) also mentioned that there might be issues with communication between young adults and their healthcare team specifically because of their age. This was due to younger patients potentially viewing doctors as an authority figure (Rao et al., 2007).

\subsubsection{Information}

In both the literature and the interviews, it was mentioned that patient education and information provided with a particular regimen could positively affect a patient's adherence. Education in terms of understanding the regimen, the disease, and benefits/purpose of the treatment was listed in the literature as an important factor in improving adherence (Osterberg \& Blaschke, 2005; Matsui, 2007; Butz, 2006). Of the pharmacies that were looked at in the literature review, two of them provided information to patients about their medication and conditions (Rexall PharmaPlus, 2018; Guardian and IDA Pharmacies, 2018). Participants in the interviews mentioned that they were concerned that easier access to online information that could be incorrect may lead to decreased adherence.

Improving instructions provided by the healthcare team seems to be an important factor to look into when trying to improve adherence to a treatment plan. In the 
interviews one of the key factors that made participants adhere to their treatment plan was a personal desire to get the benefits of the treatment. This involves providing information that is easy for patients to understand, in terms that they will understand. Matsui (2007) states the importance of providing this information both verbally and written. In the interviews participants mentioned that instructions provided with medication were inadequate. They also wanted options to be educated on a particular condition or treatment through an open discussion where concerns and incorrect opinions can be directly addressed.

\subsubsection{Medication}

A few factors specific to the medication itself have a large effect on patient adherence as well. Both the interviews and the literature showed that simpler treatment plans, for example taking only one pill a day, had a positive impact on patient adherence (Osterberg \& Blaschke, 2005; Matsui, 2007; Butz, 2006). In addition, the schedule for dosing had a large impact on adherence. The less disruptive it was to their daily life, the more likely they were to adhere to it. For example, in the interviews, some participants mentioned that they might push back or avoid taking their medication if they were in a situation where they could not leave to take it privately. Lastly, the side effects that came with the medication were another factor that caused participants to delay or avoid doses.

\subsection{Contributions}

Four major contributions arise from this research. First, is a set of design considerations that can help guide the development of solutions within this problem space. Second, the approach of using design and marketing literature provided results that identified the needs of a specific population. Third, the methods used in this study complimented each 
other, providing more in-depth user information than if only one had been used. The last contribution is the way in which the co-design sessions were conducted, leading to their success

\subsubsection{Design considerations}

This study has led to a set of design considerations that are specific to the needs of young adults on ongoing treatment plans. They expand on and support current interventions in the literature, and highlight issues that products in the market currently address.

The design considerations broadly cover functional, experiential and healthcare system guidelines that should be met to improve adherence. They can be used to guide the creation of new products that aim to improve adherence in young adults with ongoing treatment plans. In addition, they can be used to validate whether existing products on the market are suitable for and meet the needs of this particular population.

\subsubsection{Design and marketing}

Through this research, a constructivist approach in the fields of design and marketing was used to understand the issue of medication adherence in young adults with ongoing treatment plans. This perspective led to focusing on a specific market segment, exploring the unique needs, behaviours and perceptions of young adults who have ongoing treatment plans; whereas most of the literature in the area of medication adherence and products aimed at improving it are tailored either to a general medication taking population, or an older population.

By focusing on the unique needs of this market segment, some factors came up that had not been mentioned or were not as prominent in the literature. The most prevalent of these was the need for technology in a solution. The results of the study 
indicated that participants expected their medication device to be part of a connected system. This included connecting a medication carrying device to the user's phone, computer or smart watch and allowing it access to enough of their data to manage their healthcare. In most solutions, this was pushing a notification to their phone, allowing it access to information about location and time, tracking whether medication was taken as well as connecting with the healthcare team. These factors can be seen in some current solutions on the market, including AdhereTech (2018), MedMinder (2018), the Vitality GlowCap (2018), MyTherapy (2018) and Medisafe (2018). However, during this study some participants extended this by wanting the device to access their calendar and automatically produce a medication schedule for them that worked around their other activities. They also mentioned wanting it to monitor their overall health through other devices, such as a smart watch and use all the data to proactively monitor their health. This comfort with and integration of technology into their lives is a factor that can be seen as a result of their generation. During the time of the study, in 2018, the generational cohorts young adults classified as were Generations $\mathrm{Y}$ and $\mathrm{Z}$. With these generations, the availability, comfort with and desire for technology is part of what distinguishes them from other, particularly older, generations (Grewal et al., 2011; Smith \& Nichols, 2015; Nichols \& Wright, 2018).

Another factor that came up in this study, specific to this population, was the importance of integrating fads of their age group into the solution. This included adding brand names to devices, making them fun and using things like emojis or Pokémon. 
Overall, conducting user centered design research on a specific market population has led to identifying user needs which may not have been addressed with a different or more general population.

\subsubsection{Study Approach}

A constructivist approach was taken using exploratory, sequential methods to address adherence in the target population. The first method used was semi-structured interviews, followed by co-design sessions. Both methods were qualitative, using open-ended discussions to gather information from participants. These methods worked well for a constructivist approach because they allowed participants' lived experiences to inform the research through both what they said and did.

In the interviews, data was gathered about individuals' behaviours, perceptions and desires by asking them about their current state. They were able to verbally describe some of the experiences they have had and habits they created.

Through the co-design sessions, more information was gathered about the tools that they wanted and their specific features, through an object focused, generative technique. This also may have allowed them to share some of the tacit knowledge that they had not, or would not have been able to express in the interviews.

Overall, the data collected from the two methods expanded on one another, providing a more in-depth understanding of the users than could have been provided by either study alone. In addition, the use of these methods provided new considerations not identified in the literature or addressed by current marketed solutions. Moving forward, the methodology used in this research could be used as a framework to conduct similar research in the healthcare field. 


\subsubsection{Co-Design Method}

In addition to providing valuable insight into the target population, the way the co-design sessions were conducted may be useful in future studies using this method. The sessions in this study were successful, likely due to the use of designers in each group, personas and the materials selected.

Including designers in each group allowed for there to be at least one individual who was comfortable with creating models or visual representations of the ideas. This can help if some of the individuals with lived experience are not comfortable with creating physical or visual representations of their solutions. In this study, all of the groups created models of at least one of their solutions, seemingly with ease and without hesitation.

The use of the personas in this study was another unique and helpful aspect. The personas provided information gathered from previous studies, while allowing participants to discuss their lived experiences through them. Since medication adherence may be a very private topic, some individuals may not be comfortable discussing their personal experiences. The personas allowed participants to project these personal experiences onto another individual, ultimately keeping their own medication taking anonymous.

The materials used also seemed suitable to the task users were trying to complete. No comments were made during the sessions on not having a material that they needed. In addition, participants seemed to easily pick out the materials they wanted to use. 


\section{Chapter: Conclusion}

This research explored what young adults need or want in a tool that helps them improve their adherence to ongoing treatment plans. It used a user-centered, constructivist approach to explore this issue. A review of the literature defined the need for and scope of the research, as well as identifying what is currently known about barriers and interventions for medication adherence. Young adult patients were then identified as the primary users, and exploratory, qualitative methods were used to capture their experiences and opinions. First, interviews were conducted with individuals who were part of the target demographic. These interviews aimed to define how young adults currently approach medication adherence as well as the barriers they experience. Data from the interviews and the literature was then used to inform the co-design sessions. During the co-design sessions, designers, young adults on ongoing treatment plans and individuals working closely with others on ongoing treatment plans collaborated to develop solutions for the defined problem. The goal of these sessions was to identify what young adults want or think they need to help them improve their adherence. Data from the literature, interviews and co-design sessions were then analysed to develop a list

of considerations that should be use to help develop a solution which would assist young adults adhere to ongoing treatment plans.

\subsection{Design Considerations}

This study generated a set of design considerations that should be kept in mind when designing solutions that assist young adults in adhering to ongoing medication plans. These considerations can be grouped into three categories: functional guidelines, experiential considerations and components of the healthcare system. 
There were six functional guidelines, which outlined things that needed to be included in the tool. These are:

- Allowing participants to easily and discreetly carry the medication that they need

- Including reminders which are discrete yet effectively and reliably remind the user to take their medication

- Allow the user to track the pills they have taken or have left and monitor their overall health

- The system has to be smart and connect to other devices or people, allowing it to automatically know basic information about the patient, work in conjunction with other devices the user has and potentially communicate with the patient's family or healthcare team if necessary

- Refilling the device should be an easy, if not automated process for the patient and work with the pharmacy if needed to make this happen

- General functional guidelines such as making the device easy to use, sanitary, ergonomic, unisex and low cost

Five experiential considerations were identified, which define some of the user needs relating to their behaviors and opinions. These include:

- Integrating the treatment plan and related tools into patients current lifestyle; including having the tool be part of what they typically carry with them and allowing the treatment plan to be more accommodating of their schedule

- Storage and use of this device, which outlines how users currently store, pack and take their medication 
- Social considerations, which cover current support systems used by participants, issues with those support systems and the impact of social stigmas on their medication adherence

- The system should be fun or enjoyable to use, possibly by integrating medication taking with some sort of game

- Age specific considerations for this demographic, including the use of technology and current fads

There were three factors that came up which could be applied to the healthcare system to improve adherence. These include:

- Improving communication between the patient and the healthcare team; including potentially reducing unnecessary visits through automation of some processes

- Improving the quality of information a patient receives about their treatment plan and condition

- Reconsider the specific treatment plan to improve healthcare; treatments should be as simple and non-disruptive as possible, with less side effects, less doses and more flexibility in dosing schedules.

\subsection{Contributions}

The primary contribution of this research is that it identified key concepts to consider when developing solutions for medication adherence in young adults. These considerations can be used in industry to inform the design of products for this market, or to evaluate products that are currently sold.

This research was conducted through a design and marketing perspective. With this, user centered research was conducted on a specific market segment. Although much 
research has been done on adherence, many studies documented in the literature were conducted with older adults or a general population, whose responses may not accurately reflect the needs of young adults. The studies in this thesis explore this issue by actively involving the end users to ensure that the needs of this specific population are addressed, and the solutions developed were built/based on their lived experiences and opinions. This should make the end product more suitable to and more likely to be adopted by the target population.

The study also used a constructivist approach, with exploratory, sequential methods, both of which were qualitative. Semi-structured interviews allowed users to describe their experiences, while the co-design sessions added to this information by gathering users' tacit knowledge. The use of both methods in conjunction allowed for the methods to build on each other and gather more information than could have been collected with either method individually.

Finally, the way in which the co-design sessions were conducted was unique and could be useful in future studies. The key factors leading to the success of this method were: having designers as participants, the use of personas and the materials provided.

Overall, the key contribution of this research is that it identified design considerations specific to young adults on ongoing treatment plans. This added to what is currently known in the literature, while identifying methods and approaches to research that are useful in this field.

\subsection{Limitations}

The population sampled for these studies may not be a representative sample of all young adults. Most of the recruiting was conducted in a university setting, which could result in 
recruiting participants from similar socio-economic backgrounds. It could also result in participants recruited having higher levels of education. Recruitment methods used in this study were snowball and convenience sampling, which are lower in external validity than random sampling. The overall population sample was small, which may make this a pilot study. However, it would be challenging to increase the size or number of the co-design groups to involve a larger population sample. Therefore, a third method for triangulation of the data could have added more definitive results.

Although other factors exist which may affect patients' adherence needs, such as socio-economic status, level of education, specific conditions, co-existing illnesses and complexity of conditions, in this study, age was used to identify the target market. This is because when looking at a market segment, young adults as a generational cohort have similarities that can affect how they would interact with a product or service. Due to the ethical limitations in this study, information was not intentionally gathered on the factors listed above, since they would have increased the chance of social and psychological harm to the participants. Though this information was not gathered in this research, it could provide valuable insights on this populations needs; therefore, in future studies, quantitative measures can be used to identify whether the needs of young adults differ as a result of any of those factors.

In addition, the age range selected was large, so there could be a difference in the needs of individuals on the younger and older ends of this range. Although the age range used is broad, for the most part it covers one Generational cohort, with only the youngest individuals of the population falling under a different cohort in some of the literature; therefore, they can be considered relatively homogeneous in some ways. However, the 
wide range of ages could also lead to issues when generalizing the findings of this research to the entire young adult population.

In the interviews, all participants' medication plans involved one or two medications taken once daily. Results could be different for more complex or rigorous medication regimens.

Participants in both studies may have all had different reasons for taking the medication, though information on the reason for medication was not gathered during this study. An individual's specific illness or medication could play a large role in their adherence issues. This could be due to other coexisting conditions, medication side effects or symptoms that can all play a large role in medication adherence.

The data gathered in this study did not provide insights on a lot of these social determinants of health which may be impacting individual's adherence rates. Some of these factors were touched on in the research, such as social stigmas and support. Other potential factors, such as the patient's socio-economic status, their education, perceived control, self-esteem, etc. were not discussed. This is in part due to the limitations of the study design, though this information may provide valuable insights that could add to the finding of this study.

Majority of the recruitment occurred, but was not limited to, Canada. Some factors may be more or less prominent in other geographical locations, depending on their healthcare system.

The research mainly used a design perspective, borrowing from some marketing concepts. Overall, it may benefit from further integration of marketing methods and theories. 


\subsection{Next Steps}

Future research could include similar studies done to assess the needs of other stakeholders in the adherence of young adults to ongoing treatment plans. This could include other potential users, such as members of the healthcare team or patients family and friends.

Others may choose to build on the considerations defined in this study by developing solutions and testing them or evaluating the solutions developed in the codesign sessions. The findings of this study could also be validated by future research, potentially with the use of some quantitative metrics.

Future studies can also assess whether these findings are applicable across various medication plans, or across educational and socio-economic backgrounds.

This research can also be expanded on by further integration of a marketing approach. Various existing theories in the field of marketing, relating to user behavior or consumption can be compared to the findings of this study. This may allow the studies findings to be expanded on, further explained or validated.

Another avenue for future research would be to study the social determinants of health which may impact adherence rates in this population. This information could be compared to the data gathered in this study to explain and expand on the findings. 


\section{Appendices}

\section{Appendix A - Study 1 Materials}

\section{A.1 Social Media Invitation}

\section{Volunteers Needed for an interview}

Title: Improving adherence to ongoing treatments in young adults through design

We are looking for volunteers to participate in a 30-minute interview, either online, over the phone or in-person.

We would like to ask you a few questions about your experiences to gain some insight on what tools are currently used to monitor/improve how closely treatment plans are followed. This study aims to understand the factors which impact medication taking behavior in young adults, as well as identify current and desired tools to assist in improving medication taking behavior. This information will be used to identify design guidelines for a tool which assist young adults in improving medication taking behavior.

To be eligible, you must be:

- $18-30$ years of age

- Comfortable speaking English

- Have been prescribed a daily medication plan which lasted over 6 months by a medical professional

With your consent, interviews will be audio-recorded. Once the recording has been transcribed and analyzed, it will be destroyed. Topics covered in the study may be sensitive, but should you chose to participate, all questions are optional. In addition, all responses will be kept anonymous and data will be safely stored. You will be able to withdraw your data up to one week after your session. 
You will be compensated with a \$5 Tim Hortons gift card for your participation in this study

If you are interested, please e-mail Sanaz Hafezi at sanazhafezi@cmail.carleton.ca for more details on participating.

The ethics protocol for this research (108484) has been reviewed and cleared by the Carleton University Research Ethics Board. If you have any ethical concerns with the study, please email ethics@carleton.ca. 


\section{A.2 Email Invitation}

Subject: Improving adherence to ongoing treatments in young adults through design

$\mathrm{Hi}$,

I am conducting a 30-minute interview, either online, over the phone or in-person.

We would like to ask you a few questions about your experiences to gain some insight on what tools are currently used to monitor/improve how closely treatment plans are followed. This study aims to understand the factors which impact medication taking behavior in young adults, as well as identify current and desired tools to assist in improving medication taking behavior. This information will be used to identify design guidelines for a tool which assist young adults in improving medication taking behavior.

To be eligible, you must be:

- $18-30$ years of age

- Comfortable speaking English

- Have been prescribed a daily medication plan which lasted over 6 months by a medical professional

With your consent, interviews will be audio-recorded. Once the recording has been transcribed and analyzed, it will be destroyed. Topics covered in the study may be sensitive, but should you chose to participate, all questions are optional. In addition, all responses will be kept anonymous and data will be safely stored. You will be able to withdraw your data up to one week after your session.

You will be compensated with a \$5 Tim Hortons gift card for your participation in this study.

If you are interested, please e-mail Sanaz Hafezi at sanazhafezi@cmail.carleton.ca for more details on participating. 
The ethics protocol for this research (108484) has been reviewed and cleared by the Carleton University Research Ethics Board. If you have any ethical concerns with the study, please email ethics@carleton.ca.

Best,

Sanaz 


\title{
A.3 Recruitment Poster
}

\section{Carleton}

\section{Volunteers Needed for an interview}

\author{
Improving adherence to ongoing treatments in young adults through design
}

We are looking for volunteers to participate in a $\mathbf{3 0}$-minute interview, either online, over the phone or in-person.

To be eligible, you must be:

- $18-30$ years of age

- Comfortable speaking English

- Have been prescribed a daily medication plan which lasted over 6 months by a medical professional

We would like to ask you a few questions about your experiences to gain some insight on what tools are currently used to monitor/improve how closely treatment plans are followed. This study aims to understand the factors which impact medication taking behavior in young adults, as well as identify current and desired tools to assist in improving medication taking behavior. This information will be used to identify design guidelines for a tool which assist young adults in improving medication taking behavior.

You will be compensated with a $\$ 5$ Tim Hortons gift card for your participation in this study.

If you are interested, please e-mail Sanaz Hafezi at sanaz.hafezi@carleton.ca for more details on participating.

With your consent, interviews will be audio-recorded. Once the recording has been transcribed and analysed, it will be destroyed. Topics covered in the study may be sensitive, but should you chose to participate, all questions are optional. In addition, all responses will be kept anonymous and data will be safely stored. You will be able to withdraw your data up to one week after your session. There is no compensation for participation in this study.

The ethics protocol for this research (108484) has been reviewed and cleared by the Carleton University Research Ethics Board. If you have any ethical concerns with the study, please email ethics@carleton.ca. 


\section{A.4 Screener}

$\mathrm{Hi}$,

Could you please answer the questions below.

What gender do you identify as?
○ Male
○ Female
○ Non-binary
- Prefer not to answer

What is your age? (this question is optional)

Would you like to participate in an in-person or remote session? In person sessions will be held at Carleton University, located at 1125 Colonel By Dr, Ottawa, ON K1S 5B6, Canada. Remote sessions will be held on a conferencing tool where you can attend either online or on your phone.
○ In Person
○ Remote

Please give us some times when you would be available for a session. Sessions may take up to 30 minutes. 


\section{A.5 Interview Script}

Title: Improving adherence to ongoing treatments in young adults through design

Hi. Before we begin, I want to remind you that you have the right to end your participation in the study at any time during the session, for any reason.

I would also like to remind you that you are not obligated to answer any questions. All responses are optional; if you do not wish to answer a question, or are uncomfortable talking about a topic just let the researcher know.

All responses will be kept anonymous and your name will be removed from the data; for example, you may be referred to as participant 1 .

Do you have any questions for me before we begin?

Q1: Considering the medication plan you have been prescribed, what form do you take this medication in? (e.g. injection, pill, liquid)

Probe: What amount of medication are you required to take daily?

Probe: How often do you have to take this medication? How many times a day?

Q2: Are there any factors that have positively impacted how closely you follow the that treatment plan? (support systems, friends, family, tools, applications etc.) 
Q3: Are there any factors that have negatively impacted how closely you follow the that treatment plan? (other obligations, social situations, rigidity of the plan etc.)

Q4: Is there any particular way you organize your medication which helps you? (travel packs, pill boxes, keeping it in multiple locations etc)

Q5: Are there any tools or tricks you use to help you follow your medication plan? (e.g. applications, systems, organizational tools etc.)

Probe: What works well about thee tools? How do they help you?

Probe: What does not work well about this toll? Anything you dislike?

Probe: Is there anything you would like to add to the tool?

Q6: Is there anything that you would like to have (or would have liked to have) to help you follow your medication plan?

That's all of the questions that I have for you today, do you have any questions or comments for me?

Thank you for your time. Please feel free to reach out to me if you have any questions. 
[If short on participants] Also, If you know anyone else who would be interested in participating, please refer them to me. 


\section{A.6 Consent Form}

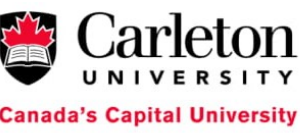

\section{Consent Form}

Title: Improving adherence to ongoing treatments in young adults through design

Date of ethics clearance: March 5, 2018 (108484)

Ethics Clearance for the Collection of Data Expires: February 28, 2019

I choose to participate in a study

on adherence in young adults. This study aims to understand the factors which impact medication taking behavior in young adults, as well as identify current and desired tools to assist in improving medication taking behavior. This information will be used to identify design guidelines for a tool which assist young adults in improving medication taking behavior. The researcher for this study is Sanaz Hafezi in the School of Industrial Design. She is working under the supervision of Dr. Lois Frankel in the School of Industrial Design.

This study involves one 30 minute interview and you will receive a $\$ 5$ Starbucks gift card as compensation. During the interview we would like to ask you a few questions about your experiences to gain some insight on what tools are currently used to monitor/improve how closely treatment plans are followed.

With your consent, interviews will be audio-recorded, though, you may still participate in the session if you choose not to be audio recorded. These recordings would be stored on an encrypted and password protected USB which will be kept in a locked cabinet at Carleton University. The recording will only be used by the researcher for analysis and will be destroyed once it has been transcribed and analysed.

All responses will be kept anonymous and your name will be removed from the data; for example, you may be referred to as participant 1 . All data will be kept confidential unless it reveals a life-threatening risk to you or anyone else; in which case the researcher is obligated to report it.

You have the right to end your participation in the study at any time during the session or for up to a week after the session, for any reason. Simply tell the researcher that you want to withdraw. If you withdraw from the study, all information you have provided will be immediately destroyed.

Page 1 of 2

This document has been printed on both sides of a single sheet of paper. Please retain a copy of this document for your records. 
This is part one of a three-part study. You are not required to participate in all three parts. The researcher will contact you with an invitation to all three sections should you wish to participate.

Some topics covered during the session may be sensitive, but you are not obligated to reveal any information. All responses are optional; if you do not wish to answer a question, or are uncomfortable talking about a topic just let the researcher know.

All research data will be kept either on a password protected computer of the researcher, on an encrypted and password protected USB and/or in a locked cabinet at Carleton University. Research data will only be accessible by the researcher and the research supervisor.

Once the project is completed, all research data may be kept for up to seven years and potentially used for other research projects on this same topic. At the end of seven years, all research data will be securely destroyed; electronic data will be erased and hard copies will be shredded.

If you would like a copy of the finished research project, you are invited to contact the researcher to request an electronic copy which will be provided to you.

The ethics protocol for this project was reviewed by the Carleton University Research Ethics Board, which provided clearance to carry out the research. If you have any ethical concerns with the study, please contact Dr. Andy Adler, Chair, Carleton University Research Ethics Board-B (by phone at 613-520-2600 ext. 4085 or via email at ethics@carleton.ca).

Researcher contact information: Sanaz Hafezi

School of Industrial Design

Carleton University

Email: sanazhafezi@cmail.carleton.ca

Do you agree to be audio-recorded:

Signature of participant

Signature of researcher
Supervisor contact information: Lois Frankel

School of Industrial Design

Carleton University

Email: loisfrankel@cunet.carleton.ca Yes _ No

Date

Date

Page 2 of 2

This document has been printed on both sides of a single sheet of paper. Please retain a copy of this document for your records. 


\section{Appendix B - Study 2 Materials}

\section{B.1 Personas}

Name: Jane

Age: 22

Number of pills per day: 2

When pills are taken: 1 in the morning $(8: 00 \mathrm{am}), 1$ at noon with lunch

Background: Jane usually keeps her morning medication at home and leaves her noon medication in her purse. For her noon medication, she must take it with food so she keeps it in her purse and takes it as soon as she finishes her meal. She usually avoids setting alarms on her phone as reminders since they are not reliable, can attract attention and are easy to ignore.

Scenario: Jane is a university student going on vacation to California with some of her friends. She has to continue taking her medication at the same time every day but is not sure how to adjust for the changing time zone or the shift in her daily routine. She is also unsure of whether she can get her medication while on vacation so she has to make sure she remembers to bring it with her.

\section{Problems:}

- Must take her medication 8:00 am and 12:00 pm EST, though the time zone in California is different

- She has to make sure she brings enough medication with her to last the whole trip 
Name: Kristen

Age: 19

\section{Number of pills per day: 1}

When pills are taken: 1 at noon

Background: Kristen is a University student; her schedule varies day by day so she finds that noon is the best time to take her medication. She will delay taking her medication if she has other obligations or feels like people will notice her taking it. She keeps her medication in a pill bottle in her backpack but is always worried that people can hear it shaking or see it when she opens her bag.

Scenario: Kristen is on her way to school and feels like people can hear her pill bottle shaking on the bus. It is past noon but she doesn't want to take the medication in public and she is already late for a meeting with one of her professors. She decides that she will take her medication later so that it doesn't interfere with her schedule.

\section{Problems:}

- Wants to keep her medication secret

- Should take her medication at noon but will delay taking it if it is disruptive

- Dislikes carrying her pill bottles 
Name: John

Age: 28

\section{Number of pills per day: 1}

When pills are taken: one at night (at 9:00)

Background: John usually keeps his medication at home on the bathroom counter so that he sees at night before he goes to bed. He counts on seeing his medication to remember to take it, and he avoids taking it more than once by taking it at night before bushing his teeth.

Scenario: John is going to Toronto for a weekend to visit some of his old friends. Him and a few others will be sleeping over at his friend's house. Not everyone there knows that he is taking medication and he does not feel comfortable setting up his medication at his friends house the way he would at home.

\section{Problems:}

- Does not want to avoid going out with his friends

- Change in his daily routine could cause him to forget medication since his regular reminding cue will be gone

- Has to remember to take his medication and make sure he does not accidentally take it twice 


\title{
B.2 Recruitment Poster
}

\section{Carleton \\ Volunteers Needed for a Co-design Session}

\author{
Improving adherence to ongoing treatments in young adults through design
}

We are looking for volunteers to participate in a $\mathbf{2}$ hour co-design session. These will be group sessions held in-person at Carleton university.

We are looking for individuals who have experience with daily medication plans to bring their expertise as well as designers to help with developing solutions. To be eligible, you must be comfortable speaking English and either:

- Have been prescribed a daily medication plan by a medical professional and/or

- Worked closely with an individual who has been prescribed a daily medication plan and/ or

- Be a designer

In the co-design session, we will present information from our research and you will be asked to help generate ideas for potential solutions in a group. The goal of this study is to identify potential solutions/tools young adults can use to help them follow medication plans while traveling. This information will be used to identify design guidelines for a tool which assists young adults in improving medication taking behavior.

All sessions will be video-recorded. Once the recording has been transcribed and analyzed, it will be destroyed. Video clips from these sessions may be used in future publications, but faces or other identifiable information will be blurred and voices will be altered.

We will be proving refreshments at the session.

If you are interested, please e-mail Sanaz Hafezi at sanazhafezi@cmail.carleton.ca for more details on participating.

Topics covered in the study may be sensitive, but should you choose to participate, all responses are optional and you may leave at any point during the session.

The ethics protocol for this research (108484) has been reviewed and cleared by the Carleton University Research Ethics Board. If you have any ethical concerns with the study, please email ethics@carleton.ca.

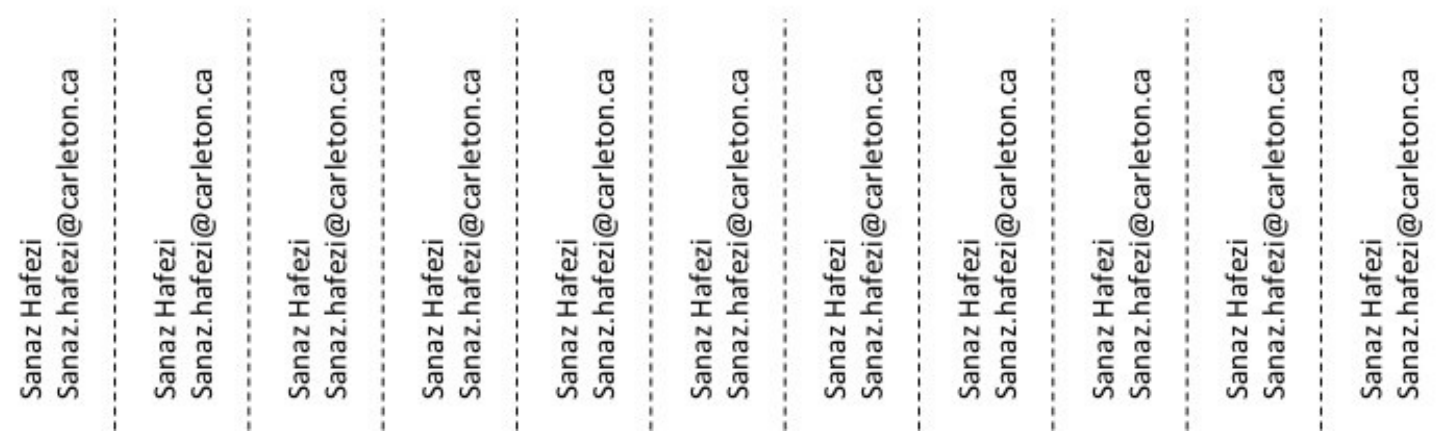




\section{B.3 Email Invitation}

Subject: Improving adherence to ongoing treatments in young adults through design

$\mathrm{Hi}$,

We are looking for volunteers to participate in a $\mathbf{2}$ hour co-design session. These will be group sessions held in-person at Carleton university.

In the co-design session, we will present information from our research and you will be asked to help generate ideas for potential solutions in a group. The goal of this study is to identify potential solutions/tools young adults can use to help them follow medication plans while traveling. This information will be used to identify design guidelines for a tool which assists young adults in improving medication taking behavior.

We are looking for individuals who have experience with daily medication plans to bring their expertise as well as designers to help with developing solutions. To be eligible, you must be comfortable speaking English and either:

- Have been prescribed a daily medication plan by a medical professional

\section{and/or}

- Worked closely with an individual who has been prescribed a daily medication plan

and/or

- Be a designer 
All sessions will be video-recorded. Once the recording has been transcribed and analyzed, it will be destroyed. Video clips from these sessions may be used in future publications, but faces or other identifiable information will be blurred and voices will be altered.

Topics covered in the study may be sensitive, but should you choose to participate, all responses are optional and you may leave at any point during the session.

We will be proving refreshments at the session.

If you are interested, please e-mail Sanaz Hafezi at sanazhafezi@cmail.carleton.ca for more details on participating.

The ethics protocol for this research (108484) has been reviewed and cleared by the Carleton University Research Ethics Board. If you have any ethical concerns with the study, please email ethics@ carleton.ca.

Best,

Sanaz 


\section{B.4 Social Media Invitation}

\section{Volunteers Needed for a co-design session}

Title: Improving adherence to ongoing treatments in young adults through design

We are looking for volunteers to participate in a $\mathbf{2}$ hour co-design session. These will be group sessions held in-person at Carleton University.

In the co-design session, we will present information from our research and you will be asked to help generate ideas for potential solutions in a group. The goal of this study is to identify potential solutions/tools young adults can use to help them follow medication plans while traveling. This information will be used to identify design guidelines for a tool which assists young adults in improving medication taking behavior.

We are looking for individuals who have experience with daily medication plans to bring their expertise as well as designers to help with developing solutions. To be eligible, you must be comfortable speaking English and either:

- Have been prescribed a daily medication plan by a medical professional

\section{and/or}

- Worked closely with an individual who has been prescribed a daily medication plan

and/or

- Be a designer 
All sessions will be video-recorded. Once the recording has been transcribed and analyzed, it will be destroyed. Video clips from these sessions may be used in future publications, but faces or other identifiable information will be blurred and voices will be altered.

Topics covered in the study may be sensitive, but should you choose to participate, all responses are optional and you may leave at any point during the session.

We will be proving refreshments at the session.

If you are interested, please e-mail Sanaz Hafezi at sanazhafezi@cmail.carleton.ca for more details on participating.

The ethics protocol for this research (108484) has been reviewed and cleared by the Carleton University Research Ethics Board. If you have any ethical concerns with the study, please email ethics@carleton.ca 


\section{B.5 Screener}

$\mathrm{Hi}$,

Thank you for your interest. Please answer the questions below so we can schedule you for a session. Please note that this information will only be used by the researcher.

\section{What gender do you identify as?}
○ Male
○ Female
Non-binary
- Prefer not to answer

What is your age? (this question is optional)

Which of the following groups do you classify as (please select all that apply)? Note that this information will only be used by the researcher; no one else at the session will know what option you choose unless you wish to share it with them.
Have been prescribed a regular daily medication plan by a medical professional
$\square \quad$ Worked closely with an individual who has been prescribed a daily medication

$$
\text { plan }
$$
Designer

Sessions will be held on the days listed below. You will only need to attend one session, but please provide us with any days you will be available.

○ Dates TBD, but options will be provided 
Please let me know if you have any allergies so I can accommodate them for the refreshments.

Thank you,

Sanaz 


\section{B.6 Consent Form}

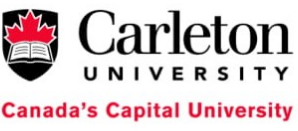

\section{Consent Form}

Title: Improving adherence to ongoing treatments in young adults through design

Date of ethics clearance: To be determined by the REB (108484)

Ethics Clearance for the Collection of Data Expires: To be determined by the REB (as indicated on the clearance form)

I choose to participate in a study on medication adherence in young adults. This study aims to identify and assess potential solutions/tools young adults can use to help them follow medication plans while travelling. This information will be used to identify design guidelines for a tool which assist young adults in improving medication taking behavior. The researcher for this study is Sanaz Hafezi in the School of Industrial Design. She is working under the supervision of Dr. Lois Frankel in the School of Industrial Design.

This study involves one 2-hour co-design session and you will receive refreshments as compensation. During the co-design session, we will present information from our research and you will be asked to design and assess potential solutions in a group.

All sessions will be video-recorded. These recordings would be stored on an encrypted and password protected USB which will be kept in a locked cabinet at Carleton University. The recording will only be used by the researcher for analysis and will be destroyed once it has been transcribed and analysed. Clips may be pulled from the video and used in future publications, though faces and other identifiable information will be blurred and voices will be altered.

All responses will be kept anonymous and your name will be removed from the data; for example, you may be referred to as participant 1 . All data will be kept confidential unless it reveals a life-threatening risk to you or anyone else; in which case the researcher is obligated to report it.

You have the right to end your participation in the study at any time during the session, for any reason, just let the researcher know. You will not be able to withdraw any data you have provided during the session since it may be mixed in with information from the other participants.

Page 1 of 2

This document has been printed on both sides of a single sheet of paper. Please retain a copy of this document for your records. 
This is part two of a three-part study. You are not required to participate in all three parts. The researcher may contact you with an invitation to all three sections should you wish to participate.

Some topics covered during the session may be sensitive, but you are not obligated to reveal any information. All responses are optional; if you do not wish to discuss anything personal, or are uncomfortable talking about a topic just let the researcher know.

All research data will be kept either on a password protected computer of the researcher, on an encrypted and password protected USB and/or in a locked cabinet at Carleton University. Research data will only be accessible by the researcher and the research supervisor.

Once the project is completed, all research data may be kept for up to seven years and potentially used for other research projects on this same topic. At the end of seven years, all research data will be securely destroyed; electronic data will be erased and hard copies will be shredded.

If you would like a copy of the finished research project, you are invited to contact the researcher to request an electronic copy which will be provided to you.

The ethics protocol for this project was reviewed by the Carleton University Research Ethics Board, which provided clearance to carry out the research. If you have any ethical concerns with the study, please contact Dr. Andy Adler, Chair, Carleton University Research Ethics Board-B (by phone at 613-520-2600 ext. 4085 or via email at ethics@carleton.ca).

Researcher contact information:

Sanaz Hafezi

School of Industrial Design

Carleton University

Email: sanazhafezi@cmail.carleton.ca

\author{
Supervisor contact information: \\ Lois Frankel \\ School of Industrial Design \\ Carleton University \\ Email: loisfrankel@cunet.carleton.ca
}

Do you agree to be video-recorded: Yes No

Signature of participant

\section{Date}

Signature of researcher

Date

Page $\mathbf{2}$ of $\mathbf{2}$

This document has been printed on both sides of a single sheet of paper. Please retain a copy of this document for your records. 


\section{B.7 Agenda for the Session}

15 minutes - arrival, consent and handout personas

15 minutes - Intro

1 hour - co-design

25 minutes - presentation and discussion

5 minutes - individual feedback 


\section{B.8 Introduction Script}

Hi. First off, thank you for participating.

Today we are going to be working on creating solutions which assists young adults in taking their medication while on trips; whether these are sleepovers or vacations.

I have provided you with persona(s) which highlight examples users and some of the issues they may have with taking their medication while traveling. A persona is a representation of someone who may end up using a developed product. The persona is based on findings from research that has been conducted. It highlights who the user might be, a scenario as well as some of the problems that they face.

Within your group(s), you can discuss and come up with ideas. We are only here for 2 hours so they do not have to be polished solutions. I have provided you with materials so feel free to sketch or build things to help you think or communicate your ideas.

I will quickly go over the persona(s) with you, then you will have an hour to create your solutions. During this time, I'll be taking notes and Anis will be video recording. We will then have 20 minutes to present and reflect on the solutions. If you come up with more than one concept, feel free to present them all. Remember that you do not have to be a designer to develop ideas, but there is a designer in each group who may be able to help you draw or make a rough model of the idea you are thinking about.

\section{[Review personas]}

Do you have any questions for me before we begin? 


\section{B.9 Feedback Form}

Please give a rating from 1-5 for each of the following statements; 1 being strongly disagree and 5 being strongly agree. If more than one solutions was presented today, please fill in the solution name and give a different ranking for each.

I believe the solution(s) presented today effectively solve the problems presented in the persona.

Strongly

$$
\text { Strongly Disagree Neutral Agree }
$$

Disagree

Agree

Solution 1:

1

2

3

4

5

Solution 2:

1

2

3

4

Solution 3:

1

2

3

4

Solution 4:

1

2

3

4

5

Solution 5:

1

2

3

4

5

Solution 6:

1

2

3

4

5

Please provide an explanation for the ratings:

I believe the solution(s) presented today are feasible.

Strongly

Strongly Disagree Neutral Agree

Agree

Solution 1:

Disagree

Solution 2:

1

2

3

4

5

Solution 3:

1

2

3

4

5

1

2

3

4 
Solution 4:

Solution 5:

Solution 6:

$$
1
$$

1

1
2

2

2
3

3

3
4

4

4
5

5

5

Please provide an explanation for the ratings:

I believe the solution(s) presented today would improve how closely young adults adhere to their medication plans.

Strongly

Strongly Disagree Neutral Agree

Agree

Solution 1:

Disagree

Solution 2:

1

2

3

4

5

Solution 3:

1

2

3

4

5

Solution 4:

1

2

3

4

5

Solution 5:

1

2

3

4

5

Solution 6:

1

2

3

4

5

1

2

3

4

5

Please provide an explanation for the ratings:

If more than one idea was presented today, please rank them from most suitable to least suitable. 
- Solution 1

- Solution 2

- Solution 3

- Solution 4

- Solution 5

- Solution 6 


\section{Bibliography or References}

Abras, C., Maloney-krichmar, D., \& Preece, J. (2004). User-centered design. In

Bainbridge, W. Encyclopedia of human-computer interaction. Thousand oaks: Sage publications. Retrieved from http://citeseerx.ist.psu.edu/viewdoc/summary?doi=10.1.1.94.381

AdhereTech. (2018). Home - Smart Wireless Pill Bottle. Retrieved September 1, 2018, from https://www.adheretech.com/

Alsous, M. (2017). Medication Adherence in Children. Health Communication, 2(1). https://doi.org/10.4172/2472-1654.100048

Annunziato, R. A., Emre, S., Shneider, B., Barton, C., Dugan, C. A., \& Shemesh, E. (2007). Adherence and medical outcomes in pediatric liver transplant recipients who transition to adult services. Pediatric Transplantation, 11(6), 608-614. https://doi.org/10.1111/j.1399-3046.2007.00689.x

Babbie, E. (2007). The practice of social research (11th ed.). Belmont: Thomson Higher Education.

Bate, P., \& Robert, G. (2006). Experience-based design: from redesigning the system around the patient to co-designing services with the patient. Quality \& Safety in Health Care, 15(5), 307-310. https://doi.org/10.1136/qshc.2005.016527

Becker, M. H., Drachman, R. H., \& Kirscht, J. P. (1972). Motivations as predictors of health behavior. Health Services Reports, 87(9), 852-862. Retrieved from http://www.ncbi.nlm.nih.gov/pubmed/4644270

Becker, M. H., \& Maiman, L. A. (n.d.). Sociobehavioral determinants of compliance with health and medical care recommendations. Medical Care, 13, 10-24. https://doi.org/10.2307/3763271

Bevan, H., Robert, G., Bate, P., Maher, L., \& Wells, J. (2007). Using a design approach to assist large-scale organizational change. The Journal of Applied Behavioral Science, 43(1), 135-152. https://doi.org/10.1177/0021886306297062

Bui, Y. N. (2009). How to write a master's thesis. Thousand Oaks, CA: Sage Publications.

Butz, A. M. (2006). Evidence-based practice: what is the evidence for medication adherence in children? Journal of Pediatric Health Care : Official Publication of 
National Association of Pediatric Nurse Associates \& Practitioners, 20(5), 338-341. https://doi.org/10.1016/j.pedhc.2006.05.003

Chauncey, W. (2014). Interview techniques for UX Practitioners. Waltham, MA: Morgan Kaufmann. Retrieved from http://proquest.safaribooksonline.com/9780124103931

Corbin, J., \& Strauss, A. (1990). Grounded theory research: Procedures, canons, and evaluative Criteria. Qualitative Sociology (Vol. 13). Retrieved from https://link.springer.com/article/10.1007/BF00988593

Creswell, J. W. (2014). Research design: Qualitative, quantitative, and mixed methods approaches. (V. Knight, J. Young, K. Koscielak, \& M. Markanich, Eds.) (4th ed.). Thousand Oaks, CA: Sage.

Creswell, J. W. (2003). Research design: Qualitative, quantitative, and mixed methods approaches. (D. Laughton, V. Novak, D. Axelsen, \& A. J. Sobezak, Eds.) (2nd ed.). Thousand Oaks, CA: Sage.

Crouch, M., \& McKenzie, H. (2006). The logic of small samples in interview-based qualitative research. Social Science Information. https://doi.org/10.1177/0539018406069584

Dean, A. J., Walters, J., \& Hall, A. (2010). A systematic review of interventions to enhance medication adherence in children and adolescents with chronic illness. Archives of Disease in Childhood, 95(9), 717-723. https://doi.org/10.1136/adc.2009.175125

Decrop, A. (1999). Triangulation in qualitative tourism research. Tourism Management, 20(1), 157-161. https://doi.org/10.1016/S0261-5177(98)00102-2

DiMatteo, M. R. (2014). Variations in patients' adherence to medical recommendations: A quantitative review of 50 years of research. Medical Care. Lippincott Williams \& Wilkins. https://doi.org/10.2307/4640729

DiMatteo, M. R. (2003). The role of effective communication with children and their families in fostering adherence to pediatric regimens. Patient Education and Counseling, 55(3), 339-344. https://doi.org/10.1016/J.PEC.2003.04.003

Duarte, J., \& Guerra, A. (2012). Uscr-centered healthcare design. In Procedia Computer Science. https://doi.org/10.1016/j.procs.2012.10.022

Gardiner, P., \& Dvorkin, L. (2006). Promoting medication adherence in children. American Family Physician, 74(5), 793-798. Retrieved from https://www.researchgate.net/profile/Lana_Dvorkin_Camiel/publication/6821018_P romoting_medication_adherence_in_children/links/09e415081702260b3f000000.pd $\mathrm{f}$ 
Gloyd, D. M. (2003). Positive user experience and medical adherence. In Proceedings of the 2003 international conference on Designing pleasurable products and interfaces - DPPI '03 (pp. 17-21). New York, New York, USA: ACM Press. https://doi.org/10.1145/782896.782902

Greene, J. C., Caracelli, V. J., \& Graham, W. F. (1989). Toward a conceptual framework for mixed-method evaluation designs. Educational Evaluation and Policy Analysis, 11(3), 255-274. https://doi.org/10.2307/1163620

Grewal, Levy, Persaud, \& Lichti. (2011). Marketing (2nd ed.). China: McGraw-Hill Ryerson Limited.

Guardian and IDA Pharmacies. (2018). Pharmacy. Retrieved September 1, 2018, from https://www.guardian-ida-pharmacies.ca/

Guest, G., Bunce, A., \& Johnson, L. (2006). How many interviews are enough?: An experiment with data saturation and variability. Field Methods, 18(1), 59-82. https://doi.org/10.1177/1525822X05279903

Hanghøj, S., \& Boisen, K. A. (2014). Self-reported barriers to medication adherence among chronically ill adolescents: A systematic review. Journal of Adolescent Health. https://doi.org/10.1016/j.jadohealth.2013.08.009

Hanson, W. E., Creswell, J. D., Plano Clark, V. L., Petska, K. S., \& Creswell, J. W. (2005). Mixed methods research designs in counseling psychology. Journal of Counseling Psychology. https://doi.org/10.1037/0022-0167.52.2.224

Hardy, M. (2013). Review of best practices for mixed methods research in the health sciences. Qualitative Social Work: Research and Practice, 12(4), 541-545. Retrieved from http://journals.sagepub.com/doi/10.1177/1473325013493540a

HeroHealth. (2017). Hero. Retrieved September 1, 2018, from https://herohealth.com/

Hinkin, C. H., Hardy, D. J., Mason, K. I., Castellon, S. A., Durvasula, R. S., Lam, M. N., \& Stefaniak, M. (2004). Medication adherence in HIV-infected adults: Effect of patient age, cognitive status, and substance abuse. AIDS (London, England), 18 Suppl 1(Suppl 1), S19-25. Retrieved from http://www.ncbi.nlm.nih.gov/pubmed/15075494

Hirschheim, R. A. (1985). User experience with and assessment of participative systems design. MIS Quarterly, 9(4), 295-304. https://doi.org/10.2307/249230

Johnson, C. M., Johnson, T. R., \& Zhang, J. (2005). A user-centered framework for redesigning health care interfaces. Journal of Biomedical Informatics. https://doi.org/10.1016/j.jbi.2004.11.005 
Johnson, R. B., Onwuegbuzie, A. J., \& Turner, L. A. (2007). Toward a definition of mixed methods research. Journal of Mixed Methods Research, 1(2), 112-133. https://doi.org/10.1177/1558689806298224

Kato, P. M., Cole, S. W., Bradlyn, A. S., \& Pollock, B. H. (2008). A video game improves behavioral outcomes in adolescents and young adults with cancer: A randomized trial. Pediatrics, 122(2), e305-e317. https://doi.org/10.1542/peds.20073134

Kuniavsky, M., Moed, A., \& Goodman, E. (2012). Observing the user experience: $a$ practitioner's guide to user research (2nd ed.). Waltham, MA: Morgan Kaufmann Publishers Inc. https://doi.org/9780123848703

Magnusson, L., Hanson, E., Brito, L., Berthold, H., Chambers, M., \& Daly, T. (2002). Supporting family careers through the use of information and communication technology - the EU project ACTION. International Journal of Nursing Studies, 39(4), 369-381. https://doi.org/10.1016/S0020-7489(01)00034-7

Mao, J.-Y., Vredenburg, K., Smith, P. W., \& Carey, T. (2005). The state of user-centered design practice. Communications of the ACM.

https://doi.org/10.1145/1047671.1047677

Martin, B., \& Hanington, B. M. (2012). Universal methods of design : 100 ways to research complex problems, develop innovative ideas, and design effective solutions. Beverly, MA : Rockport Publishers. Retrieved from https://searchworks.stanford.edu/view/9706083

Matsui, D. (2007). Current issues in pediatric medication adherence. Pediatric Drugs, 9(5), 283-289. Retrieved from http://go.galegroup.com/ps/i.do?p=AONE\&u=ocul_carleton\&id=GALE\%7CA2001 $17224 \& \mathrm{v}=2.1 \& \mathrm{it}=\mathrm{r} \& \mathrm{sid}=$ summon\&authCount $=1$

Medisafe. (2018). Medisafe. Retrieved September 1, 2018, from https://medisafe.com/

MedMinder. (2018). MedMinder Pill Dispensers. Retrieved September 1, 2018, from https://www.medminder.com/pill-dispensers-2/

MyTherapy. (2018). MyTherapy. Retrieved September 1, 2018, from https://www.mytherapyapp.com/

Nair, K. V., Belletti, D. A., Doyle, J. J., Allen, R. R., McQueen, R. B., Saseen, J. J., ... Jan, S. (2011). Understanding barriers to medication adherence in the hypertensive population by evaluating responses to a telephone survey. Patient Preference and Adherence, 195-206. https://doi.org/10.2147/PPA.S18481 
NantHealth. (2018). Vitality GlowCap. Retrieved September 1, 2018, from https://nanthealth.com/vitality/

Nichols, T., \& Wright, M. (2018). Generational differences: understanding and exploring Generation Z. In Brian W. Kulik (Ed.), SWAM 2018 Proceedings (pp. 177-185).

Albuquerque. Retrieved from http://www.swamfbd.org/uploads/Proceedings_2018.pdf\#page=177

Nikkila, S., Patel, G., Sundaram, H., Kelliher, A., \& Sabharwal, A. (2012). Wind runners: Designing a game to encourage medical adherence for children with asthma. In Proceedings of the 2012 ACM annual conference extended abstracts on Human Factors in Computing Systems Extended Abstracts - CHI EA '12 (p. 2411). New York, New York, USA: ACM Press. https://doi.org/10.1145/2212776.2223811

Osterberg, L., \& Blaschke, T. (2005). Adherence to medication. New England Journal of Medicine, 353(5), 487-497. https://doi.org/10.1056/NEJMra050100

Petry, N. M. (2002). A Comparison of young, middle-aged, and older adult treatmentseeking pathological gamblers. The Gerontologist (Vol. 42). Retrieved from https://academic.oup.com/gerontologist/article-abstract/42/1/92/641498

PILBOX. (2018). Home. Retrieved September 1, 2018, from https://pilbox.ca/en/

Pilemalm, S., \& Timpka, T. (2008). Third generation participatory design in health informatics-Making user participation applicable to large-scale information system projects. Journal of Biomedical Informatics, 41(2), 327-339. https://doi.org/10.1016/J.JBI.2007.09.004

Poulovich, B. (2015). Design to improve the health education experience: Using participatory design methods in hospitals with clinicians and patients. Retrieved April 29, 2018, from https://search.proquest.com/openview/9a54513438d899c617b0cd578f3af937/1?pqorigsite $=$ gscholar\&cbl $=48566$

Rao, D., Kekwaletswe, T. C., Hosek, S., Martinez, J., \& Rodriguez, F. (2007). Stigma and social barriers to medication adherence with urban youth living with HIV. AIDS Care, 19(1), 28-33. https://doi.org/10.1080/09540120600652303

Rapoff, M. A., Belmont, J. M., Lindsley, C. B., \& Olson, N. Y. (2005). Electronically monitored adherence to medications by newly diagnosed patients with juvenile rheumatoid arthritis. Arthritis \& Rheumatism, 53(6), 905-910. https://doi.org/10.1002/art.21603

Revenäs, Å., Opava, C. H., Martin, C., Demmelmaier, I., Keller, C., \& Åsenlöf, P. (2015). Development of a web-based and mobile app to support physical activity in 
individuals with rheumatoid arthritis: results from the second step of a co-design process. JMIR Research Protocols, 4(1), e22. https://doi.org/10.2196/resprot.3795

Rexall PharmaPlus. (2018). Pharmacy. Retrieved September 1, 2018, from https://www.rexall.ca/pharmacy

Saldaña, J. (2016). The coding manual for qualitative researchers (3rd ed.). London: Sage.

Sanders, E. B.-N., \& Stappers, P. J. (2012). Convivial design toolbox : Generative research for the front end of design. BIS.

Sanders, E. B.-N., \& Stappers, P. J. (2008). Co-creation and the new landscapes of design. Co-design, 4(1), 5-18. https://doi.org/10.1080/15710880701875068

Sieber, S. D. (1973). The integration of fieldwork and survey methods. American Journal of Sociology. The University of Chicago Press. https://doi.org/10.2307/2776390

Shoppers Drug Mart. (2018). Pharmacy. Retrieved September 1, 2018, from https://mypharmacy.shoppersdrugmart.ca/

Smith, T., \& Nichols, T. (2015). Understanding the Millennial generation authentic transformational leadership view project. Journal of Business Diversity, 15(1), 3947. Retrieved from https://www.researchgate.net/publication/324922926

Strauss, A. L., \& Corbin, J. M. (1998). Basics of qualitative research: Techniques and procedures for developing grounded theory ( $2 \mathrm{nd}$ ed.). Thousand Oaks, CA: Sage Publications.

Szefler, S. J., Mitchell, H., Sorkness, C. A., Gergen, P. J., O’Connor, G. T., Morgan, W. J., Kattan, M., Pongracic, J. A., Teach, S. J., Bloomberg, G. R., Eggleston, P. A., Gruchalla, R. S., Kercsmar, C. M., Liu, A. H., Wildfire, J. J., Curry, M. D., Busse, W. W. (2008). Management of asthma based on exhaled nitric oxide in addition to guideline-based treatment for inner-city adolescents and young adults: a randomised controlled trial. The Lancet, 372(9643), 1065-1072. https://doi.org/10.1016/S01406736(08)61448-8

Wilkinson, C. R., \& De Angeli, A. (2014). Applying user centered and participatory design approaches to commercial product development. Design Studies. https://doi.org/10.1016/j.destud.2014.06.001

World Health Organization. (2003). Adherence to long-term therapies: Evidence for Action. Retrieved from http://apps.who.int/iris/bitstream/10665/42682/1/9241545992.pdf 